Portland State University

PDXScholar

1993

\title{
Vision, Interpersonal Orientation and Personal Values in Elementary School Principals
}

Allan Leslie Weston

Portland State University

Follow this and additional works at: https://pdxscholar.library.pdx.edu/open_access_etds Let us know how access to this document benefits you.

\section{Recommended Citation}

Weston, Allan Leslie, "Vision, Interpersonal Orientation and Personal Values in Elementary School Principals" (1993). Dissertations and Theses. Paper 1177.

https://doi.org/10.15760/etd.1176

This Dissertation is brought to you for free and open access. It has been accepted for inclusion in Dissertations and Theses by an authorized administrator of PDXScholar. Please contact us if we can make this document more accessible: pdxscholar@pdx.edu. 


\author{
VISION, \\ INTERPERSONAL ORIENTATION \\ AND \\ PERSONAL VALUES \\ IN \\ ELEMENTARY SCHOOL PRINCIPALS
}

by

ALLAN LESLIE WESTON

A dissertation submitted in partial fulfillment of the requirements for the degree of

\author{
DOCTOR OF EDUCATION \\ in \\ EDUCATIONAL LEADERSHIP : \\ ADMINISTRATION AND SUPERVISION
}

Portland State University 1993 
TO THE OFFICE OF GRADUATE STUDIES:

The members of the committee approve the dissertation of Allan Leslie Weston presented April 29, 1993.
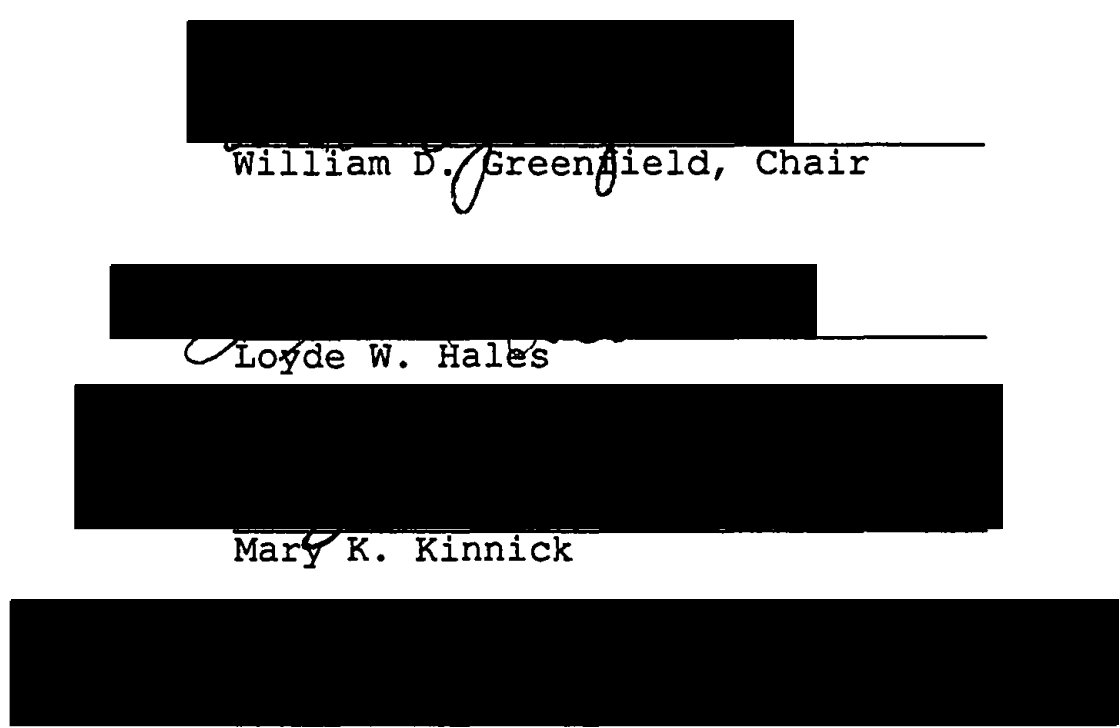

Thomas G. Chenoweth

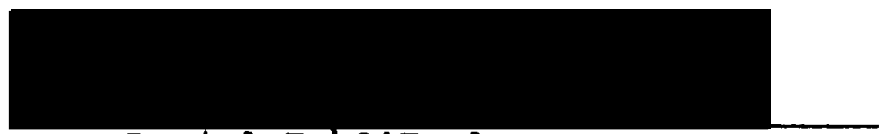

Daniel E. O'Toole

APPROVED:

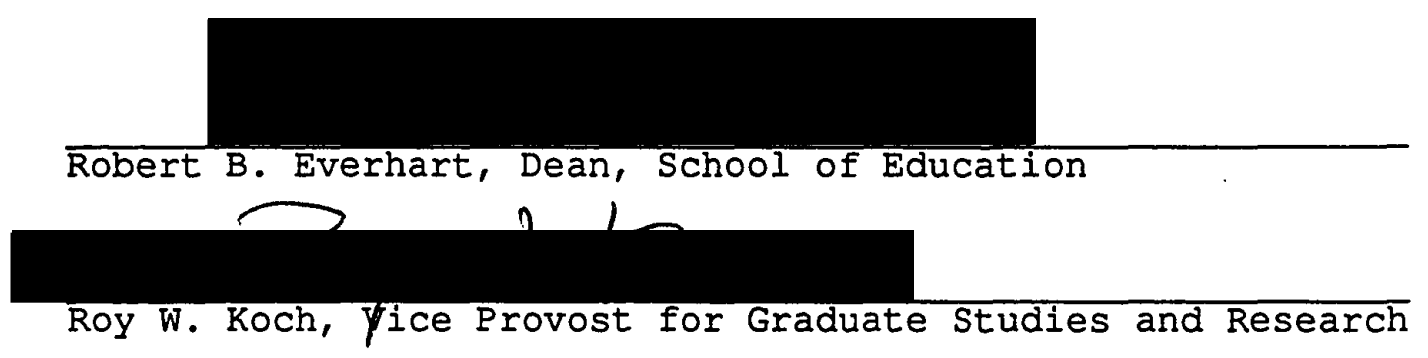


AN ABSTRACT OF THE DISSERTATION OF Allan Leslie Weston for the Doctor of Education in Educational Leadership: Administration and Supervision presented April 29, 1993.

Title: Vision, Interpersonal Orientation and Personal Values in Elementary School Principals.

APPROVED BY THE MEMBERS OF THE DISSERTATION COMMITTEE:

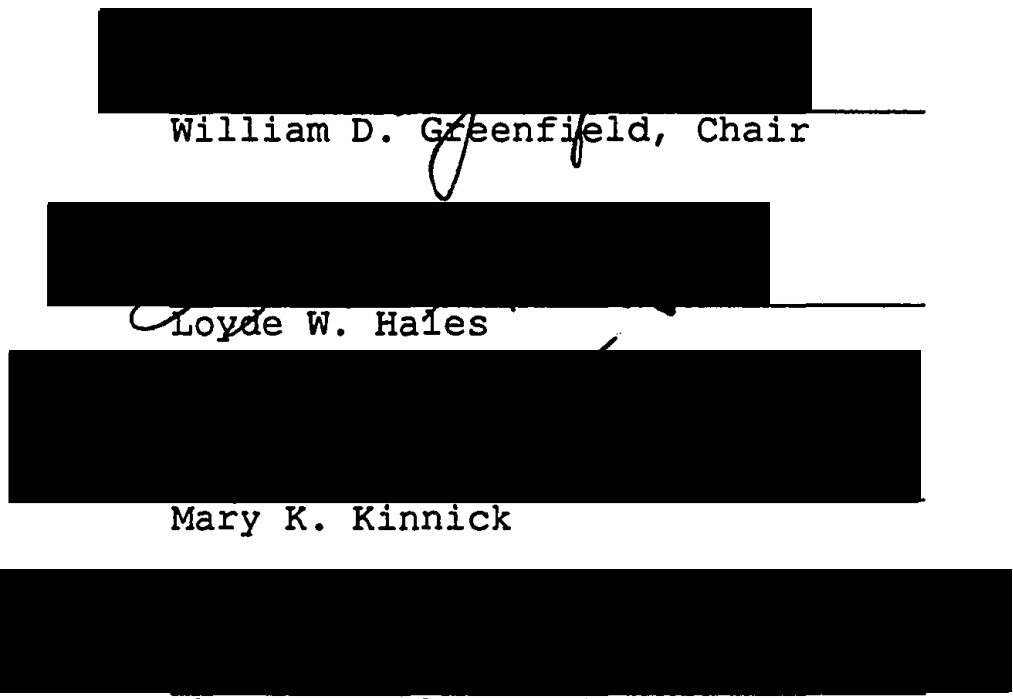

Thomas G. Chenoweth

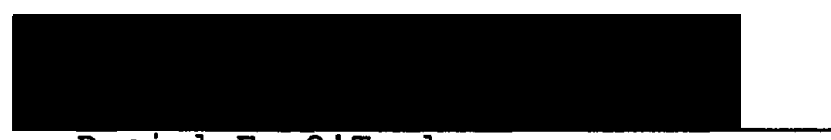

Daniel E. O'Toole

This study looked specifically at possible relationships which exist between three personal characteristics variables believed to be associated with effective leadership in 
effective leadership in elementary schools. The three variables were (1) Principal Vision, (2) Principal Interpersonal Orientation and, (3) Principal Personal Values. The relationship between selected teacher, principal and school demographic variables and teacher's perceptions of their principal's vision was also explored.

This study addressed the following research questions related to principal vision. The questions were: What are teachers' perceptions of their principal's vision?, What are the principal's predictions of the perceptions teachers have of the principal's vision?, Do principals and teachers differ in their perception of the principal's vision?

The next set of research questions addressed the relationship between principal vision as measured by the Scheel Vision Inventery and the following demographic variables: Teacher gender, teacher age, the length of time that a teacher has worked with a principal, the length of teaching experience, the size of the school, the percentage of students on free and reduced lunch, the number of years of experience of the principal, the length of time that a principal has been in a school, and principal gender.

The following research questions explored the principal's personal values as measured by the Prefile of Life Values. The questions were: What are the principal's personal values?, Is the gender of the principal related to his/her personal values?, What is the relationship between 
principal personal values and teachers' perceptions of principal vision?

The final three research questions explored the principal's Interpersonal Orientation as measured by the Mach $\mathrm{V}$ scale. The questions were: What are the principals' interpersonal orientations?, Is the interpersonal orientation of the principal related to teacher perceptions of their principal's vision?, Is the interpersonal orientation of the principal related to his/her personal values?

Data were collected from 51 principals and 841 teachers in elementary schools from 10 school districts in the Portland, Salem and Vancouver metropolitan areas. Teachers were asked to score their perceptions of their principal's vision on the school Vision Inventory, while the principal of each school was asked to predict how they felt their staff might respond on the same instrument. The principal was also asked to complete the Mach $\mathrm{V}$ interpersonal orientation scale and the Profile of Life Values. Data were analyzed by using one or more of the following statistical tests where appropriate: MANOVA; ANOVA; Chi-square; and Pearson Product Moment Correlation.

The major conclusions drawn from this study were: The major conclusions drawn from this study are: (1) principals perceived their teachers to be less positive than they in fact were in their perceptions of the principal's ability to 
encourage others to make personal sacrifices to accomplish the principal's vision; (2) male teachers perceive that their principals include them more in the vision building process than do female teachers; (3) teachers younger than 26 were less positive in their perceptions of their principal's Internalization and tended to be less positive on other scales; (4) principal's communicate their vision more effectively with those teachers who are in their first year with their current principal than any other group for vision exchange, sacrifice and total vision; (5) school and principal demographics have little impact on teacher perceptions of principal vision; (6) principals value being sensitive to the needs of others more than any of the other personal values and they value artistic expression and appreciation the least; (7) with the exception of the Artistic values, male and female principals are relatively similar in their personal values; (8) principal vision and personal values are moderately related; and (9) the relationship of interpersonal orientation of the principal to teacher perceptions of principal vision is not statistically significant. 
DEDICATION

This dissertation is dedicated to four very special people in my life who have each, in their own way, added so much to what I have achieved.

To my wife JACQUE who knows first hand what it takes to obtain a doctoral degree. The dozens of weekends she spent at home while I worked, and the countless nights she went to bed alone because of late classes and crammed assignments, make this degree as much hers as it is mine. This would not have been possible without her unquestioning support and her unwavering belief in my abilities.

To my son RYAN who will be two months old this week. He will never remember those midnight bottle feedings with Daddy sitting at the computer so that Mummy could get some much needed sleep. I will never forget what a pleasure it was to have his editorial "oohs" and "ahhs" as I pounded away at the keyboard!

To my MOTHER and FATHER who worked so hard to make sure that I had the opportunity to go to college and who always believed in me. Their ever present love and support will never be forgotten. I am pleased that they will be able to fly from their home in Australia to share in my graduation and be a part of the culmination of thirteen years of post-secondary study. 


\section{ACKNOWLEDGEMENTS}

The completion of this degree would not have been possible without the support and encouragement of many people. Their efforts are in need of acknowledgement.

My sincere thanks go to Bill Greenfield, the chair of my Committee, and my advisor at Portland State since my entry into the Doctoral program in the spring of 1991. His professionalism, expertise and sound advice have been invaluable to me as I progressed through the program. Special thanks must also go to Loyde Hales who spent countless hours providing technical and statistical advice on this dissertation. My thanks go to Mary Kinnick, Tom Chenoweth and Dan O'Toole who provided valuable feedback to me as I progressed with this project.

Special recognition needs to be given to Andy McKnight who is a programmer/analysist with the office of information systems at Portland State University. Andy's technological expertise enabled me to transfer 900 systat data entries for the Macintosh over to the IBM mainframe computer at Portland State. This enabled me to enter data at home on my personal computer and saved me hours of time commuting to and from campus. 
In this program at Portland State, I have been fortunate to have meet three colleagues, Kathy Goss, Rick Melching and Rick Dills, who have played a large part in providing me with valuable emotional and educational support when I have needed it. I thank them for their support and wish them well in their dissertations.

To Dr. Judy Taccogna, my principal, who is herself a veteran of the doctoral program at Portland State go my warmest thanks. She has witnessed the development of this dissertation from its earliest stages and has been my coach throughout the entire process. The release time, lighter work loads at crunch times, editorial comments and an occasional supportive beer have made it possible for me to work and study at the same time. It has been the little things however, such as the ceremonial "passing down" of her partly used Portland State library photocopy card, which have meant the most!

My thanks go to the hundreds of teachers and dozens of administrators in the states of oregon and Washington who have generously given up of their time in the face of severe budget cutbacks and staff reductions, to produce the "stuff" upon which this dissertation is based.

Finally, my thanks go to my friends who have understood my hermit lifestyle in the past two years. I anxiously await that long overdue Wednesday night "hoops" session! 
TABLE OE CONTENTS

PAGE

ACKNOWLEDGMENTS $\ldots \ldots \ldots \ldots \ldots \ldots \ldots \ldots \ldots \ldots \ldots$ iv

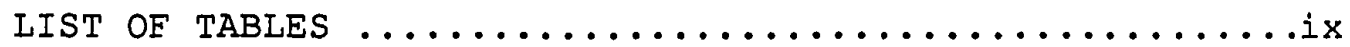

CHAPTER

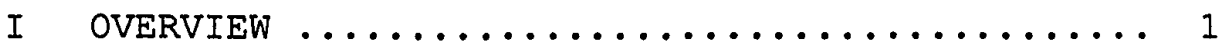

Introduction $\ldots \ldots \ldots \ldots \ldots \ldots \ldots \ldots \ldots \ldots \ldots$

Statement of the Problem ...............19

Significance of the Study ............21

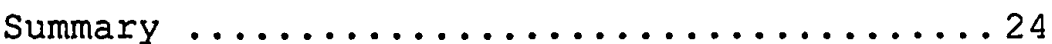

I I A REVIEW OF THE LITERATURE $\ldots \ldots \ldots \ldots \ldots \ldots$

Introduction $\ldots \ldots \ldots \ldots \ldots \ldots \ldots$

School Leadership ................26

Principal Effectiveness ...............33

Principal vision .................43

Leadership and Interpersonal orientation ...51

Leadership and Personal Values ........56

summary ......................61

II I METHODOLOGY $\ldots \ldots \ldots \ldots \ldots \ldots \ldots \ldots \ldots \ldots \ldots \ldots \ldots \ldots$

Overview......................64

Research Problem Statement ..........64

Instrumentation $\ldots \ldots \ldots \ldots \ldots 6 . \ldots \ldots 6$

Data Collection Procedures ............77 
Data Analysis Procedures ........... 81

IV PRESENTATION OF RESULTS.............88

Introduction $\ldots \ldots \ldots \ldots \ldots \ldots \ldots$

Characteristics of the Sample ........88

Sample size .................... 89

School Demographics ............... 93

Principal Demographics ............. 97

Teacher Demographics ................101

Analysis of the School Vision Inventory ...107

Analysis of the Profile of Life Values ...139

Analysis of Mach $\mathrm{V}$ Scale of Interpersonal

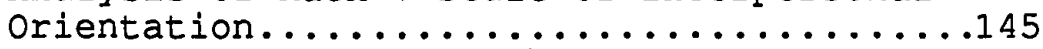

Summary .................................

$\mathrm{V}$ DISCUSSION, CONCLUSIONS, LIMITATIONS,

SIGNIFICANCE AND RECOMMENDATIONS .........151

Introduction $\ldots \ldots \ldots \ldots \ldots \ldots \ldots \ldots \ldots \ldots \ldots \ldots$

Discussion of the Results ...........151

Conclusions ..........................

Limitations of the study ...........172

Significance for Educational Leadership....176

Recommendations for Future Research ......179

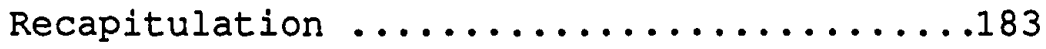

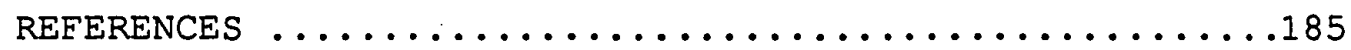

APPENDICES

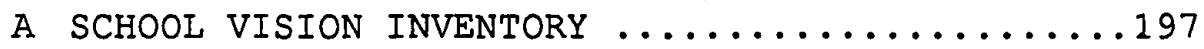


APPENDICES (Continued)

PAGE

B PROF ILE OF LIFE VALUES ................200

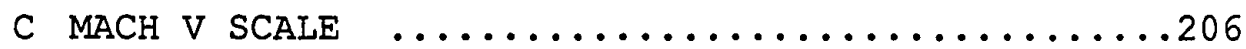

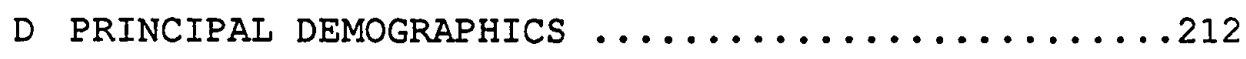

E SAMPLE LETTER TO SUPERINTENDENTS ..........214

F SAMPLE SUPERINTENDENT RESPONSE FORM ........217

G INSTRUCTION LETTER TO ACCOMPANY SURVEY PACKET...219 


\section{LIST OF TABLES}

TABLE

PAGE

Summary of Sample Size .............90

II Schools by Participating District ........92

III Aggregated Student Populations ..........94

IV Students on Free and Reduced Lunch Programs.. 95

$\mathrm{V} \quad$ Aggregated Numbers of Teachers Per School ...96

VI Ages of Principals ................ 98

VII Principal Gender ................. 99

VIII Principal Years of Experience ...........99

IX Principal Tenure in Current Position ......101

x Ages of Teachers ......................

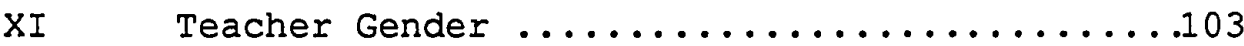

XII Years of Teaching Experience ............104

XIII Years Teaching in Current Position ........106

XIV Years Teaching with Current Principal .....107

XV Scales for School Vision Inventory ........109

XVI Means, Standard Deviations, and Coefficient Alphas for School Vision Inventory

Scales Completed by Teachers ........110

XVII Means, Standard Deviations, and Coefficient Alphas for School Vision Inventory Scales as Predicted by Principals ......112

XVIII Row Percents, Chi square and Probability Values for Teacher and Principal Responses to Each Item on the School Vision Inventory ................114 
XIX Analysis of Variance of Teacher Perceptions of Principal Vision by Gender .........118

XX Row Percents, Chi square and Probability Values for Responses to Items 17 and 18 on the school Vision Inventory for

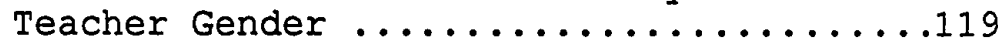

XXI Analysis of Variance of Teacher Perceptions of Principal Vision by Teacher Age .....120

XXII Significant Post Hoc Comparisons: Teacher Perceptions of Principal Vision

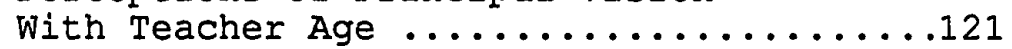

XXIII Row Percents, Chi square and Probability Values for Responses to Item 18 on the School Vision Inventory for

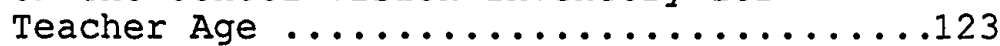

XXIV Analysis of Variance of Teacher Perceptions of Principal Vision by Teacher Years

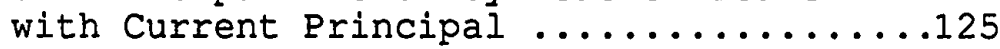

XXV Significant Post Hoc Comparisons: Teacher Perceptions of Principal Vision with Teacher Years with Current Principal ...126

XXVI Row Percents, Chi square and Probability Values for Responses to Item 18 on the School Vision Inventory for Teacher Years with Current Principal .........127

XXVII Analysis of Variance of Teacher Perceptions of Principal Vision by Teacher

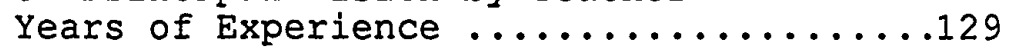

XXVIII Analysis of Variance of Teacher Perceptions of Principal Vision by School Size .....131

XXIX Analysis of Variance of Teacher Perceptions of Principal Vision by Percentage of Students on Eree and Reduced Iunch .....133

XXX Analysis of Variance of Teacher Perceptions of Principal Vision by Years of Experience of the Principal .................. 
XXXI Analysis of Variance of Teacher Perceptions of Principal Vision by Length of Time the Principal has been at the School ...137

XXXII Analysis of Variance of Teacher Perceptions of Principal Vision by Principal Gender..138

XXXIII Scales for Profile of Iife values ........140

XXXIV Means, Standard Deviations, and Coefficient Alphas for Profile of Iife Values Scales for Principals ..................141

XXXV Analysis of Variance of Profile of Life Values by Principal Gender ..........143

XXXVI Pearson Correlation Matrix with Probabilities for Principal Vision and

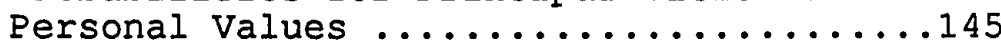

XXXVII Mean, Standard Deviation, and Coefficient Alpha for Mach $V$ Scale for Principals ...147

XXXVIII Analysis of Variance of Vision Scales by Principal Mach .................148 


\section{CHAP TER I}

OVERVIEW

One of the most significant educational change movements to have occurred in oregon in recent years, has been the passage of Oregon's Education Act for the 21st Century (House Bill 3565). This bill has charged our educational leaders with the restructuring of our current school system to include such reforms as: the implementation of non-graded primary schools, the provision of alternative high schools, restructured statewide assessment to include certificates of initial and advanced mastery, and the development of site based management. The main focus of this Bill is to bring our schools up to levels which will allow us to provide: "A restructured educational system capable of achieving the state's goals of the best educated citizens in the nation by the year 2000 and a workforce equal to any in the world by the year 2010" (p.1). How is this to be accomplished, and who or what will it take to achieve these goals?

The answer lies, in part, in the leadership of our educational organizations and in the ability of school principals to quickly come to grips with the various mandates and policies. This will require principals who are 
instructional leaders as well facilitators for all members of the organization involved in the change process. This study is therefore concerned with effective leadership. In particular, it examines three personal characteristics of principals, believed to be associated with effective schooling. The variables examined in this study include principal vision, principal interpersonal orientation, and principal personal values. The focus on these is based heavily upon the work of Blumberg and Greenfield (1986) and Greenfield (1982, 1987, 1988, 1991).

\section{INTRODUCTION}

\section{Leadership Effectiveness}

In recent years there has been a swell of interest in what has been termed the Effective Schools Research. The initial momentum for this emphasis began with the publication of studies of student academic achievement scores by researchers such as Brookover, Beady, Flood, Schweitzer and Wisenbaker (1979), Edmonds (1979), and Weber (1971). These early researchers found that the students in the "effective schools" scored better than was expected in academic achievement tests and that these schools had greatly reduced levels of student drop-out. Effective Schools. Achilles, in Greenfield (1987), noted that most of the effective schools literature clearly 
defines five correlates associated with effective schools. These are (1) the principal exercises strong leadership, (2) a school climate which is safe and orderly without being repressive and rigid, (3) high and positive expectations are held for both students and staff, (4) teachers and all school staff emphasize the basic skills which are to be tested and, (5) teachers use regular and continuous assessment to structure instructional strategies for each pupil (pp.20-21).

Underlying each of these five correlates is the significance of the principal, as the school's instructional leader, on the maintenance of a school environment conducive to the support of each of the correlates. Principal leadership is interwoven throughout the effective schools literature. Effective principals are associated with effective schools and ineffective principals with ineffective schools. While complex and not well understood, the link between effective leadership and effective schools has been begun to be systematically studied.

Much of the research presented in the current effective schools literature points to the "leadership" of the school principal as the single most significant factor in creating effective schools (Barth, 1990; Brookover \& Lezotte 1979; Edmonds, 1979; Rutter et.al.,1979; Sergiovanni, 1984, 1987). 
Burlingame (1987), is one of a growing body of researchers, however, who now question the almost sole reliance upon administrative leadership as the key to effective schools. He argues that the very reviews of research and writing which have been used to support the "leadership as most significant factor" stance, has been tainted by the preconceptions of the reviewer. Central to Burlingame's position is the view that a closer look at the case studies and original research reveals the importance of the cultural context of the school and the significance of other members of the organization in ensuring school effectiveness.

Dwyer and Smith (1987), state that when looking at effective schools the role of the instructional leader is critical; however, the significance of the leaders' role cannot be understood apart from the larger systems and events that have a direct impact on their actions. They state that some of the key variables which can influence school success are demographics, changing student populations, the history of the organization and, the changes in school leadership (pp. 174-176).

Greenfield (1987), states that instructional leadership is associated with improving schools; however, caution needs to be exercised when generalizing conclusions to schools in different communities and with different historical backgrounds. He states: "Schools are shaped by their larger 
environments, and by the values, beliefs, and standards of participants. Actions to improve schools are mediated by aspects of the school's culture and organizational context, and what works in one school may fail in another" (p. 154).

One of the underlying assumptions of this research study is that the principal, as the instructional leader, plays a key role in the development of effective schools. The principal, however, is not solely responsible for school effectiveness. The climate, culture, history, and organizational context of the school and the values, beliefs, and standards of the participants all significantly impact the effectiveness of schools.

Personal Characteristics. Recent studies associated with effective schools and the role of the principal (Cuban,1984; Dwyer, 1984; Manasse, 1985) have highlighted the significance of additional variables, such as the contextual properties of the school, the school environment, the actual work of the school principal, and the school's history, in determining instructional outcomes for children.

Greenfield (1987) states that even with this increasing attention, researchers have been limited in their attempts to study the personal qualities of the individual teachers and principals involved. He advises that, "the issue is not to study the individual characteristics per se (Bridges,1982), but rather to understand the relationships between the knowledge, skills, and dispositions of 
individuals and characteristics of the situation in which they work " (1978, p59).

Blumberg and Greenfield, in their (1986) book the Effective Principal, Perspectives on School Leadership, looked closely at eight school principals who "made a difference" in their schools. These principals, they contend, were successful in the realization of educational and organizational goals because each (1) held an image or vision of what it was he/she wanted to accomplish, (2) had a propensity to assume the initiative and take a proactive stance in relation to the demands of their work environment, and (3) was able to satisfy the routine organizational maintenance demands in a manner which enabled the principal to spend more on-the-job time in activities related to the realization of their personal vision (p. 181).

In addition to the three key elements of vision, initiative, and resourcefulness highlighted above, Blumberg and Greenfield (1986) have speculated several more specific personal qualities which they believe exist in principals who are effective in leading our schools. These are:

- Being highly goal-oriented and having a keen sense of clarity regarding instructional and organizational goals.

- Having a high degree of personal security and a well developed sense of themselves as persons.

- Having a high tolerance for ambiguity and a marked tendency to test the limits of interpersonal and organizational systems that they encounter.

- Being inclined to approach problems from a highly analytical perspective and being highly sensitive to 
the dynamics of power in both the larger systems and their own school.

- Being inclined to be proactive rather than reactive to be in charge of the job and not let the job be in charge of them.

- Having a high need to control the situation and a low need to be controlled by others - they like being in charge of things and initiating action.

- Having high needs to express warmth and affection toward others, and to receive it - being inclined toward friendliness and good-natured fellowship.

- Having high needs to include others in projects on problem solving, and moderate to high needs to want others to include them. (pp. 181-185)

Building upon his earlier work (Blumberg \& Greenfield, 1980,1986), Greenfield (1987) has suggested that the cornerstones of effective instructional leadership are the ability to exercise "moral imagination", or the ability to see how things are and how they might be, in developing a compelling "vision" regarding what is possible or desirable for the school and (2) "interpersonal competence" or the knowledge and skills needed by the principal in order to influence others in desired directions (p. 64).

This study will look at three of many variables believed to be associated with the effectiveness of the principal's leadership: vision, interpersonal orientation, and personal values. These three personal characteristics are assumed, by the researcher, to be interrelated and this study was undertaken to gain a better theoretical understanding of these interrelationships.

The first variable, Vision, is taken directly from the discussion of Blumberg and Greenfield's (1986) work 
mentioned above. The second variable, Interpersonal Orientation, is based upon Blumberg and Greenfield's (1986) discussion of interpersonal competence. Interpersonal orientation, is the manner in which the principal conducts interpersonal interactions with his/her staff. The third variable, Personal Values, refers to what it is that the principal holds up as being important when he or she makes one decision over another. A more complete discussion of the three variables, and the reasons for their use in this study, will be discussed in the following section.

Principal Vision

Tyack and Hansot (1982), in their book Managers of Virtue: Public School Leadership in America, 1820-1980, discuss the development of the public school system and its leaders since the emergence of the one room school house of the early nineteenth century. They reference the names of dozens of people, such as Emilie Applegate, Edward Cubberly, Horace Mann, Catherine Beecher, John Dewey, and Marcus Foster who have contributed significantly to not only their unique educational organizations but also to the development of their educational eras.

The one common thread weaving through the differences in philosophy, religion, race, gender, and culture of these leaders was the presence of a unique vision that each of them had for their particular educational organizations. 
Vision was the element that helped these leaders focus their attention on what it was that they wanted to achieve for themselves and their organizations and in so doing helped to create the public school system as we know it today (Tyack \& Hansot, 1982).

The ability of the principal to hold and enact on a vision has become increasingly more important in today's educational organizations and as such has started to draw a great deal more attention in the research (Astin \& Leland, 1991; Barth, 1990; Blumberg \& Greenfield, 1986; Licata, Greenfield \& Teddlie, 1989; Johnson, 1991; Sergiovanni, 1984; Vaill, 1990).

More recently, Blumberg and Greenfield (1986, p.181)

highlighted three key characteristics associated with effective principals. These are: (1) an individual commitment to a particular educational or organizational vision; (2) an ability to assume the initiative and take a proactive stance in relation to the demands of their world of work; and (3) an ability to satisfy routine organizational maintenance demands so that more time can be devoted to the realization of their personal vision. Licata, Greenfield and Teddlie (1989) defined the concept of vision as: "the capacity to see the discrepancy between how things are and how they might be and the need to compel others to act on those imagined possibilities" $(p .94)$. 
Bricker (1984) reflected that vision is not some type of strategic plan but is rather more like the compass that points the direction to be taken, that inspires enthusiasm, and that allows people to contribute and take part in the shaping of the way that will constitute the school's mission.

This research study will use principal vision as one of three key variables associated with principal effectiveness (Blumberg \& Greenfield, 1986; Greenfield, 1987; Licata, Greenfield \& Teddlie, 1989; Sergiovanni, 1984). Discussion of vision in this study will refer to the principal's ability to look at what exists in a school and reflect upon what is possible and more desirable in that specific school context.

The concept of "moral imagination", is vital to a clear understanding of the concept of vision in this study. Blumberg and Greenfield (1986) state that moral imagination is:

The element of "imagined " possibility. It is "moral" imagination because the discrepancy, the possibility envisioned, is rooted in an awareness of and a commitment to the standards of good practice, of effective schools and good teaching, that characterize membership in the normative community of educators. Thus it is "moral" in that it is the application of some standard of goodness that illuminates the discrepancy between the present and what is possible, and better. (p.228) 
This study deals with principal vision, and as such, it does not directly attempt to study the building of a shared vision within a school. The researcher is fully aware of the importance of teacher empowerment and vision development by a leadership team; however, one of the underlying assumptions in this study is that effective principals are those who effectively exchange ideas about their personal vision with the other members of the organization. Effective principals base their visions in the reality of the organizational context and place great emphasis on "moral" leadership aimed at benefiting all who stand to be affected by the decision. The assumption in this study is that principal vision does not imply hierarchy and control over members of the organization.

Licata, Greenfield and Teddlie (1990) state that principals, who effectively exchange ideas about vision and support teacher freedom to make strategic decisions in the classroom, are creating a public vision which is open to critical examination by all interested groups within the school. Licata, Greenfield and Teddlie (1990) state that, when principal vision is seen in this light,

It becomes less like dogma and more like a hypothesis that can be modified based on new information. . . Principals who understand the social realities of fostering a viable school vision may endure to provide the kind of stable and continuous leadership required to bring about needed changes in their schools. (p 99) 
One of the central assumptions of this study is that principal vision is a key variable in effective educational organizations. The School Vision Inventory (S.V.I.) (Appendix A), developed by Greenfield, Licata, and Johnson (1989), was used to assess this variable. The S.V.I is designed to be administered to the teaching staff of a school. The teachers are asked to respond to 18 statements about principal vision within their school; the principal of the school is asked to predict their staffs' responses to each of the 18 statements on the S.V.I.

The S.V.I. is composed of three subscales, the first of which measures Vision Exchange or the principal's effectiveness in exchanging ideas about a school vision with other members of the organization. The second subscale, Vision Internalization, is the effectiveness of the principal to persuade others to accept or internalize the school vision. The third subscale, Vision Sacrifice, measures the effectiveness of the principal in encouraging members of the organization to make sacrifices to ensure the fulfillment of the school vision (Greenfield, Licata \& Johnson, 1989).

The S.V.I. does not measure how the principal's vision was developed nor does it measure if this vision is held collectively by all members of the organization. The instrument, as is the case with this study, focuses upon the 
vision of the principal and the related variables of Vision Exchange, Vision Internalization and Vision Sacrifice.

\section{Principal Rersonal Values}

Principal personal values is a second variable which appears to be significant in influencing the way in which principals make decisions and hence provide leadership in their schools. Sashkin (1988) highlighted the importance of the values that the principal possesses in relationship to the search for excellence in schools. Personal values he states, help the principal focus upon what he/she believes is important in educational process.

McCall (1986) indicated that the personal values of the principal can be of paramount importance in influencing principals when they go through the vision development process. Greenfield (1985, p 25), said that values refer to the conception of what a group, organization, or individual hold to be desirable. He also said that values concern the preferred activities and processes associated with means and ends.

Although the research on principal personal values is very sparse, the significance of values in influencing the work of the principal should not be understated. Almost every action taken by the principal and every decision made is consciously or unconsciously tied to that principal's moral and ethical stance regarding the needs of children, 
staff, and community associated with his/her particular school.

Simon (1957) noted that decisions come from two sets of premises, those which are based upon facts and those which are based upon values. Blumberg and Greenfield (1986) build upon this by stating that deciding upon an action or an alternative always involves the assignment of values to facts and the exercise of judgment in arriving at that alternative (p. 225).

It is important to note that the study of personal values does not represent a return to the "traitist approach" to analyzing managerial effectiveness. Rather, it represents an attempt to study the character of principals and their qualities as human beings (Blumberg \& Greenfield, 1986).

This research study assumes that an action taken by the principal, as the instructional leader of the school, will be based upon that principal's particular set of personal values. As Greenfield (1987) argues, instructional leadership involves the assignment of values to facts as a necessary part of the decision making and action taking process.

The instrument used in this study, to determine the principal's personal values, is the Profile of Iife Values (Appendix B) which was developed by Hales and Bellarts (1991). Although the original instrument was developed to be 
used in Bellarts' research with nursing students, the instrument is very basic in its scope and thus applicable to educational administration.

The values measured by the instrument are; Intellectual, Considerate, Creative, Artistic, Recognition, Achievement, and Integrity. This instrument consists of statements with no right or wrong answers, expressed on a Likert scale from strongly agree to strongly disagree. A point system is used to assess personal values.

\section{Principal Interpersonal orientation}

Greenfield (1986) suggested that two cornerstones of effective school administration are moral imagination (the development of a compelling vision) and interpersonal competence. It is this concept of interpersonal competence from which the third key variable of this study, interpersonal orientation, will be derived.

Foote and Cottrell (1955) operationally defined interpersonal competence as "the knowledge and skills that enable an individual to shape the responses he or she gets from others" (p.7). Greenfield (1991) noted that interpersonal competence actually involves both principal knowledge and personal skills.

Peterson (1978) has shown that the average day of the principal is characterized by a countless series of face to face interactions with students, parents, supervisors and 
others. This interaction is critical to the effectiveness of the principal because it is through these interactions, that the work of the principal gets done.

Because of the highly interactive and political nature of the principalship, effective principals need to possess the interpersonal skills which will allow them to interact frequently and competently with all members of the organization on two significant dimensions. First, in the skill dimension, the principal should be sensitive to nonverbal communication signals, be able to empathize with the individual idiosyncrasies of the work demands of the various member groups within the organization, and be responsive to the political and power relationships between members both in and out of the organization. Second, in the knowledge dimension, the principal should be in command of information pertaining to teaching and learning as well as understanding the non-work dimensions of the life of his/her staff (Greenfield, 1991).

Greenfield (1991) sums up the significance of interpersonal competence when he states: "Interpersonal competence is especially crucial for a principal for it is primarily with and through teachers and others that the work of school administration is accomplished" (p.18).

The importance of interpersonal competence to principal effectiveness is clear given that the vast majority of the work of the principal involves interaction with other 
members of the organization. This study will look more

deeply at this critical variable by analyzing the interpersonal "orientation" of the principal when he or she interacts with others.

The instrument used to determine the principal's interpersonal orientation will be the MACH $\mathrm{V}$ scale (Appendix C) developed by Christie \& Geis (1970). The MACH Y instrument places the principal on an interpersonal orientation continuum which ranges from those who are high Mach (analytical, cognitive) to those who are low Mach (empathetic). Christie and Geis (1970) contend that,

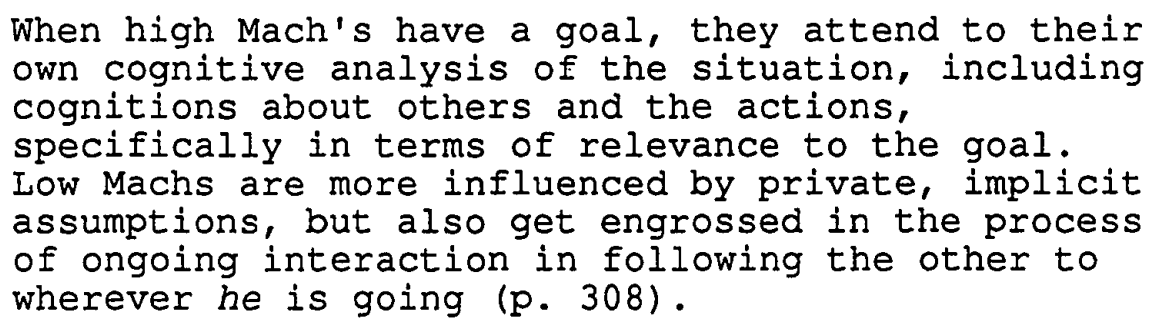

The researcher believes that the interpersonal orientation of the principal significantly impacts the relationship that he or she has with the other members of the school. The interpersonal orientation of the principal should, therefore, be directly related to the principal's interpersonal competence. As noted previously (Blumberg \& Greenfield, 1986; Greenfield, 1987, 1991) interpersonal competence is one of the key personal variables associated with principal effectiveness. 


\section{Demegraphic Variables}

This study has as its primary focus exploration of vision, interpersonal orientation and personal values of elementary principals. In an attempt to shed some light on what these schools, principals and teachers look like, the researcher examined vision, interpersonal orientation and personal values by analysing selected demographic varibles.

Literature reviews on each of the three key variables are presented in chapter two; however, in each case little or no studies exist which which link school, teacher or principal demographic variables to the principal's vision, interpersonal orientation or personal values.

While the researcher has no specific hypotheses in mind when testing these demographic data against the three key variables, he is however interested in clarifying any significant differences that there may be based on gender, age, experience, tenure, socio-economic status or size of the school.

With each demographic variable the aim is to determine the relationship of that variable to vision, interpersonal orientation and principal personal values. This clarification will help to either support or question any conclusions drawn at the end of the study. Additionally, the demographic data will help strengthen the reliability of the instruments. 
STATEMENT OF THE PROBLEM

It is the intended purpose of this research study, to try to identify those interpersonal orientation characteristics, and the particular personal values, which are present in elementary principals.

While there is a growing interest in research on principal vision there have been only limited attempts to correlate additional variables such as interpersonal orientation, personal values and biographical data.

This study will therefore address the following research questions:

1. What are the teachers' perceptions of principal vision?

2. What are the principals' predictions of the perception's teachers have of principal vision?

3. Do principals and teachers differ in their perception of principal vision?

4. Is the gender of the teacher related to teacher perceptions of principal vision?

5. Is the age of the teacher related to teacher perceptions of principal vision?

6. Is the length of time that a teacher has worked with a principal related to teacher perceptions of principal vision? 
7. Is the length of teaching experience related to teacher perceptions of principal vision?

8. Is the size of the school related to teachers' perceptions of principal vision?

9. Is the percentage of students on free and reduced lunch related to teacher perceptions of principal vísion?

10. Does the number of years of experience of the principal have any relationship to teacher perceptions of principal vision?

11. Is the length of time that a principal has been in a school related to teachers' perceptions of principal vision?

12. Is the gender of the principal related to teachers' perceptions of principal vision?

13. What are the principals' personal values?

14. Is the gender of the principal related to his/her personal values?

15. What is the relationship between principal personal values and teachers' perceptions of principal vision?

16. What are the principals' interpersonal orientations?

17. Is the interpersonal orientation of the principal related to teacher perceptions of principal vision?

18. Is the interpersonal orientation of the principal related to his/her personal values? 
SIGNIFICANCE OF THE STUDY

While the study of leadership effectiveness has received a great deal of attention in recent years, research into the personal characteristics of effective leaders has received little recent attention. An ERIC search, conducted in December of 1992, revealed 51 documents related to leader or principal vision at the elementary school level. A close inspection of each of these documents revealed that only 13 addressed principal vision as it has been discussed in this study. It should be noted that vision is referenced more frequently in relation to the school's vision, creating a shared vision among members of the school, and to a lesser extent where principal vision was referred to as meaning "the most important" vision of the school.

A further ERIC search revealed that 19 documents addressed principal personal values, nine of which were relevant at the elementary level, and seven documents addressed the principal's interpersonal orientation. No studies dealt with all three variables, principal vision, principal interpersonal orientation and, principal personal values, at either the secondary or elementary level. The three most related studies to date have been Greenfield's (1986) "Moral Imagination, Interpersonal Competence, and the Work of School Administrators", Licata, Greenfield, and Teddlie's (1989) study "Principal Vision, 
Teacher Sense of Autonomy, and Environmental Robustness" which focused upon 57 elementary schools in Louisiana, and Johnson's (1991) dissertation "Principal Vision, Environmental Robustness, and Teacher Sense of Autonomy in High Schools."

One of the most significant aspects of this study, therefore, is that it will add to the very slim body of existing research on what Blumberg and Greenfield (1986) refer to as the "person characteristics" associated with effective principals. They state that much of the research associated with the principalship is preoccupied with cause and effect assumptions about leadership and with the leadership function of administration. When this occurs, they describe three things which happen:

(1) the principal or some associated set of behaviors, characteristics, or activities is treated as an independent variable and tends to be overly emphasized by researchers; (2) the interdependency or reciprocal character of social relationships, events, and activities is deemphasized; and (3) contextual variables are virtually ignored. (p. 234)

This study is particularly concerned, through exploration of the interpersonal orientation variable, with looking at the interdependency or reciprocal character of social relationships, events and activities, in school leadership, as charged by Blumberg and Greenfield (1986). The researcher believes, that the interpersonal orientation 
of the principal, significantly impacts the relationship that he or she has with the other members of the school, hence influencing his or her overall leadership effectiveness. The researcher was particularly interested in the relationship of interpersonal orientation to vision as a preliminary step toward understanding the overall leadership equation.

By investigating the personal values of the principal, this study will further help to illuminate the "person characteristics" of effective school leaders. The researcher therefore believes, that the personal values of the principal deeply affect that principal's view of what a school should be - his/her vision, as well as the manner in which the principal interacts with other members of the organization - his/her interpersonal orientation.

This study will help to identify personal characteristics of principals associated with teacher perceptions of principal vision which may either support, refute, or clarify the propositions offered by Greenfield (1986) in this area. And, finally, it will help us better understand the interplay between the three variables; vision, interpersonal orientation and, personal values. This will be particularly relevant given the growing need for administrators who indeed can make a difference in their schools and who are also capable of dealing with the implementation and implications of change agendas, such as 
Oregon's property tax limitation law, commonly referred to as Measure 5, and Oregon's Education Act for the Twentyfirst Century.

This study's significance to the field of educational administration lies in the assumption that effective leaders possess certain interpersonal competencies and personal values associated with their ability to maintain high vision profiles. By revealing these associations between interpersonal orientation, personal values, and principal vision, we may be helping to identify skills which might be learned by others.

\section{SUMMARY}

This study is concerned with school leadership. In particular, it examines three personal characteristics of principals, believed to be associated with effective schooling. The variables examined in this study (principal vision, principal interpersonal orientation, and principal personal values) are based heavily upon the work of Blumberg and Greenfield (1986) and Greenfield (1982, 1987, 1988, 1991).

Chapter II provides a review of the educational leadership literature, as well as a review of the literature pertaining to principal vision, principal interpersonal orientation, and principal personal values. Chapter III 
describes the data collection and analysis techniques, the descriptive and inferential statistics used, sampling characteristics and procedures, and a description of the School Vision Inventory, the Mach $V$ interpersonal orientation scale and the Profile of Iife Values. Chapter IV presents the results of data analysis and Chapter $V$ includes a summary of the study and offers conclusions as well as recommendations for practice and further research. 
CHAPTER II

\title{
A REVIEW OF THE LITERATURE
}

\author{
INTRODUCTION
}

The central purpose of this chapter is to present a

review of the literature that relates to vision,

interpersonal competence and values in educational

administration. The following sections have been included.in

this literature review: (1) School Leadership, (2) Principal

Effectiveness, (3) Principal Vision, (4) Principal

Interpersonal Orientation, and (5) Principal Personal

Values.

SCHOOL LEADERSHIP

Leadership is a subject which has long excited interest among scholars and lay persons alike. The term connotes images of powerful, dynamic persons who command victorious armies, direct corporate empires from atop gleaming skyscrapers, or shape the course of nations. Why do certain leaders (Gandhi, Mohammed, Mao Tse-tung) inspire such intense fervor and dedication? How did certain leaders (Julius, Caesar, Charlemagne, Alexander the Great) build great empires? Why are certain leaders (Winston Churchill, Indira Gandhi, the Shah of Iran) suddenly deposed, despite their apparent power and record of successful accomplishments? How did certain undistinguished persons (Adolf Hitler, Claudius Caesar) rise to positions of great power? Why do some leaders have loyal followers who are willing to sacrifice their lives for their leader, and why are some other 


\begin{abstract}
leaders so despised that their followers conspire to murder them (e.g., as occurred with the "fragging" of some military officers by enlisted men in Vietnam)? (Yukl,1989, p.1).
\end{abstract}

This quote from Yukl's (1989) book, Leadership in erganizations, helps to illuminate the complexity which exists when trying to study leadership as well as the fascination which surrounds the subject.

The literature on leadership, although vast, seems to show that there are four basic approaches which can be used when attempting to classify the research (Hall, 1991; Hoy \& Miskel, 1991; Johnson, 1991; Spotts, 1976; Yukl, 1989). These four approaches are (A) the power and influence approach, (B) the behavior approach, (C) the trait approach, and (D) the situational approach (Yukl, 1981, p. 7).

The power and influence approach explains leadership in terms of the amount of power which is available to the leader, the types of power available, and how that power is exercised. A key element in the research on this approach centers around the notion of reciprocity of influences between leaders and followers (Johnson, 1991; Yukl, 1989, p. 8).

Central to the power and influence approach is the power taxonomy developed by French and Raven (1959). The five categories of power are: 
(1) Reward Power, which emphasizes that people will respond to the power agent in order to receive rewards which are believed to be controlled by the power agent.

(2) Coercive Power, which emphasizes that people will respond to the power agent in order to avoid punishments which people believe that the power agent possesses.

(3) Legitimate Power, which emphasizes that people will respond to the power agent because they believe that the agent has the right to make the request and a that it is their duty to comply.

(4) Expert Power, which emphasizes that people will respond to the power agent because they believe that the agent has special knowledge about the best way to accomplish things.

(5) Referent Power, which emphasizes that people will respond to the power agent because they admire the agent or wish to gain his/her approval (Yukl,1989, p.35).

The second of the leadership approaches relates to the behaviors of leaders on the job. This behavior approach centers around description of the actions of leaders in terms of activity patterns, managerial roles, behavior categories, and the differences in behavior patterns between effective and ineffective leaders (Yukl 1981, p.92).

The situational approach constitutes the third of the major approaches to leadership. Here the major emphasis is on the situational factors effecting leadership such as 
authority and discretion, the nature of work, ability and motivation, and the external work environment (Yukl, 1989, p.9) .

The trait approach emphasizes the personal attributes of leaders. The earliest of the leadership theories in this area go back to the $1930^{\prime}$ 's and $1940^{\prime}$ 's and were centered around personality traits and general intelligence. More recent research however has shifted this focus towards how leader attributes relate to leadership behavior and effectiveness. Some of the more common traits associated with leadership effectiveness include: "self confidence, emotional stability, energy level, initiative, stress tolerance, and lack of defensiveness" (Yukl, 1989, p. 202).

Bolman and Deal (1984, 1991 and 1992) organized theories of organizational leadership into four frames or categories. The first of these is the structural frame which emphasizes structure, rationality and efficiency. Leaders within this frame set clear lines, value analysis and data, solve problems with rules and policies, and hold people accountable for results. The second is the human resource frame which focuses on the individual's interaction with the organization. Leaders in this frame value empowerment, facilitation, relationships, and feelings. The third or political frame emphasizes the conflict which exists between groups for scarce resources. Leaders in this frame place much importance on building coalitions, building power 
bases, and negotiating compromises. The final, or symbolic frame, places emphasis on the meaning and predictability which can be formulated out of the chaos of organizations. Leaders in this frame pay attention to myth, ceremony, ritual, and other symbolic forms.

Yukl (1989, p. 269), presented an integrated model of leadership which combines all of the key approaches of leadership. Previously, argues Yukl, leadership was only looked at in terms of its parts. For example, researchers would study the effects of personal power or leadership behavior as a way of improving organizational effectiveness. Yukl's model incorporates all of the key variables in a way which emphasizes their interconnectedness.

Central to the Yukl model is the notion that the overall effectiveness of an organization is mediated by a core set of intervening variables, such as subordinate effort, role clarity and ability, organization of work, cooperation and teamwork, resources, and external coordination. These intervening variables are in turn affected by the interaction of factors such as a leader's personal power, his/her specific traits and skills, his/her leadership behavior and a vast array of situational variables (Yukl, 1989).

Hall (1991) has noted that the practice of studying leadership under one of the four approaches alone is often misrepresentitive of the complexity of the world of the 
leader. He stressed that the current move toward the conceptualization of leadership involving a combination of factors was much more acceptable. He states:

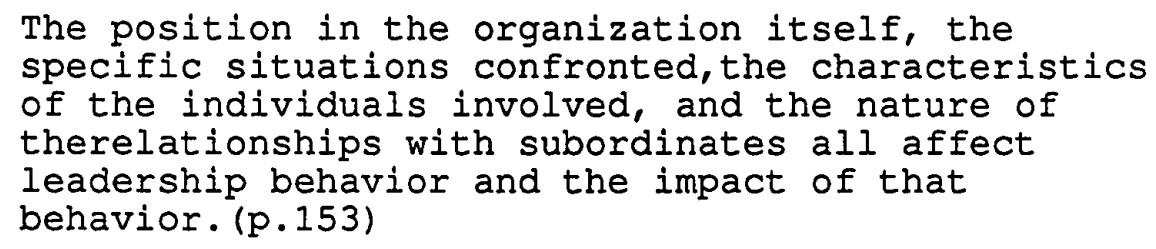

Sergiovanni (1991) sees leadership in terms of a set of driving forces which act to push the organization forward. In the school environment the five driving forces of leadership are: (1) technical, (2) human, (3) educational, (4) symbolic, and (5) cultural (p.100).

The technical force assumes that one of the basic premises of any organization is the need for proper management. Principals with strong technical force would be competent at dealing with tasks such as planning, coordinating, scheduling, and organizing. Leaders with a strong technical force, it is argued, provide work places which are characterized by order, reliability, and security for the members of the organization which, in turn frees them up to concentrate on the major purposes of their work (Sergiovanni, 1991, p.101).

The human force of leadership centers around the leader's ability to harness the social and interpersonal potential within the organization. In schools' this would 
mean meeting the interpersonal needs of teachers and students and providing growth opportunities for staff members and students, as well as providing support and encouragement (Sergiovanni, 1991, p.101).

The educational force relates to the power that the principal has because of his/her expert knowledge about schooling and other areas pertaining to education. Areas of expertise would include: " diagnosing educational problems; counseling teachers; providing for supervision, evaluation and staff development; and developing curriculum " (Sergiovanni, 1991, p.102).

The symbolic force centers around the leader, focusing the attention of the organization towards important goals and behaviors and signaling to others what is valuable in the school. Typical symbolic leadership behaviors would include examples such as presiding over ceremonies and other special occasions, as well as spending time in classrooms and spending time with students (Sergiovanni, 1991, p.101).

The cultural force involves the leader's ability and responsibility to build into the organization a common strand of beliefs, values and culture that tend to give the organization a unique identity over time.

Examples of leadership activities associated with the cultural force include:

Articulating school purposes and mission; socializing new members to the school; telling 


\begin{abstract}
stories and maintaining or reinforcing myths, traditions or beliefs; explaining the "way things operate around here"; developing and displaying a system of symbols (as exemplified in the fourth force) over time; and rewarding those who reflect this culture. (Sergiovanni, 1991, p.105)
\end{abstract}

\title{
PRINCIPAL EEFECTIVENESS
}

Fiedler (1967) proposes a very simple yet straightforward criterion for effectiveness: specifically, the extent to which a group accomplishes its primary task. He illustrates that, even though the groups output is not entirely a function of the leader's skills, the leader's effectiveness is judged on how well the group achieves its task (p.9).

The first true scientific studies of public school leadership were conducted by the National Education Association in the late $1920^{\prime} \mathrm{s}$. These studies were specifically designed to generate demographic data about principals as a group and centered around the opinions and perceptions of principals about a variety of job related issues. Typically these studies were atheoretical and it wasn't until the 1960's and 1970's that researchers began to realize the importance of the school principal as a key change agent in local, state, and national educational policy (Greenfield, 1982). 
Hemphill, Griffiths, and Frederikson (1962, pp. 330344) conducted a national research study of 232 principals to determine key characteristics associated with the nature of the job, principal selection and ideas, and materials useful in principal training. The researchers concluded that specific differences are present between the administrative behaviors exhibited by men and women. Specifically, men are more prone to comply with suggestions made by others and to analyze administrative tasks. They make more concluding decisions, follow pre-established procedures more often, and took a greater number of terminal actions. Women on the other hand, were more prone to exchange information, maintain organizational relationships, and respond to outsiders. They were also more inclined to ask subordinates for information, were more knowledgeable about instruction and teaching techniques, did more work, and discussed situations more often with superiors.

Gross and Herriot (1965) conducted a study of 175 elementary principals to determine the existing levels of Executive Professional Leadership, a measure which stresses the executives role in improving the quality of staff performance. Their results suggest that principals showing a high degree of professional leadership will have more productive staffs who also experience higher morale. They also concluded that school principals should not rely solely 
on the provision of routine administrative services to their staff.

Gross and Herriot (1965) also suggest that there are four personal characteristics which could be used to predict those principals who have high levels of Executive Professional Leadership. These are: (a) high levels of academic achievement in college, (b) the motive of service, (c) a commitment to off duty time on the job, (d) and a high degree of interpersonal skill (pp. 150-157).

An investigation by Lipham and Francke (1966) into the nonverbal behavior of principals and military executives who were classified as either innovators or noninnovators, suggested that the nonverbal actions of administrators projected clear images to others. These images were determined to be critical factors in how effectively principals communicate to others. This particular study began to highlight the complexity of personal and interpersonal factors critical to understanding the principalship (Greenfield, 1989) .

After reviewing more than 75 research studies and reports Persell and Cookson (1982, pp. 23-28) determined that good principals display nine recurrent behaviors. They are:

(1) Demonstrating a commitment to clear academic goals, being prepared to give of their time, and being hard working and fair minded role models to their teachers. 
(2) Creating a climate of high expectations by setting a tone of respect for teachers and students.

(3) Functioning as an instructional leader by becoming directly involved in instructional policy on the face to face level with teachers.

(4) Being a forceful and dynamic leader by welcoming new ideas, having a high tolerance for ambiguity, being analytical, and by adopting a practical stance on life.

(5) Consulting effectively with others by involving the faculty in the decision making process and encouraging genuine exchange amongst teachers.

(6) Creating order and discipline by obtaining support and materials or by minimizing factors that may disrupt the learning process.

(7) Marshaling resources both inside and outside of the school environment in order to create a system that will tolerate diversity.

(8) Using time well by devoting more of their time to "out of office" activities.

(9) Evaluating results of the clear goals that they have set for their schools.

Greenfield (1982, pp. 17-18) suggests that there are six characteristics associated with effective principal performance: (1) the ability to work closely with others on a face to face basis; (2) the ability to manage conflict and 
ambiguity; (3) the ability to integrate the cluster of demands competing for the time of the principal; (4) the ability to adapt to the ever changing human, social and environmental conditions; (5) the ability to formulate action plans and decisions responding to a system in constant motion; and (6) skill in assessing and evaluating the consequences of schooling for children by applying the knowledge pertaining to effective managerial and educational practice.

Burns (1978) suggested a theory of leadership which proposes that leadership exists when people with certain motives and purposes activate resources so that they can motivate and satisfy the needs of those who would follow. According to Burns there are two general types of leadership: (1) transactional leadership which focuses on extrinsic motivation and needs, and (2) transformative leadership, which focuses on the more intrinsic moral and other higher order needs motivation. Transformational leadership occurs at two stages: the first, is concerned with higher order psychological needs for esteem and autonomy and the second, is concerned with moral questions aimed at what is good, right and dutiful, as well as questions centered around ones sense of obligation (Sergiovanni, 1991).

Etzioni (1988) followed through closely upon this moral dimension of leadership. Etzioni's (1961) original work 
suggested that there were three broad strategies that a leader can use to get people involved and motivated. The three were: (1) coercive, which centers around getting those within the organization to do what the leader wishes by forcing the threat of penalties upon them, (2) remunerative, which motivates people to act because they are enticed by the thought of rewards such as money, career advancement, social standing or grades, and (3) normative, where people are motivated to act because they feel that they are doing something which is intrinsically satisfying or that they. believe is right or good.

of all three strategies, normative has the greatest chance of motivating people to do what they are supposed to do because it relies upon the moral involvement of people through the shared commitment to values, beliefs, and norms (Etzioni, 1988).

Sergiovanni (1991) also emphasizes the importance of normative strategies when he stated that:

Moral involvement has the best chance of ensuring and maintaining inspired commitment and performance from students, teachers, and parents. Strategic commitment to moral involvement does not preclude the tactical use of coercive and remunerative compliance, but it does suggest that the overarching framework for compliance must be normative. (p.55)

Greenfield (1991) declares that discussing leadership in terms of how principals exercise influence is critical to 
understanding the nature of leadership in schools. He suggests that attempting to lead through coercive or remunerative strategies is likely to diminish a principal's ability to lead teachers. Given the primarily social and cultural goals of schools, normative power is the best means of influencing participants.

Levinson (1968), Schriesheim et al (1982) and Greenfield (1991) have agreed that the most powerful basis for the use of normative power lies in the importance and trust that the follower places in the leader. The key element in this leadership by consent approach, is that beliefs cannot be changed unless one is willing to change them.

A central theory to understanding this relationship between normative power and principal effectiveness is Wieck's (1976) work on educational organizations as loosely coupled systems. Central to Weick's position is that schools, unlike most other types of organizations, are made up of several structural groups which have the ability to function successfully without tight structural ties (couplings) to other groups. The counselor's office is loosely coupled to the principal's office, although each seem to be somehow attached. The counselor may go for days without interacting with the principal yet both are performing vital functions for the school so in essence the two are loosely coupled (Weick, 1976). 
Because teachers are professionally independent in relative terms within their schools, principals have a much better chance of influencing them if they rely upon personal sources of influence. Greenfield (1991) has noted that personal influence resides in qualities attributed to the leader such as information, functional or technical expertise, the ability to be helpful, level of commitment to goals, values, beliefs and trustworthiness. He continues by showing that this personal influence resides in qualities attributed to the leader by those whom one desires to influence $(p .27)$.

After conducting an in-depth study of eight school principals, Blumberg and Greenfield (1980) concluded that success and effectiveness of a principal is related to (1) that principal's commitment to the realization of an individual vision, (2) his/her ability to take the initiative and take a proactive stance toward the demands of their work-world environment, and (3) his/her ability to handle routine maintenance demands so as to be able to spend more on the job time in the pursuit of their personal vision (p.208) .

Gardner (1990, p. 119) said that, for leaders to be effective and function in the complex world of today, they need critically important skills which involve (1) agreement building by listening to all people at all levels, (2) networking by encouraging people to come together to create 
change, (3) the exercise of non-jurisdictional power by creating consensus rather than power, and (4) institution building through empowerment of their co-workers.

Astin and Leland (1991), in their discussion of outstanding women leaders, continue this extrapolation of effective leadership traits by highlighting several key components. Although originally centered around women leaders, their recommendations apply equally to both sexes. Effective leadership, they believe, includes the ability to assess a situation, to engage others in collective efforts, and to bring about needed change. They continue by saying that leaders need to be politically adept, be willing to take risks, and be perceptive particularly in relationship to their environments. Paramount, however, is the need for the acute development and critical use of outstanding interpersonal skills (Astin \& Leland, 1991, p115).

Yukl (1989) suggests that listening to others, being aware of negative reactions, increasing the frequency of face to face interactions, and trying to discover the underlying values and needs of those with whom they interact will help illuminate the various demands and constraints placed upon them. Each of these suggestions helps the principal "humanize" the problem and become a more effective communicator.

Terrence Deal in Greenfield (1987), in distinguishing between effective schools and effective principals, stated 
that effective schools meet the human needs, get things done, create meaning for the learners, and negotiate an agreement between existing factions. Effective principals focus their time and attention in each of these areas. Deal states that effective principals:

\begin{abstract}
Rotate their lenses like a kaleidoscope, finding different patterns in the social world that they are asked to administer. They enjoy providing the leadership for each. They know better than to concentrate their efforts on one view - even if researchers and policy makers tell them that they should.
\end{abstract}

(Greenfield, 1987, p. 244)

Much of the literature on effective leadership to date has focused upon the role of the principal as the leader, instructional supervisor, change agent, decision maker, and conflict manager. This focus seems more concerned with what it is that the effective principal should do rather than what it is that he or she actually does. Other critical dimensions such as personal, organizational, and environmental factors, that may have a great influence on the principal, seem to have been largely ignored in the research (Greenfield 1982).

Blumberg and Greenfield (1986) have noted that much of the research on leadership effectiveness has overemphasized the behaviors, characteristics, or activities of principals and, consequently, the interdependency or reciprocal nature of the social relationships within a school, along with the 
contextual variables, have been virtually ignored. This current literature review would lead one to believe that little has changed since 1986 in that Blumberg and Greenfield's conclusions could still be drawn today. This study will attempt to look at three personal variables believed to be associated with the effectiveness of the principal's leadership: vision, interpersonal orientation, and personal values. These three personal characteristics variables are assumed, by the researcher, to be interrelated and this study will be undertaken to gain a better theoretical understanding of these interrelationships.

An ERIC search in December of 1992 revealed that, to date, no studies have dealt with all three variables, principal vision, principal interpersonal orientation and, principal personal values, at either the secondary or elementary level.

PRINCIPAL VISION

One of the most comprehensive reviews of the literature pertaining to principal vision was conducted by Johnson (1991) as part of his unpublished doctoral dissertation; Principal Vision, Environmental Robustness, and Teacher Sense of Autonomy in High Scheols. Johnson states that 
The concept of vision is as rooted in antiquity as it is in contemporary dialogue. Over a thousand years before the birth of Christ, King Solomon prophesied: "Without a vision, the people will perish" (Proverbs 29:18). From prophets to presidents, vision is on the lips of the people. President Bush talks of "that vision thing." In the 1990 hit movie Dick Tracy (Beatty, Producer), gangster Big Boy Caprice, when challenged why he should be the mob boss of the city responds: "Because I have a vision. A big boss must have a vision." From sacred to secular, from ancient manuscript to American comic strip, from faith to farce, the concept of vision is experiencing a new birth as an essential component of our leadership genre. ( $p .35$ )

The ability of the principal to hold and act upon a vision has become increasingly more important in today's educational organizations and, as such, has started to draw a great deal more attention in the research (Astin \& Leland, 1991; Barth, 1990; Blumberg \& Greenfield 1980,1986;

Johnson, 1991; Licata, Greenfield \& Teddlie, 1989; Sergiovanni, 1984; Vaill, 1990).

Blumberg and Greenfield (1986, p181) highlighted three key characteristics associated with effective principals. These are (1) an individual commitment to a particular educational or organizational vision, (2) an ability to assume the initiative and take a proactive stance in relation to the demands of their world of work, and (3) an ability to satisfy routine organizational maintenance demands so that more time can be devoted to the realization of their personal vision. 
Licata, Greenfield, and Teddlie (1989) defined the concept of vision as: "the capacity to see the discrepancy between how things are and how they might be and the need to compel others to act on those imagined possibilities" (p.94). Bricker (1984) reflected that vision is not some sort of strategic plan but is rather more like the compass which points the direction to be taken, that inspires enthusiasm, and that allows people to put into and take part in the shaping of the way that will constitute the school's mission.

Sergiovanni (1991) highlights that vision in school leadership needs to be understood differently than what it is in the corporate sector. He states that vision should not be construed as a strategic plan that serves as a road map in charting a course for the organization. Rather, it should be seen as a compass that points the direction to be taken. Vision, he continues, should evoke a sense of enthusiasm and belonging on the part of the stakeholders. People should be allowed to buy into and take part in the shaping of the school's mission. The development of this vision requires that there be a building of shared consensus about the purposes and beliefs so that people can bond together around common themes (p.180).

In his study of highly successful leaders, Bennis (1984) concluded that having a compelling vision was a key ingredient to those leaders' success. His conception of 
vision refers to the capacity of a person to communicate a view of a desired state of affairs that evokes in other members of the organization a commitment to work towards that state of affairs.

According to Barth (1990), during the course of the average day a principal may engage in several hundred interactions. A personal vision can give the principal a point of reference which can guide these interactions. Without a vision, he continues, our behavior becomes reflexive, inconsistent and short-sighted and "our activities in school become empty vessels of discontent" Barth (1990, p.211).

In his 1990 book, Improving schools from within, Barth presented five reasons why school practitioners need to develop visions. They are: (1) commonalties in vision occur across a vast array of educators hence they are the best chance for school reform and therefore are more likely to be acted upon by those concerned; (2) research in schools generally covers a broad base, asking few questions of lots of people, whereas visions are developed by individual insight over many years and hence add richness and credibility to school people; (3) visions are ideas, and as such, when shared with other people, they can give the person a sense of satisfaction and recognition; (4) the personal visions of adults, no matter how fragmented and rudimentary, are not inconsequential to children; and (5) by 
not articulating visions of what the school should be like, principals are inviting random prescription from the outside (pp. 149-152).

Vision should start out with a single person and principals should talk openly about their beliefs, values, dreams and ideals. Principals are the ones who are responsible for starting the dialogue about what schools should stand for, believe in, and where the school or district should be headed (Peters \& Austin, 1985).

Sergiovanni (1990) states that vision is a critical part of the school's purpose and should influence the direction that a school takes, as well as the decision that the staff, community and students make as they travel that path. He states that "purposes" with the following characteristics have the most chance of succeeding: (1) they should be clear enough that you know when you are achieving them; (2) they should be accessible enough that they can be achieved with the existing resources; (3) they are important enough to reflect the core values and beliefs of the school; (4) they are powerful enough that they can inspire and touch people in a world which is managerially loose and culturally tight; (5) they should be few in number and focused so that people can distinguish what is important and what is not; (6) they should be characterized by consonance in that most of the purposes should hang together as a group; (7) they 
should encourage cooperation in the school and not competition; (8) they are difficult enough to evoke challenge and cause people to persist; and (9) they are resilient enough to stand the test of time and therefore are not easily challenged (p.60).

Kouzes and Posner (1987), in a study of more than 7,500 managers from private and public institutions, found that over half of the respondents sought visionary characteristics as part of their leadership style. In another study by the same researchers, which looked at 1,500 top executives across twenty countries, they found that 75 percent of the respondents thought that in today's world a leaders should convey a strong sense of vision; 98 percent said that this would be important in the year 2000 .

An effective vision should be one that speaks to the heart and represents values that are important to the individual. This vision should so excite the people in an organization that they feel motivated to support, act on behalf of, and feel proud to belong to that organization (Mauriel, 1989).

Cuban (1987) developed a set of criteria for judging the visions of leaders. The five key components are: (1) clarity, or the ability of the vision to be understood by followers; (2) fit, or how well the vision fits the aspirations of the followers; (3) history, or whether the vision is consistent with or departs from the history of the 
organization; (4) flexibility, or the ability of the vision to be modified by the followers; and (5) moral principles, or the extent to which the vision is anchored in a set of ethical values (p.276).

Bennis and Nanus (1985) contend that, without a vision, leadership becomes ineffective and as such helps to maintain the status quo. They argue that ultimately this lack of visionary leadership could lead to the disintegration of our society because of the lack of purpose and cohesion (p.228).

The reduction of goal and vision ambiguity is critical to the ability of the principal to translate his/her vision into action. Effective principals, after defining their vision for their schools, seek the support of staff to implement policies and procedures associated with that vision (Blase, 1987).

LeSourd and Grady (1990) defined visionary principals as those who are highly motivated by their personal convictions, committed to achieving school goals, value a prominent shared school philosophy, believe in innovation, and have an image of a better school in the future. Nonvisionary principals have stability rather than change as their central focus. They focus on emphasizing the day to day management functions instead of motivation which leads to visualizations of the future (pp. 105-106).

Vision or "moral imagination" was defined by Licata, Teddlie and Greenfield (1989) as: "The capacity to see the 
discrepancy between how things are and how they might be and the need to compel others to act on those imagined possibilities" (p.94).

Blumberg and Greenfield (1986), as the result of an indepth study involving four elementary and four high school principals, concluded that vision is a critical factor in the effectiveness of principals. They found that the implementation of a particular principal's vision was directly related to the principal's ability to develop warm working relationships with others as well as a shared concern for good practice and the best interests of students.

Blumberg and Greenfield (1986) see vision as the capacity to exercise moral imagination and as the foundation upon which the moral authority of the principal rests. Vision is what allows a principal to lead a school well and as such is of critical importance for principals because it is they who will determine what is to become of the school. In their words: "As the principal goes, so goes the school" (p.228).

The literature on leadership vision has begun to steadily increase over the past 10 years, however, most of the references to vision are as components of larger articles or books on leadership (Astin \& Leland, 1991; Barth, 1990; Blumberg \& Greenfield, 1980, 1986; Greenfield, 1987, 1991; Licata, Greenfield \& Teddlie, 1989; Johnson, 1991; Licata, 
Greenfield \& Teddlie, 1989; Sergiovanni, 1984, 1987;Vaill, 1990) .

Few studies have used principal vision as one of the central variables related to leadership effectiveness. An ERIC search, conducted in December of 1992, revealed 51 documents related to leader or principal vision at the elementary school level. A close inspection of each of these documents revealed that only 13 addressed principal vision as it has been discussed in this study. It should be noted that vision is referenced more frequently in relation to the school's vision, creating a shared vision among members of the school, and to a lesser extent where principal vision was referred to as meaning " the most important" vision of the school.

\section{LEADERSHIP AND INTERPERSONAL ORIENTATION}

Gross and Herriot (1965), in a study of 175 elementary principals, suggest that there are four personal characteristics which could be used to predict those principals who have high levels of Executive Professional Leadership: (a) high levels of academic achievement in college; (b) the motive of service; (c) a commitment to off duty time on the job; and (d) a high degree of interpersonal skill. Gross and Herriot (1965) seem to be the first 
educational researchers to have seen the true importance of interpersonal competence in school principals.

Greenfield (1986) said that the research is clear about what it is that principals actually do at work and indicates that most school principals actually spend very little time supervising teachers. He continues by stating that the principal's work is "largely social in character, occurs outside of classrooms, and involves a lot of verbal, face to face interaction with multiple actors on the school scene" (p.3) .

Dwyer, et.al. (1985), in a study of the work activity of elementary school principals, concluded that most of the work conducted by principals centered around communication with the variety of groups with which they come in contact. The second largest work activity was that of monitoring work structures, student and staff relationships, plant and equipment, and safety. More than $60 \%$ of the principal's behavior was focused in these two areas.

Greenfield (1986) argues that reforms in educational administration which are centered on instructional matters may be misleading; most of what principals actually do is to respond to "situational imperatives" which are events and activities that demand immediate attention. If not attended to, these imperatives have a high potential to threaten the stability of the school situation, including matters pertaining to curriculum, and instruction. Greenfield 
argues that calling for improved instructional leadership is no more than "prescription" that shows a poor understanding of the principal's work situation. He continues by stating that more attention needs to be given to the lower-order concepts of "moral imagination" and "interpersonal competence" in order to illuminate that which is actually encountered by school principals on a daily basis (pp. 4-5). Foote and Cottrell (1955) refer to interpersonal competence as the personal knowledge and skills that can enable an individual to shape the responses that he or she gets from others. Quoted in Greenfield (1986), Weinstein (1969) said that interpersonal competence is actually the interrelationship of the following ten basic elements:

- Interpersonal task - The response that one actor is intending to elicit from another.

- Interpersonal competence - Being able to achieve interpersonal tasks.

- Lines of Action - What one actor actually does to elicit a desired task response from another.

- Encounter - Any contact between people that involves an interpersonal task by at least one party to the exchange.

- Situation - All the potentially meaningful stimuli present in an encounter.

- Defining the Situation - The process by which participants in an encounter select and organize situational stimuli into a coherent understanding of what is actually occurring during an encounter.

- Projected Definition of the Situation - These are ines of action by one actor intended to influence another actor's definition of the situation.

- Working Consensus - This is the definition of the situation to which participants in the encounter jointly subscribe.

- Situational Identity - All relevant situational characteristics determining who the actors are and what they represent to one another. 
- Identity Bargaining - The process by which actors influence their own or each other's situational identity. (Weinstein,1969, p.16)

Greenfield (1986) states that the last of these elements, "identity bargaining", is critical for the school principal because it is the process whereby one has influence over another person to achieve a desired response. He states that: "The challenge for the principal is to develop a working consensus among teachers as to what the situation is and what needs to be done given that definition of the situation " (p.17).

Greenfield (1986) continues by stating that to be interpersonally competent a principal needs to possess an extensive set of lines of action by having a great deal of familiarity with the work of teachers as well as being knowledgeable about the viewpoints that teachers hold of themselves, their students, community, colleagues, and their work (p.18).

Blumberg and Greenfield (1980), in an in-depth study of four elementary and four secondary school principals, concluded that the principalship is a highly personal role which involves numerous opportunities to teach teachers to problem solve so that the problems of the teachers do not become the principal's problems. Successful principals, they believe, rely upon their ability to listen to and dialogue with members of the organization. They contend that the 
degree of the principal's interpersonal competence, particularly in the area of establishing and maintaining desired identities, mediates much of what a principal does on a day to day basis and that this is what more than likely determines the difference between those principals who are successful and those who are not (p.198).

Astin and Leland (1991), in their book, women of Influence, women of Vision, define effective leadership as including the ability to assess a situation, to engage others in collective efforts, and to bring about needed change. They said that leaders need to be politically adept, be willing to take risks, and be perceptive particularly in relationship to their environments. Paramount, however, is the need for the acute development and critical use of outstanding and interpersonal skills ( $p$. 115) .

Schools are largely social in nature; the principal may encounter literally dozens of interactions with staff, students, community, parents, and supervisors which are often brief, fractured, and ambiguous. Very little of the research on principal effectiveness addresses the interpersonal competence of the principal and even less addresses the principal's interpersonal orientation.

The importance of interpersonal competence to principal effectiveness is clear, given that the vast majority of the work of the principal involves interaction with other 
members of the organization. This study will look more deeply at this critical variable by analyzing the interpersonal "orientation" of the principal when he or she interacts with others.

\section{LEADERSHIP AND PERSONAL VALUES}

Krathwohl, Bloom and Masia (1964) see values in terms of a social product that has been internalized or accepted by a person because of the way in which it fits that persons particular sense of worth. The highest level of personal value exists when a person commits to that particular value, and the lowest level exists when one simply believes in it existence.

Omery $(1989, \mathrm{p} .500)$ stated that values relate to the effective disposition of human behavior, are organized in a hierarchical order, have motivational worth, and are expressed as behaviors or verbalized standards of conduct (in Bellarts, 1992, p. 13).

The following section from Greenfield in Sergiovanni and Corbally (1986 eds.) illustrates the powerful appeal of values:

A recent recruitment advertisement for the British Army took up two pages in the Sunday Times and was headed: "A tough act to follow." It showed the marble pillars of the chapel at Sandhurst inscribed with the names of former cadets whose

"careers ended in the Great War." The text with 


\begin{abstract}
the picture asks those who are considering a career as an army officer to examine their. intentions. It comes quickly to the point: "The question isn't how deeply you are moved. It's whether you are prepared to do what they did." It goes on to say that applicants must be prepared to die, "To accept the possibility of being killed or wounded. And as an officer, you must lead your men to accept it, too." Now that is an up-front and honest appeal to higher values. Nor does the text invoke the usual inducements: money, travel, women, the good life. While one may argue with its values, the point to be made here is simply that this statement recognizes what an army does and makes no bones about the fact those who are to leaders within it have to be committed to certain values and have the task of committing others to those same values as well. (p.166)
\end{abstract}

Hoy and Miskel (1991, p. 215) have defined values as " the shared conceptions of what is desirable". They argue that values serve to illuminate the basic character of any organization and as such help to determine the actions of those within the organization. It is these shared values, they continue, which help members understand what the organization stands for and what standards they should uphold. Hoy and Miskel also contend that when people understand these values they are more likely to feel like part of the organization.

Thomas Greenfield, in a discussion on leadership and organizational culture, in Sergiovanni and Corbally (1986 eds.), indicated that leaders will often try to get others to commit to the values that they personally believe are good. He continues by saying that organizations are in essence built around a unifying set of values in which the 
members of the organization believe. The business of being a leader centers around ones' ability to get others to commit to these particular values.

Blumberg and Greenfield (1980), in a study of elementary and secondary principals, found three central characteristics associated with highly effective school leadership: (1) these principals did not allow themselves to become consumed by routine organizational maintenance demands, (2) they tended to be active and take the initiative and, (3) they were highly committed to certain personal values about schools and children.

Sergiovanni (1990) emphasized that the key to successful schooling is bonding the people within the organization together around common purposes and beliefs that gives them a sense of what is of value within the organization.

Rescher (1982) has shown that values exist in two distinct categories: egocentric, where the focus is on the self through privacy, comfort, and /or success, and group oriented, where the focus is on interaction with others through pride, reputation, patriotism, social justice, and aesthetics. In both cases, values are formed through personal deliberation which is followed by a behavioral response $(p .16)$.

Bellarts (1992), in a study of personal values, work values and job interests of nursing students, suggested that 
nursing education faculty needed to be aware of their own values and how these values relate to teaching, learning, and professional practice. Bellarts also concluded that selected biographic variables such as age, job interests, and educational preparation played a significant role in determining the personal values of nursing students.

Stark and Lowther (1989), in discussions on University teaching and learning, said that shared personal and professional values is the basis upon which the integration of liberal learning styles into professional education can occur.

Harris (1986), in a paper presented to the Association for Supervision and Curriculum Development, challenged educational leaders to (1) improve their technical competence in teaching and learning, (2) increase their leadership clarity to include a purpose and commitment to the ideals for a better society and, (3) to have more leadership aimed at enhancing the personal and traditional values of public education.

Marshall (1992), in a study of 26 administrators whom she labeled "atypical" because they veered away from the norm of white, male risk avoiders, found that values came into play when administrators were forced to deal with dilemmas arising from chronic tensions in public schooling. She concluded that administrators value the use of persuasion and being open about problems rather than top- 
down management. Other values included a sensitivity to the needs of teachers and, most of all, a concern for each child's ability and equal opportunity to thrive, even to the point of risking their own careers (p. 382).

Simon (1957) noted that decisions come from two sets of premises, those which are based upon facts and those which are based upon values. Blumberg and Greenfield (1986), build upon this by stating that, deciding upon an action or an alternative always involves the assignment of values to facts and the exercise of judgment in arriving at that alternative (p. 225).

Blumberg \& Greenfield $(1980,1986)$ state that it is important to note that the study of personal values does not represent a return to the "traitist approach" to analyzing managerial effectiveness, but rather, represents an attempt to study the character of principals and their qualities as human beings

The actions taken by the principal, as the instructional leader of the school, will be based upon that principal's particular set of personal values. As Greenfield (1987) argues, instructional leadership involves the assignment of values to facts as a necessary part of the decision making and action taking process.

The literature on principal personal values is very sparse. The significance of values in influencing the work of the principal, however, should not be understated. 
Almost every action taken by the principal and every decision made is consciously or unconsciously tied to that principal's moral and ethical stance regarding the needs of children, staff, and community associated with his/her particular school.

\section{SUMMARY}

This chapter presented a review of the literature that relates to vision, interpersonal competence and values in. educational administration. The following sections were included in this literature review: (1) Leadership (2) Principal Effectiveness (3) Principal Vision (4) Principal Interpersonal Orientation and (5) Principal Values. Key to the central focus of this research study is Etzioni's (1961) original work suggesting that there are three broad strategies that a leader can use to get people involved and motivated. The three were: (1) coercive, (2) remunerative and, (3) normative. Of all three strategies, normative has the greatest chance of motivating people to do what they are supposed to do because it relies upon the moral involvement of people through the shared commitment to values, beliefs, and norms (Etzioni,1988).

Sergiovanni (1991) stated that:

Moral involvement has the best chance of ensuring and maintaining inspired commitment and performance from students, teachers, and parents. 


\begin{abstract}
Strategic commitment to moral involvement does not preclude the tactical use of coercive and remunerative compliance, but it does suggest that the overarching framework for compliance must be normative. (p.55)
\end{abstract}

Levinson(1968), Schriesheim, et. al. (1982), and Greenfield (1991) have agreed that the most powerful basis for the use of normative power lies in the importance and trust that the follower places in the leader. One of the underlying assumptions of this study is that the three personal characteristic variables of vision, interpersonal orientation and personal values, are all compatible with normative strategies of leadership.

Another central theorist to this research study is Greenfield (1991). He declares that discussing leadership in terms of how principals exercise influence is critical to understanding the nature of leadership in schools. He suggests that attempting to lead through coercive or remunerative strategies is likely to diminish a principal's ability to lead teachers. Given the primarily social and cultural goals of schools, normative power is the best means of influencing participants.

This literature review has highlighted that the vast majority of research and scholarly writing in the field of leadership effectiveness has focused primarily upon prescribing behaviors, characteristics and activities of principals as they should be in schools. This review has 
confirmed Blumberg and Greenfield's (1986) conclusion that contextual variables and social relationship variables have received little attention in the principal effectiveness literature.

The literature on principal interpersonal competence, and interpersonal orientation in particular, was very limited. References to principal personal values received slightly more attention in the literature, however this was mainly as smaller segments of larger studies or leadership books.

The increase in references to leadership vision in the literature has been noticeable, however most of these references have tended to incorporate principal vision into the shared school vision concept which is very important, but not the focus of this study. 
CHAPTER III

METHODOLOGY

OVERVIEW

The primary function of this research study was to look at the relationship between three variables (vision, interpersonal orientation, and personal values) believed to be significantly related to principal effectiveness. Due to the non-random nature of these attribute variables and the inappropriateness of their manipulation, this study was based upon descriptive research methodologies.

Three separate survey instruments were used to gather quantitative data from a population of urban elementary school principals. Both descriptive and inferential statistics were used.

\section{RESEARCH PROBLEM STATEMENT}

It was the intended purpose of this research study to address the elementary principal's vision, the significance of interpersonal orientation, and the importance of principals' personal values as well as the importance of selected demographic variables, through the following research questions. 
1. What are the teachers' perceptions of principal vision?

2. What are the principals' predictions of the perception's teachers have of principal vision?

3. Do principals and teachers differ in their perception of principal vision?

4. Is the gender of the teacher related to teacher perceptions of principal vision?

5. Is the age of the teacher related to teacher perceptions of principal vision?

6. Is the length of time that a teacher has worked with a principal related to teacher perceptions of principal vision?

7. Is the length of teaching experience related to teacher perceptions of principal vision?

8. Is the size of the school related to teachers' perceptions of principal vision?

9. Is the percentage of students on free and reduced lunch related to teacher perceptions of principal vision?

10. Does the number of years of experience of the principal have any relationship to teacher perceptions of principal vision?

11. Is the length of time that a principal has been in a school related to teachers' perceptions of principal vision? 
12. Is the gender of the principal related to teachers' perceptions of principal vision?

13. What are the principals' personal values?

14. Is the gender of the principal related to his/her personal values?

15. What is the relationship between principal personal values and teachers' perceptions of principal vision?

16. What are the principals' interpersonal orientations?

17. Is the interpersonal orientation of the principal related to teacher perceptions of principal vision?

18. Is the interpersonal orientation of the principal related to his/her personal values?

\section{INSTRUMENTATION}

Survey questionnaires were the only data collection method used in this study. The questionnaires were distributed to schools in two parts. Part 1, which was completed by the teaching faculty at each participating school, consists of the School Vision Inventory (Appendix A) Part 2, which was completed by the principal at each participating school, consists of three questionnaires; the School Vision Inventory (Appendix A), the Profile of Iife Values (Appendix B) and, the Mach V scale (Appendix C), used to measure interpersonal orientation. 
A demographic data section was included as part of the teacher survey (Part 1) with questions relating to gender, age, years of teaching experience, years teaching in current position and, years working with the current principal. Additionally, a demographic instrument (Appendix D), was used with the principal survey (Part 2), to elicit selected biographical information about each of the principals as to their gender, age, years of experience in administration, school size and, staff size. This information will give the researcher a feel for the demographic characteristics of the principal and teacher samples.

\section{The School Vision Inventory}

Originally developed by Greenfield, Licata and Johnson (1989) the School Vision Inventory assesses the degree to which a principal can get others to accept, share and eventually implement that principal's educational vision.

The vision instrument consists of 18 statements. The first two statements on the instrument ask teachers if they believe that their principal has a vision of what their school should be. Teachers respond either true or false to both statements. If a false response was given to either statement, the teachers were asked not to complete the remainder of the vision questionnaire, but instead to go to the end of the survey and complete only the demographic data section. 
The remaining items require teachers to respond to 16 statements pertaining to teachers' perceptions of principal vision. Responses were measured via a four point likert scale with possible choices ranging from strongly disagree to strongly agree.

The School Vision Inventory consists of three subscales. The first subscale (Vision Exchange) consists of five items and measures principals effectiveness in exchanging ideas about his/her vision of what the school should be with others in the school environment. These five items are:

1. My principal effectively exchanges ideas with teachers to achieve this vision.

2. My principal effectively exchanges ideas with students to achieve this vision.

3. My principal effectively exchanges ideas with parents to achieve this vision.

4. My principal effectively exchanges ideas with superiors to achieve this vision.

5. My principal effectively exchanges ideas with members of the community to achieve this vision.

The second subscale, (Vision Internalization) measures the effectiveness of the principal in getting others to internalize or accept his/her school vision. This particular subscale consists of the following four items: 
1. This vision can be achieved.

2. This vision serves the best interests of all the children in this school.

3. I share in this vision.

4. I have accepted this vision of my own free will.

The third subscale, (Vision Sacrifice) relates to the principal's ability to encourage others to make sacrifices to accomplish his/her vision of what the school should be like, and whether or not individuals actually do make these sacrifices. The five vision sacrifice items are:

1. My principal regularly encourages teachers to make personal sacrifices to accomplish this vision.

2. My principal regularly encourages other members of the school community to make personal sacrifices to accomplish this vision.

3. I make personal sacrifices to accomplish this vision.

4. Other members of the school community make personal sacrifices to accomplish this vision.

5. My principal regularly makes personal sacrifices to accomplish this vision.

The School Vision Inventory was scored by assigning numeric values to each possible response for each statement, (Strongly Disagree $=1$, Disagree $=2$, Agree $=3$, Strongly Agree $=4$ ). The theoretical range on the items for the 
Vision Internalization Subscale is $4-16$; the range for the Vision Exchange Subscale is $5-20$; and the range for Vision Sacrifice Subscale is $5-20$.

The original School Vision Inventory, developed by Greenfield, Licata and Johnson (1989), consisted only of true and false response choices. Johnson (1991), after using the instrument in its original form for his dissertation, recommended that the response choices be changed from a true/false to Likert scale. This change has been made for this study.

In addition, Johnson (1991) added an item to the instrument which addressed the extent to which teachers perceived that the vision was being successfully reached. This item " My school is making meaningful progress toward accomplishing our vision", has been included in this study.

A final item has been added to the instrument for the purposes of this study. It is " My principal included me in the vision building process", and it addresses the concept of the development of a shared vision between all members of the school.

Both of these additional items require likert scale responses and were scored identically to the other items on the instrument, using the 1 through 4 point system described above. Since the school was the unit of study for both of these questions, mean scores were computed for each school. A total vision score was calculated from the means of the 
Vision Internalization, Vision Sacrifice and Vision Exchange subscales.

Greenfield, Licata and Johnson (1989), reported that Alpha reliability coefficients for the set of 17 individual items, using individual teacher and school mean item scores, were .85 and .87 respectively.

The School Vision Inventory measures teachers' perceptions of their principal's vision. The researcher was also interested in the principal's perception of how principal vision was perceived in the school. To achieve this, the principal at each school was asked to complete the School Vision Inventory by selecting the response to each statement, which he or she predicts was the one most frequently selected by his or her staff.

The Profile of Iife Values

The Profile of Life values is a survey instrument developed by Bellarts and Hales (1992) as a measure of personal values. Although the original instrument was developed to be used in Bellart's research with nursing students, the instrument is very applicable to educational administration and in particular principal personal values. Its use in this study was as part of the principal survey only and was not administered to teachers.

The personal values selected for this particular instrument were: Intellectual, Considerate, Creative, 
Artistic, Recognition, Achievement, and Integrity. Bellarts (1992) defined these values as follows:

Achievement: Concerns the desire to attain, accomplish, or succeed; desired results; perform successfully.

Artistic: Doing something tastefully - skillfully; the showing of good taste - fine arts.

considerate: The act of giving careful thought or attention; sensitive to others.

Creative: Having or using imaginative or inventive ideas; resourceful in dealing with new or unusual experiences.

Intellectual: The act of acquiring, using knowledge; the seeking of new information; determining how truths were known through inquiry or research.

Recognition: Reputation; Identity; acknowledgment by others of status.

Integrity: The importance of being correct, sincere, honest; exact in accordance with the facts. (p.15)

The Profile of Life Values, consists of 56 statements

with no right or wrong answers, expressed on a four point Likert scale from strongly agree to strongly disagree. Each of the 7 personal values (Intellectual, Considerate, Creative, Artistic, Recognition, Achievement, and Integrity) constitutes an eight point scale within the Iife Values instrument. A point system was used to assess personal values (Strongly Disagree $=1$, Disagree $=2$, Agree $=3$, Strongly Agree $=4$ ). Mean scores werecalculated for each personal value. 
Bellarts (1992) reported the following Alpha reliability coefficients for the personal values used in this instrument: Intellectual .783; Considerate .816; Creative .880; Recognition .866; Artistic .872; Achievement .814; Integrity .869 (p.93).

\section{The Mach V Scale}

Originally developed by Christie and Geis (1970), the Mach $\mathrm{V}$ scale was designed to measure Interpersonal Orientation. This orientation was reported as a single numerical score ranging from 40 - 160 with 100 being the theoretical neutral point. Respondents who achieve higher Mach scores were reported to have a more impersonal interpersonal orientation and, conversely, the lower the Mach score the more personal is the interpersonal orientation.

At first glance, one may assume that the more personal the interpersonal orientation of the principal the more effective he or she would be as a leader. However the exact opposite is porposed in this study. Great care needs to be taken not to confuse traditional and everyday notions of "personal" and "impersonal" with the more theoretical way the concepts have been operationalized in the Mach $V$ instrument.

Personal (or Low Mach) oriented respondents are generally characterized as those who overemphasize the need 
to please and give into the needs of others, who lack decisiveness, give in quickly to their emotions without analyzing situations, are less adept at monitoring the other person in interpersonal situations, and are much less skilled at bargaining and judging subtle changes in others in group situations (Christie and Geis, 1970)

Impersonal (or High Mach) oriented respondents are generally more "politic" than personal. In comparison to Low Mach's, High Mach's: tend to be more statistical or cognitive in that they think clearly about interactional situations; they are more adept at standing back and processing information about a situation; they are much more successful in bargaining and persuasion; they are much more consistently accurate in assessing how those with whom they interact differ from themselves; they are more subtle about changing their point of view in group discussions; are more skilled at achieving the possible by adapting their interactional tactics to the specific conditions at hand and; are skilled at getting others to "buy into" their point of view through negotiation and bargaining (Christie and Geis, 1970).

Scoring for the Mach $\mathrm{V}$ instrument is based upon the respondent's choice of the statement, which is mest like them and the statement which is least like them, from a set of three statements provided. The three statements, in each set, represent one High Mach item, one Low Mach item and, 
one "buffer" or neutral item. If a respondent chooses the High Mach item as the statement most like themselves and the Low Mach item as the statement least like themselves, they achieve a score of 7 points. If the reverse is true they receive only 1 point. A score of 3 is achieved if the respondent selects the Low Mach statement as the one least like them, as well as selecting the neutral statement. A score of 5 is achieved if the respondent selects the High Mach statement as the one most like them, as well as selecting the neutral statement.

Christie and Geis (1970), state that in highly structured situations, administrators who are high Mach's in their interpersonal orientation, are likely to be poorly suited and generally ineffective. However, in loosely structured situations, they are much more likely to be effective. The opposite is true for low Mach administrators, as they are much more likely to be effective in tightly structured organizations (p.358).

This study assumes that schools as organizations, are very loosely structured and as such have high levels of leadership ambiguity. It is therefore assumed that because of this loose and ambiguous structure, principals who have high Mach scores in interpersonal orientation would be more effective leaders than principals with low Mach scores. Two minor alterations have been made to the original Mach $V$ instrument for the purposes of this study. The first 
of these was an attempt, by the researcher, to eliminate gender bias from the 60 original statements by re-phrasing direct gender references, to make them more gender neutral. The second alteration, was changing the format for answering the questions.

The move to eliminate gender bias was decided after the researcher administered all three instruments, including the original Mach V instrument, to 20 Portland State University undergraduate students of mixed gender, and asked the students to complete the instrument and respond to its format. None of the students made any comments about the School Vision Inventory or the Profile of Iife Values. However, nine students commented on the gender bias of the Mach $V$ scale, five of whom refused to complete the majority of that instrument.

An example of this is statement 1 (A). In its original form it reads, "It takes more imagination to be a successful criminal than a successful business man". The gender neutral statement now reads, " It takes more imagination to be successful in crime than to be successful in business". Six of the original 60 statements were rephrased in this way, with great care being taken not to alter the original meaning or emphasis of the statement. The second minor alteration was the elimination of the separate sheet provided at the end of the survey for the respondent to place their answers. This researcher felt that 
the addition of a separate answer sheet to the principal survey (which actually contains three separate instruments) would not only lengthen an instrument which is already 8 pages long, but would also tend to be confusing to the principal, as it breaks the "answering flow" or pattern established in the first two instruments.

In place of the answer sheet, the letters " $L$ " and " $M$ " were placed at the beginning of each of the 60 statements, with instructions for the principal to circle "L" if the statement is least like them and to circle " $M$ " if the statement is most like them. The buffer, or third statement of the set of three, was to be left blank as it was in the original instrument.

It is important to note that these two alterations were made in an attempt to "streamline" the instrument for use in this study. The researcher is confident that the statistical reliability of the Mach $\mathrm{V}$ instrument, which was originally reported by Christie and Geis (1970) as an Alpha coefficient of between .65 and .67, will not be affected.

\section{DATA COLLECTION PROCEDURES}

The data for this research study were collected from principals and their staff, in elementary schools, in the Portland, Vancouver and Salem metropolitan school districts. 
subjects

The subjects chosen for this research project were elementary school principals from 10 school districts within the Portland, Vancouver and Salem metropolitan areas. These 10 districts, although varying in size, represent a total of 127 elementary schools. Letters were sent to the superintendent of each of these districts (Appendix E), outlining the study and asking permission to conduct research within their district. A response letter (Appendix F) on which the superintendent was either to reject or grant permission to conduct the research, was included with the superintendent's letter, along with a return stamped envelope, addressed to the researcher.

Superintendents who granted permission to conduct research, were asked to provide the name of a contact person within the district, who was to be a liaison between the researcher and the school principals. The role of this liaison person, usually the director of elementary schools or assistant superintendent, was simply to provide a list of schools, within the district, which had volunteered to participate in the study. Most liaison people preferred to announce the study at the regularly scheduled elementary principal's district meetings, and then to ask the principals to volunteer before a set date. The liaison then 
contacted the researcher with a list of participating schools from that district.

The total number of schools responding to the survey was 51 and this represented $40.47 \%$ of the total 126 possible. As one of the survey instruments, the school Vision Inventory asks for a response from the teaching staff at each of the surveyed schools, the number of teacher respondents equaled 841 . It was hoped that relatively equal numbers of both male and female principals would respond and that each of the 10 districts would be proportionally. represented.

Due to the fact that the researcher works in an administrative position within one of the school districts and works with several of the principals used in this study, the names of the districts and the principals concerned were kept anonymous. All of the districts however were fairly similar in their geographical location, percent of schools within the state S.E.S brackets, and general curriculum and instructional philosophies.

Oregon elementary school principals were sampled for this study for two reasons. First, the researcher works in the elementary setting and this is where his primary interests lie and second, this study is built significantly upon a 1991 dissertation by Dan Johnson which looked at principal vision, environmental robustness and teacher sense of autonomy. Johnson's (1991) dissertation was concerned, 
however, with 34 high schools across the state of oregon. To date, no study has looked at principal vision, interpersonal orientation, and personal values at the elementary level.

\section{Administration of the Survey Instruments}

After approval was granted from Portland State University Human Subjects in Research Review Committee to conduct this study, and letters from superintendents granting permission to conduct research in their districts had been collected, the researcher began the process of contacting the principals of the participating schools. Information packets, containing enough copies of each of the instruments, were mailed to the principal of each of the 100 elementary schools. Letters to the principal, explaining the instruments as well as instructions for completion and delivery back to the researcher, were also included. (Appendix G)

It was anticipated that the principal, at each of the schools, would entrust the collection of all of the school Vision Inventories, at each site, to a particular staff member who would be responsible for collecting the surveys and mailing them back to the researcher in the pre-stamped envelopes which were included.

At this point the principal would also complete the principal survey (School Vision Inventory, Profile of Life 
Values and, Mach $\mathrm{V}$ scale of interpersonal orientation) and place them in the return envelope with the teacher school Vision Inventories. The whole packet was then returned to the researcher.

\title{
DATA ANALYSIS PROCEDURES
}

Once the data had been collected from the participating schools and principals it was be entered on the mainframe computer at Portland State University. The statistical analysis program SYSTAT were used to perform the various statistical procedures outlined in this section.

\author{
Descriptive Analyses \\ Descriptive analyses were run to determine means, \\ standard deviations and range values for each of the \\ following variables; vision internalization, vision \\ exchange, vision sacrifice, total vision, principal's \\ predicted vision, high mach, low mach, mach total, values- \\ Intellectual, values-considerate, values-creative, values- \\ artistic, values-recognition, values-achievement, values- \\ integrity, values-total. Summary statistics were also \\ generated for the demographic data.
}


Statistical Techniques

Besearch Question 1. What were the teachers' perceptions of principal vision? This question was analyzed by comparing means, standard deviations and coefficient alphas for each of the vision scales for teacher responses on the school Vision Inventory.

Research Question 2. What were the principals' predictions of the perception's teachers have of principal vision? This question was analyzed by comparing means, standard deviations and coefficient alphas for each of the vision scales (Internalization, Exchange, Sacrifice, Total Vision) for principals' predictions of teacher responses on the School Vision Inventory.

Research Ouestion 3. Do principals and teachers differ in their perception of principal vision? This question was answered by comparing row percents, Chi square and probability values for teacher and principal responses on the Scheol Vision Inventory.

Research Question 4. Is the gender of the teacher related to teacher perceptions of principal vision? This question was examined by MANOVA and followed by ANOVAs with gender of the teacher as the independent variable and the three vision scales plus total vision as the dependent variables. Chi square analyses were run on statements 17 and 18 of the School Vision Inventory as they were not part of 
the vision scales. As a final analysis, a Pearson Product Correlation was run on all three vision scales, total vision and teacher gender.

Research Question 5. Is the age of the teacher related to teacher perceptions of principal vision? This question was also examined by MANOVA and followed by ANOVAs with the grouped ages of the teacher as the independent variable and the three vision scales plus total vision as the dependent variables. Following significant ANOVAs, the statistical hypothesis for each pairwise mean comparison was tested using Tukey HSD. Chi Square analyses were run on statements 17 and 18 of the School Vision Inventory. As a final analysis, a Pearson Product Correlation was run on all three vision scales, total vision and teacher age as a continuous variable.

Research Question 6 . Is the length of time that a teacher has worked with a principal related to teacher perceptions of principal vision? As with question 4 and question five, this question was examined by MANOVA and followed by ANOVAs with the grouped years of working with current principal as the independent variable and the three vision scales plus total vision as the dependent variables. Chi Square analyses were run on statements 17 and 18 of the School Vision Inventory. As a final analysis, a Pearson Product Correlation was run on all three vision scales, 
total vision and teacher years with current principal as a continuous variable.

Besearch Question 7. Is the length of teaching experience related to teacher perceptions of principal vision? Once again the following format was used: MANOVA, followed by ANOVAs with the grouped years of teaching experience as the independent variable and the three vision scales plus total vision as the dependent variables. Chi Square analyses were run on statements 17 and 18 of the School Vision Inventory. As a final analysis, a Pearson Product Correlation was run on all three vision scales, total vision and teacher years of experience as a continuous variable.

Research Question 8 . Is the size of the school related to teacher perceptions of principal vision? This question was also examined by MANOVA and followed by ANOVAs with the grouped school size as the independent variable and the three vision scales plus total vision as the dependent variables. As a final analysis, a Pearson Product Correlation was run on all three vision scales, total vision and school size as a continuous variable.

Research Question 9. Is the percentage of students on free and reduced lunch related to teacher perceptions of principal vision? This question was also examined by MANOVA and followed by ANOVAs with the grouped percentage of 
students of free and reduced lunch as the independent variable and the three vision scales plus total vision as the dependent variables. A Pearson Product Correlation was run on all three vision scales, total vision and percentage of students on free and reduced lunch as a continuous variable.

Research Question 10. Does the number of years of experience of the principal have any relationship to teacher perceptions of principal vision? This question was also examined by MANOVA and followed by ANOVAs with the grouped years of experience as a principal as the independent variable and the three vision scales plus total vision as the dependent variables. As a final analysis, a Pearson Product Correlation was run on all three vision scales, total vision and years as a principal as a continuous variable.

Research Question 11. Is the length of time that a principal has been in a school related to teacher's perceptions of their principal's vision? This question was also examined by MANOVA and followed by ANOVAs with the grouped length of time a principal has been at a school as the independent variable and the three vision scales plus total vision as the dependent variables. As a final analysis, a Pearson Product Correlation was run on all three 
vision scales, total vision and the length of time that the principal has been at a school as a continuous variable. Research Question 12. Is the gender of the principal related to teacher perceptions of principal vision? This question was examined by MANOVA and followed by ANOVAs with the principal gender as the independent variable and the three vision scales plus total vision as the dependent variables. A Pearson Product Correlation was run on all three vision scales, total vision and principal gender. Besearch Question 13. What were the principals' personal values? This question was analyzed by comparing means, standard deviations and coefficient alphas for each of the value scales (Intellectual, Considerate, Recognition, Achievement, Artistic, Integrity, Creative) for principals' responses on the erofile of Iife values.

Research Question 14. Is the gender of the principal related to his/her personal values? This question was examined by MANOVA and followed by ANOVAs with the principal gender as the independent variable and the seven value scales as the dependent variables. A Pearson Product Correlation was run on all seven value scales and principal gender.

Research Question 15. What is the relationship between principal personal values and teachers' perceptions of principal vision? This question was answered using a Pearson 
Product Correlation on all seven value scales, the three vision scales and total vision.

Research Question 16. What were the principals' interpersonal orientations? This question was analyzed by comparing means, standard deviations and coefficient alpha scores for principals on the Mach $V$ scale.

Besearch Question 17. Is the interpersonal orientation of the principal related to teacher perceptions of principal vision? This question was examined by MANOVA and followed by ANOVAs with the principal Mach (high/low) as the independent variable and the three vision scales and total vision as the dependent variables. A Pearson Product Correlation was run on all three vision scales, total vision and principal Mach as a continuous variable.

Besearch Ouestion 18. Is the interpersonal orientation of the principal related to his/her personal values? This question was examined by MANOVA and followed by ANOVAs with the principal Mach (high/low) score as the independent variable and the seven value scales as the dependent variables. A Pearson Product Correlation was run on all seven value scales and principal Mach as a continuous variable. 
CHAPTER IV

\section{PRESENTATION OF RESULTS}

\section{INTRODUCTION}

The aim of this chapter is to present the results of this research study. The demographic data for teachers, principals and schools is presented. The research questions are discussed, using descriptive and inferential statistics. Vision, personal values and interpersonal orientation were the three key variables used in this study and they were measured using the School Vision Inventory, Profile of Iife Values and, Mach $\mathrm{V}$ instruments respectively.

\section{CHARACTERISTICS OF THE SAMPLE}

Demographic data for this study are described in terms of sample size, as well as school, teacher and principal demographic variables. The school demographic variables are school district, student population, percentage of students on free or reduced lunch, and number of teaching staff. The principal demographic variables are sex, age, years of experience as a principal, and years in current position. The teacher demographic variables are sex, age, years of 
teaching experience, years teaching in current position, and years working with current principal.

SAMPLE SIZE

This study contains data which were gathered solely from elementary schools in the metropolitan Portland, Salem, and Vancouver areas. Listings of school districts in these geographical locations were obtained from the Directory of Oregen Schools (1992/1993).

\section{Participating Districts}

The superintendents of nineteen school districts were contacted initially to gain permission to conduct research. of the original nineteen, ten districts volunteered to participate. It should be noted that Portland Public Schools, the largest district in the state, failed to respond to the request and therefore did not participate.

The total number of schools in the ten participating districts was 126, of which 66 volunteered to participate. This represents $52.38 \%$ of the total possible sample. Surveys were sent to each of these 66 schools; however, eight schools failed to return the survey packets to the researcher after they had received them. An additional five schools were deleted from the data sample because fewer than 
$50 \%$ of the teaching staff completed the school Vision

Inventory, and three schools were deleted by the researcher because of incorrectly completed Mach $\mathrm{V}$ scales. The total number of schools used for data analysis in this study was 51 which represented $40.47 \%$ of the original 126 target population. A summary of sample size is represented in Table I.

TABLE I

SUMMARY OF SAMPLE SIZE

\begin{tabular}{lcc}
\hline Category & Number & Percentage \\
\hline Schools counted in survey & 51 & 40.47 \\
Schools not participating & 59 & 46.83 \\
Schools rejected (< 50\% SVI) & 5 & 3.97 \\
Schools rejected because of & 3 & 2.38 \\
incomplete MachV scale & 8 & 6.35 \\
Schools failing to return survey & & 100.00 \\
\hline Totals & 126 & \\
\hline
\end{tabular}

This research study was conducted during one of the most challenging times in the history of oregon education. The budget cutbacks brought on by the passage of Measure 5, Oregon's property tax limitation law, seems to have made its greatest impact on the metropolitan school districts. All of 
the nineteen districts approached in this study are currently in the process of reducing their operating budgets for the 1993/1994 school year. The involvement of building level and central office level administrators in the planning process for these cutbacks was the single greatest reason given for non-participation in the study. One superintendent wrote," We are in the process of closing a school next year and I can't justify this one more thing to my principals. Sorry!"

Two superintendents gave permission to conduct the. research in their districts and then asked that the researcher personally contact the principals of the schools by telephone to see if they would participate. Concern for the amount of time it would take for their staff to participate and limiting the amount of interruptions to teacher's time were the most frequent reasons stated by principals when rejecting the researcher's request to conduct the study in their schools.

Given the pressure on school districts to make cutbacks in their programs because of Measure 5 and the associated uneasy atmosphere which exits in schools, the researcher believes that the $40.47 \%$ response rate of returned surveys for this study is actually very respectable. 
Schools Participating from Each District

The number of schools participating from each district was obtained through the superintendent's office, the office of his/her appointed central office representative, or from the researcher's personal contact with the principals in the two districts noted in the previous section. Table II shows the distribution of schools by participating district.

TABLE II

SCHOOLS BY PARTICIPATING DISTRICT

District Number Percent of Total

\begin{tabular}{crr}
\hline 1 & 9 & 17.65 \\
2 & 3 & 5.88 \\
3 & 4 & 7.84 \\
4 & 2 & 3.92 \\
5 & 9 & 17.65 \\
6 & 4 & 7.84 \\
7 & 2 & 3.92 \\
8 & 8 & 15.69 \\
9 & 9 & 17.65 \\
10 & 1 & 1.96 \\
\hline Total & 100.00 \\
\hline
\end{tabular}

The greatest number of participating schools from any one district was nine and this represented $17.65 \%$ of the 
total sample while the least number of participating schools from any one district was one and this represented $1.96 \%$ of the total sample.

Districts were numbered and not named because anonymity was guaranteed to all participants. Because a proportionate number of schools from each district did not respond, the number of schools participating from each district is not an indication of the size of the district and hence should not be used as a determinant in identifying particular districts.

\section{SCHOOI DEMOGRAPHICS}

Several school demographic questions were included at the end of the principal questionnaire (Appendix D). These questions were aimed at determining the current student population, percentage of students on free and reduced lunch, and current number of classroom teachers.

\section{Student Population}

While districts participating in this study came from metropolitan Portland, Vancouver, and Salem; not all schools participating were typical "inner suburban" schools. One district which lies on the outskirts of metropolitan Portland actually had some schools in semi-rural locations 
yet still within a 25 mile radius of central Portland. One of these schools participated, and it had the lowest student population (121) of all schools surveyed. The largest school surveyed had a student population of 735 . Based on the ungrouped data, the mean student population for schools participating in this study was 503.55 ; the standard deviation was 137.63 .

Student populations were classified into four groups, with $33.33 \%$ of the total falling in the 300 to 400 range Table III shows the aggregated student populations.

TABLE III

AGGREGATED STUDENT POPULATIONS

Student Population Frequency Percent

\begin{tabular}{rrr}
\hline $601+$ & 12 & 23.53 \\
$501-600$ & 14 & 27.45 \\
$401-500$ & 17 & 33.33 \\
$0-400$ & 8 & 15.69 \\
\hline Totals & 51 & 100.00 \\
\hline
\end{tabular}

Percentage of Students on Free or Beduced Iunch

One indicator commonly used in research in schools is the percentage of students on free or reduced lunch 
programs. This often gives the researcher an indication of the socio-economic status of children. The mean score for these schools was 27.71 ; the standard deviation was 18.96 . The highest percentage of students at any one school on free and reduced lunch programs was $90 \%$ and the lowest percentage of students at any one school was three percent. Table IV shows the aggregated data for students on free and reduced lunch programs by school. Values are represented in four aggregated groups to allow for ease of comparison.

TABLE IV

STUDENTS ON FREE AND REDUCED LUNCH PROGRAMS

Aggregated 8 of Students Number of Percent of per School Schools

\begin{tabular}{rrr}
\hline $41+$ & 9 & 17.65 \\
$26-40$ & 11 & 21.57 \\
$16-25$ & 16 & 31.37 \\
$0-15$ & 15 & 29.41 \\
\hline Totals & 51 & 100.00 \\
\hline
\end{tabular}

\section{Number of Classroom Teachers}

One question on the principal survey asked the principal to indicate the number of classroom teachers at the school. This question was included primarily to gauge 
the response ratio for teachers on the School Vision

Inventory. The researcher would take the packet of surveys as they were returned from each school, count the number of teacher surveys included in the packet and match that against the number of classroom teachers as indicated by the principal. If less than $50 \%$ of the teachers in the school responded to the School Vision Inventory then that particular school was not included in the sample; five schools were excluded. The school reporting the smallest number of classroom teachers had six; whereas, the school with the largest number of classroom teachers reported 29. Using ungrouped data the mean number of teachers for schools reported in this study was 20.18 ; the standard deviation was 5.55. See Table V.

TABLE V

AGGREGATED NUMBERS OF TEACHERS PER SCHOOL

\begin{tabular}{lcc}
\hline Numbers of teachers & Frequency & Percent \\
\hline $26+$ & 12 & 23.53 \\
$21-25$ & 12 & 23.53 \\
$16-20$ & 18 & 35.29 \\
$6-15$ & 9 & 17.65 \\
\hline Totals & 51 & 100.00 \\
\hline
\end{tabular}


PRINCIPAL DEMOGRAPHICS

Several questions, placed at the bottom of the principal survey packet, were aimed at highlighting key principal demographic data. These questions asked the principals for their age, gender, years as a principal, and the number of years in their current position.

\section{Principal Age}

One of the questions on the demographic data section of the principal survey packet asked the principal to indicate his/her age. One of the more common practices in school leadership seems to be for principals to spend 10 to 15 years in the classroom before moving into administration. Consequently the range of principal ages should have fallen between 30 and 40 years. This study examined the relationship between principal age and vision, interpersonal orientation, and personal values.

Table VI shows the frequencies and percents for principal ages for this data sample. As a point of reference, $62.75 \%$ of all principals surveyed were over the age of 45 years. The youngest principal surveyed was 32 years of age while the oldest principal was 62 years. The mean for age of principals was 44.00 , the standard deviation was 8.46 . 
TABLE VI

AGES OF PRINCIPALS

\begin{tabular}{ccc}
\hline Age in Years & Frequency & Percent \\
& & \\
\hline 62 & 4 & 7.84 \\
55 & 1 & 1.96 \\
54 & 3 & 5.88 \\
53 & 1 & 1.96 \\
51 & 3 & 5.88 \\
50 & 7 & 13.73 \\
49 & 6 & 11.76 \\
48 & 4 & 7.84 \\
47 & 3 & 3.88 \\
45 & 2 & 5.92 \\
44 & 3 & 5.88 \\
43 & 3 & 9.80 \\
41 & 5 & 3.92 \\
40 & 2 & 1.96 \\
39 & 1 & 1.96 \\
38 & 1 & 1.96 \\
37 & 1 & \\
\hline 32 & 1 & 100.00 \\
\hline
\end{tabular}

\section{Principal Gender}

Principals were asked to indicate their gender in the demographic section of the principal survey packet. The distribution of principals by gender was almost evenly divided. The number of female principals participating in this research study was 26 (50.98\% of the sample); the number of males who participated was 25 (represented $49.02 \%$ 
of the sample). Table VII shows the distribution of principals by gender.

TABLE VII

PRINCIPAL GENDER

\begin{tabular}{ccc}
\hline Gender of Principal & Frequency & Percent \\
\hline Male & 25 & 49.02 \\
Female & 26 & 50.98 \\
\hline Totals & 51 & 100.00 \\
\hline
\end{tabular}

Years of Experience as a Principal

Principals were asked to indicate the number of years of experience that they have had as a principal. Table VIII shows the aggregated values for principal experience.

TABLE VIII

PRINCIPAL YEARS OF EXPERIENCE

Years of Experience Frequency Percent

\begin{tabular}{lll}
\hline $11+$ & 16 & 31.37 \\
$6-10$ & 17 & 33.33 \\
$1-5$ & 18 & 35.29 \\
\hline Totals & 51 & 100.00 \\
\hline
\end{tabular}


The fewest number of years of experience for a principal was one and the greatest number of years of experience for a principal was 26. Based on ungrouped data, the mean for years of experience for a principal was 8.98 ; the standard deviation was 5.78 .

\section{Years as a Principal in current Position}

The final principal demographic data question related to the years that the principal had served in his/her current school. When one thinks about a principal's ability to share a vision with the members of his/her school and the length of time that the principal has been with those members of the school, several questions come to mind. If a principal is very new to a building do they have time to illuminate their vision for the staff, or are those principals who have more tenure with their particular schools, more likely to have more clearly exchanged visions because they have longer to accomplish this task? These data were collected to explore the relationship between length of time in the school and teacher perceptions of principal vision.

The shortest period of time was one year and the longest was nine. The mean for length of time in current position was 3.37 , the standard deviation was 1.77 . The vast majority of principals have been in their schools for five 
years or less. This represents $92 \%$ of all principals surveyed. Table IX shows the number of years that principals have spent in their current position.

TABLE IX

PRINCIPAL TENURE IN CURRENT POSITION

\begin{tabular}{ccc}
\hline Number of Years & Frequency & Percent \\
\hline 9 & 1 & 1.96 \\
8 & 1 & 1.96 \\
7 & 0 & 0.00 \\
6 & 2 & 3.92 \\
5 & 8 & 15.69 \\
4 & 11 & 21.57 \\
3 & 11 & 21.57 \\
2 & 9 & 17.65 \\
1 & 8 & 15.69 \\
\hline
\end{tabular}

TEACHER DEMOGRAPHICS

Several questions were included on the bottom of the teacher's version of the School Vision Inventory which were aimed at highlighting key teacher demographic data. These questions asked teachers for their age, gender, years of teaching experience, years teaching in current position, and 
the number of years that they had been with their current principal.

Teacher Age

One of the demographic data questions in the teacher survey packet asked teachers to indicate their age. While the ages of principals tended to fall fairly heavily into the 40 to 50 years age bracket, the ages for teachers were much more evenly distributed. Table $X$ shows teacher ages.

TABLE $X$

AGES OF TEACHERS

\begin{tabular}{ccr}
\hline Age of Teachers & Frequency & Percent \\
\hline $51+$ & 97 & 12.12 \\
$46-50$ & 150 & 18.75 \\
$41-45$ & 216 & 27.00 \\
$36-40$ & 147 & 18.37 \\
$31-35$ & 81 & 10.12 \\
$26-30$ & 74 & 9.25 \\
$21-25$ & 35 & 4.37 \\
\hline
\end{tabular}

As can be seen in the above table, the largest proportion of teachers who participated in this study fell in the 41 to 45 year age category. The two next largest areas were the 36 to 40 and the 46 to 50 year age categories. The oldest teacher surveyed was 65 and the 
youngest was 21 years old. The mean age, from ungrouped data, was 41.32 years; the standard deviation was 8.43 . A total of 41 teachers declined to indicate their age on the survey questionnaire.

\section{Teacher Gender}

Teachers were asked to indicate their gender when completing the School Vision Inventory. This was done so that the researcher could examine the relationship between the gender of the teacher and their perceptions of principal vision. of the 841 teachers who completed the survey, 123 were male and 706 were female. Table XI indicates teacher gender.

TABLE XI

TEACHER GENDER

\begin{tabular}{lcc}
\hline Gender & Frequency & Percent \\
\hline Male & 123 & 14.63 \\
Female & 706 & 83.95 \\
Did not Comment & 12 & 1.43 \\
\hline Totals & 841 & 100.00 \\
\hline
\end{tabular}

This gender distribution is fairly typical of elementary teachers in that less men are attracted to 
elementary schools. Many Oregon districts list male elementary teachers as a category under affirmative action hiring practices.

Years of Teaching Experience

The data on years of experience for teachers were collected so that the researcher could examine the relationship between the teacher perceptions of principal vision and the length of time that a teacher had been in the profession. Table XII represents aggregated years of teaching experience for teachers.

TABLE XII

YEARS OF TEACHING EXPERIENCE

\begin{tabular}{rcc}
\hline Years of Experience & Frequency & Percent \\
\hline $21+$ & 175 & 21.36 \\
$16-20$ & 187 & 22.83 \\
$11-15$ & 156 & 19.04 \\
$6-10$ & 152 & 18.55 \\
$1-5$ & 149 & 18.19 \\
\hline Totals & 819 & 100.00 \\
\hline
\end{tabular}

Based on ungrouped data, the mean score for years of teaching experience was 14.18; the standard deviation was 
7.99. The respondents ranged from a low of one year experience to a high of 33 years. This sample had a high representation of experienced teachers, with $63 \%$ of those surveyed having more than ten years experience. However, 22 teachers did not indicate their years of teaching experience or responded with statements such as "too many to count" or "none of your business !" These were not included in the years of experience data sample.

\section{Years Teaching in current position}

The number of years that a teacher has been teaching in a particular grade level was included in the demographic data to explore the concept of the stability of the teacher in the school and his/her perceptions of principal vision. By far the largest group were those who had been in their current positions for one to two years; they represented $33.13 \%$ of the sample. More than $62 \%$ of those teachers participating had been teaching at their current grade level for less than six years. The mean, from ungrouped data, was 5.89; the standard deviation was 5.59. The teachers ranged from 1 to 29 years in current position. Twenty teachers chose not to answer this question. Table XIII shows years teachers have been in current positions. 
TABLE XIII

YEARS TEACHING IN CURRENT POSITION

\begin{tabular}{ccc}
\hline Years in Current Position & Frequency & Percent \\
\hline $11+$ & 138 & 16.08 \\
$6-10$ & 165 & 20.09 \\
$3-5$ & 246 & 29.96 \\
$1-2$ & 272 & 33.13 \\
\hline Totals & 821 & 100.00 \\
\hline
\end{tabular}

Number of Years Teaching with current Principal

The final question in the teacher demographic section of the survey asked the teachers to indicate the number of years that they had been with their current principal. This question was included to help explore the relationship between how much time a teacher had been with a principal and teachers' perceptions of principal vision. Approximately one quarter of all teachers who responded had been with their principals for one year or less, while 45.50\% of teachers had been with their current principal for two years or less. The mean for length of time with the principal was 2.88 years, the standard deviation was 1.72 , and the range was from one year to 12 years. Only 17 teachers did not complete this question. Table XIV shows the 
number of years that teachers in this study had been with their current principal.

TABLE XIV

YEARS TEACHING WITH CURRENT PRINCIPAL

\begin{tabular}{ccc}
\hline $\begin{array}{l}\text { Years with Current } \\
\text { Principal }\end{array}$ & Frequency & Percent \\
\hline $5-12$ & 115 & 13.95 \\
4 & 140 & 16.99 \\
3 & 194 & 23.54 \\
2 & 167 & 20.26 \\
1 & 208 & 25.24 \\
\hline Totals & 824 & 100.00 \\
\hline
\end{tabular}

ANALYSIS OF THE SCHOOL VISION INVENTORY

The vision instrument consists of 18 statements. The first two statements on the instrument ask teachers if they believe that their principal has a vision of what their school should be. Teachers were to respond either true or false to both statements. If a false response is given to either statement, the teachers are asked not to complete the remainder of the vision questionnaire, but instead to go to 
the end of the survey and complete only the demographic data section.

The remaining items required teachers to respond to 16 statements pertaining to the teacher's perception of his/her principal's vision. Responses are measured via a four point Likert scale, with possible choices ranging from strongly disagree to strongly agree.

The School Vision Inventory consists of three subscales. The first subscale (Vision Internalization) measures the effectiveness of the principal in getting others to internalize or accept his/her school vision. This particular subscale consists of four items. The second subscale (Vision Exchange) consists of five items and measures the principal's effectiveness in exchanging ideas about his/her vision of what the school should be with others in the school environment. The third subscale (Vision Sacrifice) relates to the principal's ability to encourage others to make sacrifices to accomplish his/her vision of what the school should be like, and whether or not individuals actually do make these sacrifices. There are five vision sacrifice items.

Johnson (1991) added an item to the instrument which addressed the extent to which teachers perceived that the vision was being successfully reached. This item, "My school is making meaningful progress toward accomplishing our vision", was included in this study as item 17. 
A final item was added to the instrument for the purposes of this study. It is " My principal included me in the vision building process," and it addresses the concept of the development of a shared vision between all members of the school. It is item 18 in the scheol Vision Inventory.

Table XV shows the assignment of School Vision Inventory items to their respective scales.

TABLE XV

SCAIES FOR SCHOOI VISION INVENTORY

\begin{tabular}{llllll}
\hline Scale & \multicolumn{2}{l}{ Items } & & & \\
\hline Vision Internalization & 3 & 4 & 5 & 6 & \\
Vision Exchange & 7 & 8 & 9 & 10 & 11 \\
Vision Sacrifice & 12 & 13 & 14 & 15 & 16 \\
& & & & & \\
\hline
\end{tabular}

The School Vision Inventory was scored by assigning numeric values to each possible response for each statement, (Strongly Disagree $=1$, Disagree $=2$, Agree $=3$, Strongly Agree $=4)$. The range on the items for the Vision Internalization Subscale is $4-16$; the range for the Vision Exchange Subscale is $5-20$; and the range for the Vision Sacrifice Subscale is 5 - 20. A total vision score for each respondent was calculated by summing the subscale scores of 
Vision Internalization, Vision Sacrifice and Vision Exchange subscales.

\section{Teacher Perceptions of Principal Vision}

Research question one was "What are the teachers' perceptions of principal vision?" The responses to the teachers' perceptions of their principal's vision were scored. The mean, standard deviation, and Coefficient Alpha for each of the Vision scales is reported in Table XVI.

TABLE XVI

MEANS, STANDARD DEVIATIONS, AND COEFFICIENT ALPHAS FOR SCHOOL VISION INVENTORY SCALES COMPLETED BY TEACHERS

\begin{tabular}{lcccc}
\hline Scale & Mean & $\begin{array}{c}\text { Percent } \\
\text { of } \\
\text { Maximum }\end{array}$ & $\begin{array}{c}\text { Standard } \\
\text { Deviation }\end{array}$ & $\begin{array}{c}\text { Coefficient } \\
\text { Alpha }\end{array}$ \\
\hline Internalization & 13.54 & 84.46 & 2.01 & .901 \\
Exchange & 15.86 & 79.30 & 2.53 & .864 \\
Sacrifice & 14.09 & 70.45 & 2.69 & .814 \\
Total Vision & 43.49 & 77.66 & 5.44 & .865 \\
Note: The scale range for Internalization is 4.00 to 16.00 \\
$\begin{array}{l}\text { The scale range for Exchange is } 5.00 \text { to } 20.00 \\
\text { The scale for Sacrifice is } 5.00 \text { to } 20.00\end{array}$ \\
The scale for Total Vision is 16.00 to 54.00 & \\
The means for the vision scales ranged from 13.54 for \\
Vision Internalization to 15.86 for vision Exchange, with \\
standard deviations ranging from 2.01 for Internalization to
\end{tabular}


2.69 for Sacrifice. The Coefficient Alphas ranged from .814 for Sacrifice to .901 on Internalization. Vision Internalization was scored on a four item rather than five item scale and hence the lower mean.

Vision Internalization is the principal's ability to persuade others to accept and share his/her vision of what a school should be. Vision Exchange is the principal's ability to exchange ideas about his/her vision with other members of the school and community. Vision Sacrifice is the principal's ability to act and motivate others to give something up to achieve his/her vision.

The results of this analysis show that the high mean score for internalization indicates that teachers strongly agree that their principals are effective at persuading others to accept and share their vision. Principals were perceived effective to a lesser degree with Vision Exchange, and were perceived as least effective in terms of Vision Sacrifice. This lower perception in the sacrifice category may have been due to misunderstanding of the term "sacrifice" as it is used in the school Vision Inventory.

The Total Vision score of 43.49 was fairly high and thus indicated that teachers tended to agree that principals were effective in advancing their vision within the schools sampled in this study. 
Principal's Predictions of Teachers Perceptions of Principal Vision

Research question two asked "What are the principal's predictions of the perceptions teachers have of principal vision?" Principals were given a copy of the Scheol Vision Inventory as part of their survey packet and asked to predict how they thought their staff would perceive their vision. Means, standard deviations, and Coefficient Alphas were calculated and are reported in Table XVII.

TABLE XVII

MEANS, STANDARD DEVIATIONS, AND COEEFICIENT ALPHAS FOR SCHOOL VISION INVENTORY SCALES AS PREDICTED BY PRINCIPALS

\begin{tabular}{lcccc}
\hline \multicolumn{1}{c}{ Scale } & Mean & $\begin{array}{c}\text { Percent } \\
\text { of } \\
\text { Maximum }\end{array}$ & $\begin{array}{c}\text { Standard } \\
\text { Deviation }\end{array}$ & $\begin{array}{c}\text { Coefficient } \\
\text { Alpha }\end{array}$ \\
\hline Internalization & 13.22 & 82.63 & 1.30 & .581 \\
Exchange & 15.65 & 78.25 & 1.55 & .593 \\
Sacrifice & 14.65 & 73.25 & 2.23 & .805 \\
Total Vision & 43.51 & 77.70 & 3.49 & .725 \\
\hline
\end{tabular}

The means for the vision scales as predicted by principals ranged from 13.22 for Vision Internalization to 15.65 for Vision Sacrifice, with standard deviations ranging from 1.03 for Internalization to 2.23 for Sacrifice. The 
Coefficient Alphas ranged from .581 for Internalization to .805 on Sacrifice. Vision Internalization was scored on a four item rather than five item scale and hence the lower mean.

The results of this analysis show that the high mean score for internalization indicates that principals strongly agree that their teachers see them as being effective at persuading others to accept and share their vision. Principals predicted that their teachers would perceive that they were effective to a lesser degree with Vision Exchange and Vision Sacrifice.

Again, the Total Vision score of 43.51 was fairly high and thus indicated that principals predicted that teachers agreed that principals were effective in advancing their vision within the schools sampled in this study.

\author{
Principals and Teachers Perceptions of Principal Vision \\ Research question three asked "Do principals and \\ teachers differ in their perceptions of principal vision?" \\ In order to compare, on an item to item basis, principal's \\ predictions of teacher's perceptions of principal vision and \\ teacher's actual perceptions of principal vision, row \\ percents, Chi square, and probability values for each item \\ on the School Vision Inventory were calculated. This \\ information is reported in Table XVIII.
}


TABIE XVIII

ROW PERCENTS, CHI SQUARE AND PROBABILITY VALUES FOR

TEACHER AND PRINCIPAL RESPONSES TO EACH ITEM ON THE SCHOOL VISION INVENTORY

\begin{tabular}{|c|c|c|c|c|c|c|c|}
\hline Item & Type & $\begin{array}{c}\text { Response } \\
2 \\
\text { Row } 6\end{array}$ & $\begin{array}{c}\text { Response } \\
3 \\
\text { Row? }\end{array}$ & $\begin{array}{c}\text { Response } \\
4 \\
\text { Row }\end{array}$ & $\mathbf{N}$ & $\begin{array}{c}\text { Chi } \\
\text { Square } \\
\text { (Pearson) }\end{array}$ & p \\
\hline 3 & $\begin{array}{l}\text { Teacher } \\
\text { Principal }\end{array}$ & $\begin{array}{l}2.21 \\
0.00\end{array}$ & $\begin{array}{l}62.29 \\
68.63\end{array}$ & $\begin{array}{l}35.50 \\
31.37\end{array}$ & $\begin{array}{r}814 \\
51\end{array}$ & 1.67 & .434 \\
\hline 4 & $\begin{array}{l}\text { Teacher } \\
\text { Principal }\end{array}$ & $\begin{array}{l}2.83 \\
0.00\end{array}$ & $\begin{array}{l}46.44 \\
35.29\end{array}$ & $\begin{array}{l}50.74 \\
64.71\end{array}$ & $\begin{array}{r}814 \\
51\end{array}$ & 4.56 & .102 \\
\hline 5 & $\begin{array}{l}\text { Teacher } \\
\text { Principal }\end{array}$ & $\begin{array}{l}2.83 \\
1.96\end{array}$ & $\begin{array}{l}51.78 \\
68.63\end{array}$ & $\begin{array}{l}45.39 \\
29.41\end{array}$ & $\begin{array}{r}813 \\
51\end{array}$ & 5.47 & .065 \\
\hline 6 & $\begin{array}{l}\text { Teacher } \\
\text { Principal }\end{array}$ & $\begin{array}{r}3.69 \\
13.73\end{array}$ & $\begin{array}{l}48.83 \\
74.51\end{array}$ & $\begin{array}{l}47.48 \\
11.76\end{array}$ & $\begin{array}{r}813 \\
51\end{array}$ & 31.06 & .000 \\
\hline 7 & $\begin{array}{l}\text { Teacher } \\
\text { Principal }\end{array}$ & $\begin{array}{r}10.06 \\
5.88\end{array}$ & $\begin{array}{l}48.34 \\
70.59\end{array}$ & $\begin{array}{l}41.60 \\
23.53\end{array}$ & $\begin{array}{r}815 \\
51\end{array}$ & 9.50 & .009 \\
\hline 8 & $\begin{array}{l}\text { Teacher } \\
\text { Principal }\end{array}$ & $\begin{array}{l}14.91 \\
11.76\end{array}$ & $\begin{array}{l}58.15 \\
72.55\end{array}$ & $\begin{array}{l}26.94 \\
15.69\end{array}$ & $\begin{array}{r}798 \\
51\end{array}$ & 4.32 & .115 \\
\hline 9 & $\begin{array}{l}\text { Teacher } \\
\text { Principal }\end{array}$ & $\begin{array}{l}8.19 \\
5.88\end{array}$ & $\begin{array}{l}57.57 \\
70.59\end{array}$ & $\begin{array}{l}34.24 \\
23.53\end{array}$ & $\begin{array}{r}806 \\
51\end{array}$ & 3.35 & .187 \\
\hline 10 & $\begin{array}{l}\text { Teacher } \\
\text { Principal }\end{array}$ & $\begin{array}{l}9.14 \\
1.96\end{array}$ & $\begin{array}{l}56.21 \\
72.55\end{array}$ & $\begin{array}{l}34.65 \\
25.49\end{array}$ & $\begin{array}{r}733 \\
51\end{array}$ & 6.23 & .044 \\
\hline 11 & $\begin{array}{l}\text { Teacher } \\
\text { Principal }\end{array}$ & $\begin{array}{l}9.22 \\
9.80\end{array}$ & $\begin{array}{l}64.81 \\
78.43\end{array}$ & $\begin{array}{l}25.97 \\
11.76\end{array}$ & $\begin{array}{r}770 \\
51\end{array}$ & 5.22 & .074 \\
\hline 12 & $\begin{array}{l}\text { Teacher } \\
\text { Principal }\end{array}$ & $\begin{array}{l}49.50 \\
29.41\end{array}$ & $\begin{array}{l}37.50 \\
50.98\end{array}$ & $\begin{array}{l}13.00 \\
19.61\end{array}$ & $\begin{array}{r}808 \\
51\end{array}$ & 7.85 & .020 \\
\hline 13 & $\begin{array}{l}\text { Teacher } \\
\text { Principal }\end{array}$ & $\begin{array}{l}54.49 \\
37.25\end{array}$ & $\begin{array}{l}36.92 \\
54.90\end{array}$ & $\begin{array}{l}8.59 \\
7.84\end{array}$ & $\begin{array}{r}780 \\
51\end{array}$ & 6.76 & .034 \\
\hline 14 & $\begin{array}{l}\text { Teacher } \\
\text { Principal }\end{array}$ & $\begin{array}{r}19.16 \\
7.84\end{array}$ & $\begin{array}{l}56.02 \\
72.55\end{array}$ & $\begin{array}{l}24.82 \\
19.61\end{array}$ & $\begin{array}{r}814 \\
51\end{array}$ & 6.16 & .046 \\
\hline 15 & $\begin{array}{l}\text { Teacher } \\
\text { Principal }\end{array}$ & $\begin{array}{l}27.99 \\
25.49\end{array}$ & $\begin{array}{l}55.09 \\
64.71\end{array}$ & $\begin{array}{r}16.92 \\
9.80\end{array}$ & $\begin{array}{r}786 \\
51\end{array}$ & 2.37 & .305 \\
\hline 16 & $\begin{array}{l}\text { Teacher } \\
\text { Principal }\end{array}$ & $\begin{array}{l}15.00 \\
11.76\end{array}$ & $\begin{array}{l}49.88 \\
68.63\end{array}$ & $\begin{array}{l}35.12 \\
19.61\end{array}$ & $\begin{array}{r}800 \\
51\end{array}$ & 7.02 & .030 \\
\hline
\end{tabular}


TABLE XVIII

ROW PERCENTS, CHI SQUARE AND PROBABILITY VALUES FOR TEACHER AND PRINCIPAL RESPONSES TO EACH ITEM ON THE SCHOOL VISION INVENTORY (continued)

\begin{tabular}{|c|c|c|c|c|c|c|c|}
\hline Item & Type & $\begin{array}{c}\text { Response } \\
2 \\
\text { Row염 }\end{array}$ & $\begin{array}{c}\text { Response } \\
3 \\
\text { Row }\end{array}$ & $\begin{array}{c}\text { Response } \\
4 \\
\text { Row? }\end{array}$ & $\mathbf{N}$ & $\begin{array}{c}\text { Chi } \\
\text { Square } \\
\text { (Pearson) }\end{array}$ & 모 \\
\hline 17 & $\begin{array}{l}\text { Teacher } \\
\text { Principal }\end{array}$ & $\begin{array}{l}5.43 \\
3.92\end{array}$ & $\begin{array}{l}65.84 \\
70.59\end{array}$ & $\begin{array}{l}28.73 \\
25.49\end{array}$ & $\begin{array}{r}811 \\
51\end{array}$ & 0.54 & .762 \\
\hline 18 & $\begin{array}{l}\text { Teacher } \\
\text { Principal }\end{array}$ & $\begin{array}{r}11.61 \\
9.80\end{array}$ & $\begin{array}{l}56.05 \\
70.59\end{array}$ & $\begin{array}{l}32.33 \\
19.61\end{array}$ & $\begin{array}{r}801 \\
51\end{array}$ & 4.37 & .112 \\
\hline
\end{tabular}

Table Note: (1) Response items 1 and 2 were combined $=2$

(2) Response 2 = Strongly Disagree + Disagree

Response 3 = Agree \& Response 4 = Strongly Agree

For each of the vision items three through eighteen, the null hypothesis was that the response to the item is independent of the category (principal/teacher) of the respondent. The null hypothesis was rejected, and the corresponding research hypothesis, that response to the item is dependent upon the category (principal/teacher), was accepted for each of the following items.

(a) Item number six, "I have accepted this vision of my own free will" which is part of the Internalization scale, was rejected at the .05 level of significance (Chi square $=$ 31.06). The principals thought that their teachers would be less positive than they were in their responses. 
(b) Item number seven "My principal effectively

exchanges ideas with teachers to achieve this vision" and item number ten "My principal effectively exchanges ideas with superiors to achieve this vision", which are both part of the Vision Exchange scale, were rejected at the .05 level of significance (Chi square $=9.50$ and 6.23 , respectively). Teachers tended to be more diverse but also more positive on these items than were the principals.

(c) Four of the five Vision Sacrifice scale items were rejected at the .05 level of significance. They were item twelve "My principal regularly encourages teachers to make personal sacrifices to accomplish this vision" (Chi square $=$ 7.85), item thirteen "My principal regularly encourages other members of the school community to make personal sacrifices to accomplish this vision" (Chi square $=6.76)$, item fourteen "I make personal sacrifices to accomplish this vision" (Chi Square $=6.16$ ) and, item sixteen "My principal regularly makes personal sacrifices to accomplish this vision" (Chi Square $=7.02)$. The teachers were less positive on all of these items than the principals' thought they would be.

It is important to note at this stage that on 68 teacher surveys and four principal surveys reference was made to the word "Sacrifice" as it appeared in the instrument. Mostly this appeared as a question mark against the word but on several surveys comments such as "Too harsh 
a word", "I give it freely and I'm not forced", "Is this meant to be negative or positive ?"," I want to do it but I don't have to do it" appeared. This would tend to indicate that teachers were not as comfortable with the word sacrifice and may not have understood it in the way that an administrator would, hence the null hypothesis rejection for the sacrifice scale items may be due in part to misunderstanding of the word sacrifice rather than true differences in the concept of sacrifice as it pertains to the instrument.

Teacher Gender and Teacher Perceptions of Principal Vision Research question four asked "Is the gender of the teacher related to teacher perceptions of principal vision?" To answer this question a MANOVA was performed, using the three vision scales as dependent variables and the gender of the teacher as the independent variable. The multivariate statistical hypothesis was not rejected, using Wilks' Lambda (with 3, 825 df, $E=2.37, \underline{p}=.07$ ). A level of significance of .05 was required to reject the null hypothesis and this was not achieved.

To further test this question, an ANOVA was conducted, using the Total Vision Score as the dependent variable and gender as the independent. For Total Vision the null hypothesis was rejected at the .05 level of significance ( $E$ 
$=5.66 ; \mathrm{p}=.02)$. See Table XIX. On the Total Vision Scale, the mean (44.27) for the principals' predictions of the teachers' perceptions was greater than the mean (43.35) for the teachers; the standard deviations were 6.48 and 5.22, respectively.

TABLE XIX

ANALYSIS OF VARIANCE OF TEACHER PERCEPTIONS OF PRINCIPAL VISION BY GENDER

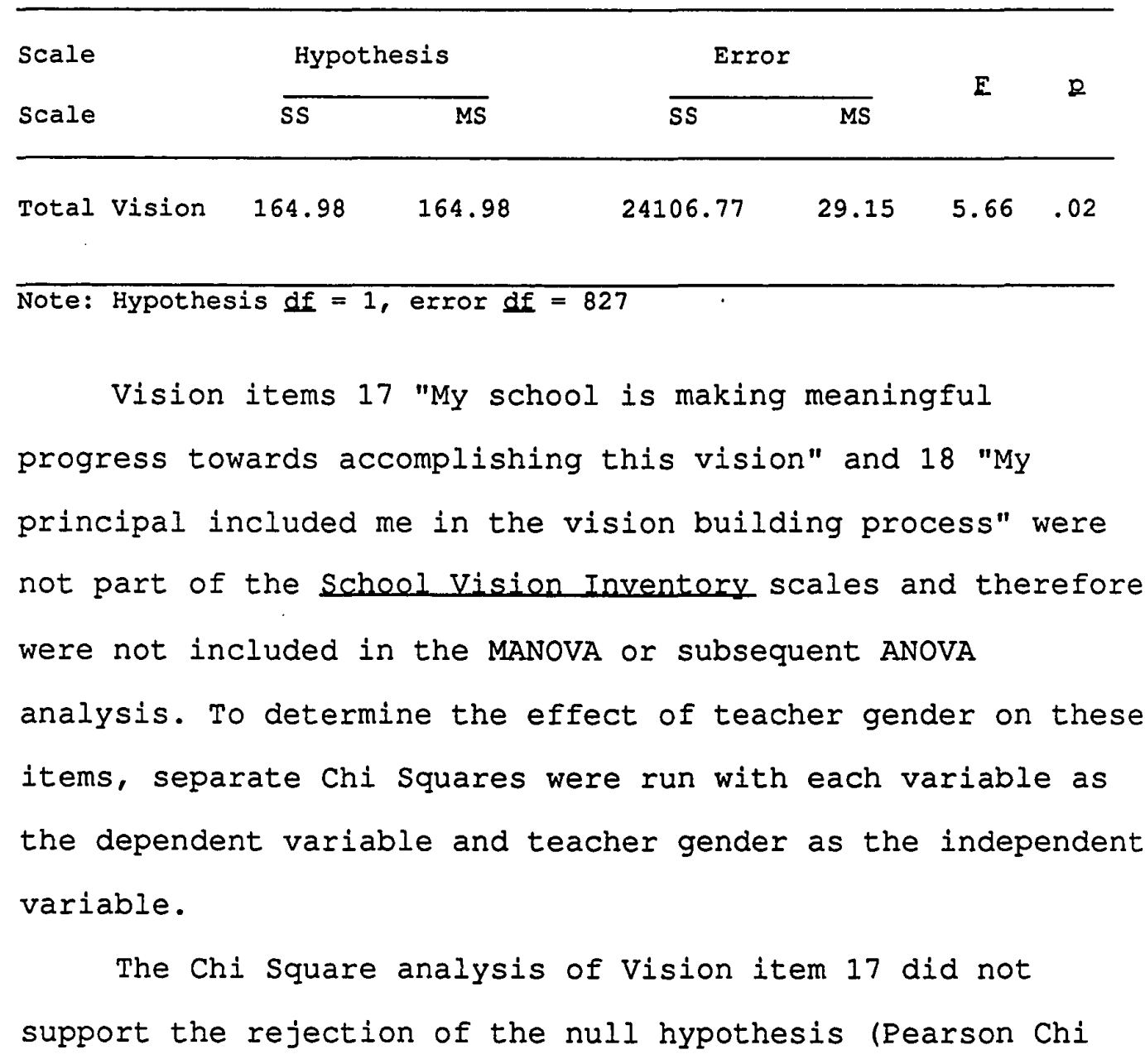


Square $=3.44, \underline{d f}=2, \underline{p}=.18$ ). However, the null

hypothesis was rejected for Vision item 18 (Pearson Chi Square $=12.85$, df $=2, \underline{p}<.001)$. Males agreed more than females that their principals included them in the vision building process. See Table Xx.

TABLE XX

ROW PERCENTS, CHI SQUARE AND PROBABILITY VALUES FOR RESPONSES TO ITEM 17 AND 18 ON THE SCHOOI VISION INVENTORY FOR TEACHER GENDER

\begin{tabular}{llcccccc}
\hline Item Gender & $\begin{array}{c}\text { Response } \\
2\end{array}$ & $\begin{array}{c}\text { Response } \\
\text { Row\% }\end{array}$ & $\begin{array}{c}\text { Response } \\
\text { Row }\end{array}$ & $\begin{array}{c}\text { Chi } \\
\text { Row }\end{array}$ & N & $\begin{array}{c}\text { Square } \\
\text { (Rearson) }\end{array}$ & R \\
\hline 17 & Male & 5.08 & 59.32 & 35.59 & 118 & & \\
& Female & 5.26 & 67.45 & 27.30 & 685 & 3.44 & .180 \\
18 & Male & 9.32 & 44.07 & 46.61 & 118 & & \\
& Female & 11.98 & 58.14 & 29.88 & 676 & 12.85 & .000
\end{tabular}

$\begin{array}{ll}\text { Note: } & \text { Response categories were combined for this instrument } \\ & \text { Response } 2=\text { strongly disagree + disagree } \\ \text { Response } 3=\text { agree } & \\ \text { Response } 4=\text { strongly agree }\end{array}$

As a final measure of analysis, Pearson correlations were run on Vision Internalization, Vision Sacrifice, and Vision Exchange with Teacher Gender. Correlations for gender were Internalization $(.03 ; \mathrm{p}=.42)$, Sacrifice $(.08 ; \mathrm{p}=$ $.03)$, Exchange $(.08 ; p=.41)$ and Total Vision $(.06 ; p=$ .08) respectively. Only Sacrifice was significant to the .05 level when correlated with teacher gender, and this is suspect due to the low correlation value. 
Teacher Age and Teacher Perceptions of Principal Vision

Research question five asked "Is the age of the teacher related to the teacher perceptions of principal vision?" For this question, using age in years, teachers were placed in seven groups: $21-25,26-30,31-35,36-40,41-45$, $46-50$, and over 50 .

A MANOVA was performed, using the three vision scales as dependent variables and the teacher's age as the independent variable. The multivariate statistical hypothesis was rejected, using Wilks' Lambda $(18,2353 \mathrm{df}, \mathrm{E}=$ $3.12, \underline{p}=0.01)$.

See Table XXI for analysis of variance of teacher perceptions of principal vision by teacher age.

TABLE XXI

ANALYSIS OF VARIANCE OF TEACHER PERCEPTIONS OF PRINCIPAL VISION BY TEACHER AGE

\begin{tabular}{|c|c|c|c|c|c|c|}
\hline \multirow{2}{*}{$\begin{array}{l}\text { Scale } \\
\text { Scale }\end{array}$} & \multicolumn{2}{|c|}{ Hypothesis } & \multicolumn{2}{|c|}{ Error } & \multirow{2}{*}{$\mathbf{E}$} & \multirow{2}{*}{$p$} \\
\hline & SS & MS & sS & MS & & \\
\hline Internalization & 81.41 & 13.57 & 3309.26 & 3.97 & 3.42 & .00 \\
\hline Exchange & 90.35 & 15.06 & 5289.92 & 6.34 & 2.37 & .03 \\
\hline Sacrifice & 94.75 & 15.79 & 5990.25 & 7.18 & 2.20 & .04 \\
\hline Total Vision & 167.96 & 27.99 & 24675.65 & 29.59 & 0.95 & .46 \\
\hline
\end{tabular}


variables and teacher age as the independent variable. To further test this question, an ANOVA was conducted using the Total Vision Score as the dependent variable and teacher age as the independent. The null hypothesis was rejected for Internalization $(E=3.42, \underline{D}=.00)$, Exchange $(E=2.37, \underline{p}=$ $.03)$, and Sacrifice $(E=2.20, \underline{p}=.04)$.

Following significant ANOVAs, the statistical hypothesis for each pairwise mean comparison was tested using Tukey HSD, at the .05 level of significance. See Table XXII for results.

TABLE XXII

SIGNIFICANT POST HOC COMPARISONS: TEACHER PERCEPTIONS OF PRINCIPAL VISION WITH TEACHER AGE

Vision Scale Tukey HSD

\begin{tabular}{ll}
\hline Internalization & I-II, I-IV, I-V, I-VI, I-VII \\
Exchange & I-VII, III-VII
\end{tabular}

Note: $I=$ ages $<=25$, II $=$ ages $26-30$, III $=$ ages $31-35$, $\mathrm{IV}=$ ages $36-40, \mathrm{~V}=$ ages $41-45, \mathrm{VI}=$ ages $46-50$ VII $=$ ages $>=51$

Significant group differences between the pairwise mean comparisons were found in this analysis. For the Internalization scale, the mean for teachers 25 years of age or younger (12.67) was significantly lower than for teachers aged 26-30 (13.85), teachers aged 36-40 (13.79), teachers 
aged 41-45 (13.59), teachers aged 46-50 (13.53) and teachers aged over 51 (13.71). The only age group which was not significantly different from those teachers younger than 26 was the 31-35 year old group; their mean was still higher at (13.31). For the Exchange scale, significant differences were found between mean scores for teachers younger than 26 (15.35) and those aged over 51 (16.50). Significant differences were also found between mean scores for teachers aged between 31-35 (15.33) and teachers aged over 51 (16.50). In the pair-wise mean comparisons, no significant difference was found on the Sacrifice scale. This indicates that principals are not as effective at persuading and exchanging ideas about their vision with younger teachers (less than 26 years old) as they are with older teachers. To determine the effect of teacher age on items 17 and 18 of the School Vision Inventory, separate Chi squares were run with each variable as the dependent variable and teacher age as the independent variable.

The Chi Square analysis of Vision item 17 did not support the rejection of the null hypothesis (Pearson Chi Square $=17.71, \mathrm{df}=12, \mathrm{p}=.125) ;$ however, the null hypothesis was rejected for Vision item 18 (Pearson Chi Square $=24.63, \mathrm{df}=12, \mathrm{p}=.017$ )

For item 18, a greater proportion of teachers aged less than 26 and aged between 31 and 35 tended to disagree that their principal included them in the vision building process 
whereas teachers older than 51 strongly agreed that they were included in the process. See Table XXIII.

TABLE XXIII

ROW PERCENTS, CHI SQUARE AND PROBABILITY VALUES FOR RESPONSES TO ITEM 18 ON THE SCHOOL VISION INVENTORY FOR TEACHER AGE

\begin{tabular}{|c|c|c|c|c|c|c|c|}
\hline Item & Age & $\begin{array}{c}\text { Response } \\
2 \\
\text { Row }\end{array}$ & $\begin{array}{c}\text { Response } \\
3 \\
\text { Row } 8\end{array}$ & $\begin{array}{c}\text { Response } \\
4 \\
\text { Row } 8\end{array}$ & $\mathbf{N}$ & $\begin{array}{c}\text { Chi } \\
\text { Square } \\
\text { (Pearson) }\end{array}$ & $\mathrm{p}$ \\
\hline 18 & $\begin{array}{l}\text { VII } \\
\text { VI } \\
\text { V } \\
\text { IV } \\
\text { III } \\
\text { II } \\
\text { I }\end{array}$ & $\begin{array}{r}9.78 \\
8.16 \\
10.68 \\
12.50 \\
16.67 \\
12.16 \\
16.67\end{array}$ & $\begin{array}{l}47.83 \\
66.67 \\
58.74 \\
45.83 \\
56.94 \\
52.70 \\
60.61\end{array}$ & $\begin{array}{l}42.39 \\
25.17 \\
30.58 \\
41.67 \\
26.39 \\
35.14 \\
22.73\end{array}$ & $\begin{array}{r}93 \\
147 \\
206 \\
144 \\
72 \\
74 \\
66\end{array}$ & 24.63 & .017 \\
\hline
\end{tabular}

Note: Response categories were combined for this instrument

Response 2 = strongly disagree + disagree

Response 3 = agree

Response 4 = strongly agree

$I=$ ages $<=25$, II $=$ ages $26-30$, III = ages $31-35$,

IV $=$ ages $36-40, V=$ ages $41-45, V I=$ ages $46-50$

VII $=$ ages $>=51$

As a final measure of analysis, Pearson correlations were run on Vision Internalization, Vision Sacrifice, and Vision Exchange with Teacher Age. Correlations for age were Internalization (-.00), Sacrifice (-.09), Exchange (+.06) and Total Vision $(-.02)$ respectively. Only the correlation of Sacrifice with teacher age was significant at the .05 level. This correlation is suspect due to teachers' negative comments about "sacrifice"; only $0.81 \%$ of the variance is accounted for. 
Iength of Time Teaching with current Principal and Teacher Perceptions of Principal Vision

Research question six asked, "Is the length of time that a teacher has worked with a principal related to teacher perceptions of principal vision?" For this question teachers were placed in five groups: teachers who had one year with their current principal were in the first group, teachers with two years with their current principal were in the second group, teachers with three years with their principal were in the third group, teachers with four years with their principal were in the fourth group, and teachers who had been with their principal for five or more years were in the fifth group.

To answer this question, a MANOVA was performed, using the three vision scales as dependent variables and the years with current principal as the independent variable. The multivariate statistical hypothesis was rejected, using Wilks' Lambda (with 12, 2161 df $, \underline{E}=2.82, \underline{p}<.001$ ). Upon rejection of the multivariate analysis, ANOVAs were performed, using the three vision scales as dependent variables and teacher years with current principal as the independent variable. To further test this question, an ANOVA was conducted, using the Total Vision Score as the dependent variable and teacher years with current principal as the independent variable. See Table XXIV. 
TABLE XXIV

ANALYSIS OF VARIANCE OF TEACHER PERCEPTIONS OF PRINCIPAL VISION BY TEACHER YEARS WITH CURRENT PRINCIPAL

\begin{tabular}{lccccccc}
\hline Scale & \multicolumn{2}{c}{ Hypothesis } & \multicolumn{2}{c}{ Error } & & E & R \\
\cline { 2 - 6 } Scale & SS & MS & SS & MS & & \\
\hline Internalization & 13.23 & 3.31 & 3377.43 & 4.04 & 0.82 & .55 \\
Exchange & 99.06 & 24.77 & 5281.21 & 6.32 & 3.92 & .00 \\
Sacrifice & 78.13 & 19.53 & 6006.87 & 7.19 & 2.72 & .03 \\
Total Vision & 381.35 & 95.34 & 24462.27 & 28.26 & 3.26 & .01 \\
& & & & & & \\
\hline
\end{tabular}

Note: Hypothesis $\mathrm{df}=4$, error $\mathrm{df}=836$

The statistical hypothesis for years of teaching with their current principal was not rejected for Vision Internalization ( $\underline{p}=.35)$; however, it was rejected for Vision Exchange ( $p=.01)$, Vision Sacrifice $(p=.03)$ and Total Vision $(p=.01)$.

Following significant ANOVAs, the statistical hypothesis for each pairwise mean comparison was tested, using Tukey HSD at the .05 level of significance. Significant group differences between the pairwise mean comparisons were found in this analysis. For the Exchange scale, the mean score for teachers with one year of experience with their principal (16.33) was significantly higher than for teachers two years with their principal 
(15.45), and teachers with four years with their principal (15.53). All other groups had means lower than group one for Exchange. For the Sacrifice scale, the mean score for teachers with one year of experience with their principal (14.58) was significantly higher than for teachers with five or more years with their principal (13.11). Teachers with one year experience with their principal had higher means than all other years with current principal groups. See Table XXV for results.

TABLE XXV

SIGNIFICANT POST HOC COMPARISONS: TEACHER PERCEPTIONS OF PRINCIPAL VISION WITH TEACHER YEARS WITH CURRENT PRINCIPAL

Vision Scale

Tukey HSD

\begin{tabular}{ll}
\hline Exchange & I-II, I-IV \\
Sacrifice & I-V \\
Total Vision & I-II, I-IV \\
Note: $I=1$ years, II $=2$ years, III = 3 years, \\
$\quad$ IV $=4$ years, $V=5+$ years
\end{tabular}

For Total Vision, the mean score for teachers with one year of experience with their principal (44.46) was significantly higher than for teachers with four years with their principal (43.58) and those with two years with their current principal (42.61). Teachers with one year experience 
with their principal had higher means than all other years with current principal groups for total vision.

To determine the effect of the number of years teaching with their current principal on items 17 and 18 of the School Vision Inventory, separate Chi Squares were run with each variable as the dependent variable and teacher years with current principal as the independent variable.

The Chi Square analysis of Vision item 17 did not support the rejection of the null hypothesis (Pearson Chi Square $=8.69$, df $=8, \underline{p}=.369$ ) however it did support the rejection of the null hypothesis for Vision item 18 (Pearson Chi Square $=17.01, d f=8, p=.031$. Those with four or one year tended to be more positive and those with two and five years less positive. See Table XXVI.

TABLE XXVI

ROW PERCENTS, CHI SQUARE AND PROBABILITY VALUES FOR RESPONSES TO ITEM 18 ON THE SCHOOL VISION INVENTORY FOR TEACHER YEARS WITH CURRENT PRINCIPAL

\begin{tabular}{|c|c|c|c|c|c|c|c|}
\hline Item & Years & $\begin{array}{c}\text { Response } \\
2 \\
\text { Row }\end{array}$ & $\begin{array}{c}\text { Response } \\
3 \\
\text { Row } 8\end{array}$ & $\begin{array}{c}\text { Response } \\
4 \\
\text { Row } 8\end{array}$ & $\mathbf{N}$ & $\begin{array}{l}\text { Chi } \\
\text { Square } \\
\text { (Pearson) }\end{array}$ & $\mathrm{q}$ \\
\hline 18 & $\begin{array}{l}5+ \\
4 \\
3 \\
2 \\
1\end{array}$ & $\begin{array}{r}12.17 \\
7.46 \\
10.70 \\
19.35 \\
8.08\end{array}$ & $\begin{array}{l}54.78 \\
52.99 \\
57.22 \\
54.19 \\
59.09\end{array}$ & $\begin{array}{l}33.05 \\
39.55 \\
32.09 \\
26.45 \\
32.83\end{array}$ & $\begin{array}{l}115 \\
134 \\
187 \\
155 \\
198\end{array}$ & 17.01 & .030 \\
\hline
\end{tabular}

$\begin{array}{ll}\text { Note: } & \text { Response categories were combined for this instrument } \\ & \text { Response } 2 \text { = strongly disagree + disagree } \\ \text { Response } 3=\text { agree \& Response } 4 \text { = strongly agree }\end{array}$


As a final measure of analysis, Pearson correlations were run on Vision Internalization, Vision Sacrifice, and Vision Exchange with teacher years with principal. Correlations for the non-coded teachers years with principal were Internalization (-.02), Sacrifice (-.09), Exchange $(-.08)$, and Total Vision $(-.09)$ respectively. The correlation of Sacrifice, Exchange and Total Vision with teacher years with current principal were significant at the .05 level. However, the correlation with Sacrifice is suspect because of a possible difference in teacher and principal interpretation of "sacrifice." None of the correlations accounted for more than $0.81 \%$ of the variance.

\section{Teacher Experience and Teacher Perceptions of Principal} Vision

Research question seven asked, "Is the length of teaching experience related to teacher perceptions of principal vision?" For this question, teachers were placed in five groups: Iess than six years of experience, 6-10 years of experience, 11-15 years of experience, 16-20 years of experience, and those teachers with more than 20 years of teaching experience.

To answer this question, a MANOVA was performed, using the three vision scales as dependent variables and years of teaching experience as the independent variable. The 
multivariate statistical hypothesis was rejected using Wilks' Lambda (with 12, 2206 df, $E=1.75, \underline{0}<.05$ ). Upon rejection of the multivariate analysis, ANOVAs were performed using the three vision scales as dependent variables and teacher experience as the independent variable. To further test this question, an ANOVA was conducted using the Total Vision Score as the dependent variable and teacher experience as the independent. The statistical hypothesis for the years of experience for teachers was not rejected for Vision Internalization $(\underline{p}=$ $.06)$, Vision Exchange $(\underline{p}=.15)$, Vision Sacrifice $(\underline{p}=.08)$ and Total Vision $(p=.22)$. See Table XXVII.

TABLE XXVII

ANALYSIS OF VARIANCE OF TEACHER PERCEPTIONS OF PRINCIPAL VISION BY TEACHER YEARS OF EXPERIENCE

\begin{tabular}{|c|c|c|c|c|c|c|}
\hline \multirow[t]{2}{*}{ Scale } & \multicolumn{2}{|c|}{ Hypothesis } & \multicolumn{2}{|c|}{ Error } & \multirow{2}{*}{$E$} & \multirow{2}{*}{ P } \\
\hline & $\overline{\text { SS }}$ & $\overline{\mathrm{MS}}$ & $\overline{\text { sS }}$ & $\overline{M S}$ & & \\
\hline Internal & 11.23 & 2.81 & 3379.44 & 4.01 & 0.69 & .06 \\
\hline Exchange & 43.68 & 10.92 & 5336.59 & 6.38 & 1.71 & .15 \\
\hline Sacrifice & 61.24 & 15.31 & 6023.76 & 7.21 & 2.12 & .08 \\
\hline Total Vision & 170.59 & 42.65 & 24673.03 & 29.51 & 1.45 & .22 \\
\hline
\end{tabular}


variable and teacher years of experience as the independent variable.

The Chi Square analyses of Vision item 17 did not support the rejection of the null hypothesis (Pearson Chi Square $=8.52$, df $=8, \underline{p}=.385$ ) or for Vision item 18 (Pearson Chi Square $=8.38$, df $=8, \underline{p}=.397)$.

As a final measure of analysis, Pearson correlations were run on Vision Internalization, Vision Sacrifice, and Vision Exchange with teacher years of experience. Correlations for years of experience were Internalization $(-.08 ; \underline{p}=.02)$, Sacrifice $(-.12 ; \underline{\underline{L}}=.00)$, Exchange $(-.02 ;$ $\underline{p}=.62)$ and Total Vision $(-.10 ; \underline{p}=.01)$ respectively. Sacrifice was significant to the .01 level, and Internalization and Total Vision were significant to the .05 level when correlated to teacher years of experience. However, the correlation with Sacrifice is suspect because of a possible difference in teacher and principal interpretation of "sacrifice." None of the correlations accounted for more than $1.44 \%$ of the variance.

\section{School Size and Teacher Perceptions of Principal Vision} Research question eight asked, "Is the size of the school related to teacher perceptions of principal vision?" The purpose of this question was to determine if principals could effectively communicate their vision in larger schools where their time and resources are more tightly stretched. 
To answer this question, schools were grouped according to their current student populations. Group one included all those schools with student populations under 400, group two included those with populations between 401 and 500, group three included schools with populations between 501 and 600 , and group four consisted all of those schools with student populations over 600 .

Following a similar pattern to previous research questions a MANOVA was performed, using the three vision scales as dependent variables and the size of the school as the independent variable. The multivariate statistical hypothesis was not rejected using Wilks' Lambda ( with 12, 116 df, $E=1.69, \underline{p}=0.08$ )

An ANOVA was conducted, using the Total Vision Score as the dependent variable and school size as the independent. The statistical hypothesis for the size of the school was not rejected for Total Vision $(\underline{p}=.17)$. See Table XXVIII.

TABLE XXVIII

ANALYSIS OF VARIANCE OF TEACHER PERCEPTIONS OF PRINCIPAL VISION BY SCHOOL SIZE

\begin{tabular}{|c|c|c|c|c|c|c|}
\hline \multirow[t]{2}{*}{ Scale } & \multicolumn{2}{|c|}{ Hypothesis } & \multicolumn{2}{|c|}{ Error } & \multirow{2}{*}{$E$} & \multirow{2}{*}{ R } \\
\hline & $\overline{\text { SS }}$ & $\overline{M S}$ & $\overline{\text { SS }}$ & $\overline{M S}$ & & \\
\hline Total Vision & 32.76 & 10.92 & 292.46 & 6.22 & 1.76 & .17 \\
\hline
\end{tabular}


Pearson correlations were run on Vision

Internalization, Vision Sacrifice, and Vision Exchange with school size. These Correlations for school size were; Internalization $(+.29 ; \mathrm{p}=.04)$, Sacrifice $(+.08 ; \mathrm{p}=.61)$, Exchange $(+.07 ; \underline{p}=.57)$ and Total Vision $(+.17 ; \mathrm{p}=.24)$. only one of the variables, Vision Internalization, was significant $(p<.05)$. There was a statistically significant, positive correlation between Internalization and the size of the school; $8.4 \%$ of the variance was accounted for.

Free and Reduced Lunch and Teacher Perceptions of Principal vision

Research question nine asked, "Is the percentage of students on free and reduced lunch related to teacher perceptions of principal vision?" Free and reduced lunch statistics are commonly used in studies of schools to determine the socio-economic status of the population within that school. High levels of free and reduced lunch support usually indicate that there are greater numbers of children who come from lower income families. The researcher was interested in exploring possible relationships between student population socio economic status and teacher perceptions of principal vision.

To answer this question, schools were grouped according to percentage of students attending that school who where 
receiving free or reduced lunch support. The first group represented those schools with less than 168 of their students receiving free or reduced lunch, the second group had between $16 \%$ and $25 \%$ of their students receiving support, the third had between $26 \%$ and $40 \%$ of their students receiving support and, the fourth group had over $40 \%$ receiving support.

Once again a MANOVA was performed, using the three vision scales as dependent variables and the percentage of students receiving free or reduced lunch as the independent variable. The multivariate statistical hypothesis was not rejected using Wilks' Lambda (with 12, 116 df, $E=0.99, \underline{E}=$ $0.47)$

An ANOVA was conducted, using the Total Vision Score as the dependent variable and percentage of students on free and reduced lunch as the independent variable. See Table XXIX.

TABLE XXIX

ANALYSIS OF VARIANCE OF TEACHER PERCEPTIONS OF PRINCIPAL VISION BY PERCENTAGE OF STUDENTS ON FREE AND REDUCED LUNCH

\begin{tabular}{|c|c|c|c|c|c|c|}
\hline \multirow[t]{2}{*}{ Scale } & \multicolumn{2}{|c|}{ Hypothesis } & \multicolumn{2}{|c|}{ Error } & \multirow{2}{*}{$E$} & \multirow{2}{*}{ R } \\
\hline & SS & $\overline{M S}$ & SS & MS & & \\
\hline Total Vision & 34.42 & 11.47 & 209.80 & 6.19 & 1.85 & .15 \\
\hline
\end{tabular}


once again, the statistical hypothesis for the percentage of students on free and reduced lunch was not rejected for Total Vision $(p=.15)$.

Pearson correlations were run on Vision Internalization, Vision Sacrifice, and Vision Exchange with percentage of students on free and reduced lunch. Correlations for free and reduced lunch with the Vision Scales were Internalization $(+.14 ; \mathrm{D}=.34)$, Sacrifice $(+.08 ; \underline{p}=.59)$, Exchange $(+.09 ; \mathrm{p}=.56)$ and Total Vision $(+.12 ; p=.42)$. None of the variables meet the .05 level of significance criterion; hence, none of the null hypotheses were rejected.

Principal Experience and Teacher Perceptions of Principal Vision

Research question ten asked, "Does the number of years of experience of the principal have any relationship to teacher perceptions of principal vision?" When looking at any aspect of human endeavor, it is easy to assume that the longer one has to work at that endeavor the more likely that the endeavor will be achieved. The researcher decided to test the "practice makes perfect" adage in relation to the years of experience of the principal and teacher's perceptions of his/her vision.

For this question, principals were grouped according to their years of experience under the following categories. 
Group one consisted of those principals with less than 6 years experience, group two consisted of principals with six to ten years experience, and group three consisted of principals with more than ten years experience. MANOVA was again selected, using the three vision scales as dependent variables and the years of experience of the principal as the independent variable. The multivariate statistical hypothesis was not rejected using Wilks' Lambda (with 8,90 df, $E=1.06, \underline{p}=0.40$ ).

In addition, an ANOVA was conducted using the Total Vision Score as the dependent variable and years of experience as a principal as the independent variable. The statistical hypothesis for the years of experience for principals was not rejected for Total Vision $(\underline{p}=.40)$. See Table xxx for the analysis of variance of teacher perceptions of principal vision by years of experience of the principal.

TABLE XXX

ANALYSIS OF VARIANCE OF TEACHER PERCEPTIONS OF PRINCIPAL VISION BY YEARS OF EXPERIENCE OF THE PRINCIPAL

\begin{tabular}{|c|c|c|c|c|c|c|}
\hline \multirow[t]{2}{*}{ Scale } & \multicolumn{2}{|c|}{ Hypothesis } & \multicolumn{2}{|c|}{ Error } & \multirow{2}{*}{$\mathbf{E}$} & \multirow{2}{*}{ P } \\
\hline & SS & $\overrightarrow{M S}$ & SS & MS & & \\
\hline Total Vision & 12.16 & 6.08 & 313.07 & 6.52 & 0.93 & .40 \\
\hline
\end{tabular}


Pearson correlations were run on Vision Internalization, Vision Sacrifice, and Vision Exchange with years of experience of the principal. Correlations for years of experience of the principal were Internalization (-.14), Sacrifice (-.16), Exchange (-.07) and Total Vision (-.13). None of the variables were statistically significant at the .05 level.

Principal Time at School and Teacher Perceptions of Principal Vision

Research question eleven asked, "Is the length of time that a principal has been in a school related to teacher perceptions of principal vision?" This question explored the hypothesis that the longer a principal is at a school the higher will be the teachers' perceptions of principal vision. Principals were grouped according to the length of time they had been in their current position. Group one consisted of those who had been at their school for one year, group two were those who had been there for two years, group three were those who had been there for three years, group four were those who had been there for four years and, group five were those who had been at their schools for five or more years.

Following a similar pattern to previous research questions a MANOVA was performed, using the three vision scales as dependent variables and the principal's length of 
time at the school as the independent variable. The multivariate statistical hypothesis was not rejected using Wilks' Lambda (with 16, 132 df, $E=1.06, \underline{p}=.40$ ). In addition, an ANOVA was conducted using the Total Vision Score as the dependent variable and the years that the principal had been at the school as the independent variable. The statistical hypothesis for the years of experience at the school was not rejected for Total Vision $(\underline{p}=.43)$. See Table XXXI.

\section{TABLE XXXI}

ANALYSIS OF VARIANCE OF TEACHER PERCEPTIONS OF PRINCIPAL VISION BY LENGTH OF TIME THAT THE PRINCIPAL HAS BEEN AT THE SCHOOL

\begin{tabular}{llllllll}
\hline \multirow{2}{*}{ Scale } & \multicolumn{2}{l}{ Hypothesis } & & \multicolumn{2}{c}{ Error } & & \\
\cline { 2 - 6 } & SS & MS & & SS & MS & & P \\
\hline Total Vision & 25.44 & 6.36 & & 299.78 & 6.52 & 0.98 & .43
\end{tabular}

Note: Hypothesis df $=4$, error df $=46$

Pearson correlations were run on Vision

Internalization, Vision Sacrifice, and Vision Exchange with the number of years that the principal has been at the school. The Correlations for principal years at a school were Internalization $(-.06 ; p=.32)$, Sacrifice $(-.26 ; p=$ $.28)$, Exchange $(-.20 ; p=.65)$ and Total Vision $(-.21 ; p=$ 
.36). None of the variables were significant at the .05 level.

Principal Gender and Teacher Perceptions of Principal Vision

Research question twelve asked, "Is the gender of the principal related to teacher perceptions of principal vision?"

To answer this question, a MANOVA was performed, using the three vision scales as dependent variables and principal gender as the independent variable. The multivariate statistical hypothesis was not rejected using Wilks' Lambda (with 4,46 df, $E=0.97, \underline{p}=0.43$ ). In addition, an ANOVA was conducted using the Total Vision Score as the dependent variable and principal gender as the independent variable. As can be seen, the statistical hypothesis for principal gender was also not rejected for Total Vision $(\underline{p}=.48)$. See Table XXXII.

TABLE XXXII

ANALYSIS OF VARIANCE OF TEACHER PERCEPTIONS OF PRINCIPAL VISION BY PRINCIPAL GENDER

\begin{tabular}{lllllll}
\hline \multirow{2}{*}{ Scale } & \multicolumn{2}{l}{ Hypothesis } & & \multicolumn{2}{c}{ Error } & \\
\cline { 2 - 6 } & SS & MS & SS & MS & & \\
& & & & & & \\
Total Vision & 3.38 & 3.38 & 321.84 & 6.57 & 0.52 & .48 \\
\hline
\end{tabular}

Note: Hypothesis $\mathrm{df}=1$, error df $=49$ 


\begin{abstract}
Pearson correlations were run on Vision Internalization, Vision Sacrifice, and Vision Exchange with principal gender. The following correlations for principal gender were found; Internalization $(-.12 ; p=.39)$, Sacrifice $(+.05 ; p=.74)$, Exchange $(-.13 ; \underline{p}=.34)$ and Total Vision $(-.10 ; p=.48)$. None of the correlations were statistically significant at the .05 level.
\end{abstract}

\title{
ANALYSIS OF THE PROFILE OF LIFE VALUES
}

The Profile of Life Values was used in this research project to study the personal values of elementary school principals. It consists 56 statements which are divided among seven internalized value scales: Intellectual, Recognition, Considerate, Creative, Artistic, Achievement, and Integrity.

The principals were asked to respond to each of the items on a four point likert scale: strongly disagree, disagree, agree, strongly agree. The items were then scored from one to four with one representing strongly disagree and four representing strongly agree. The maximum possible score on any scale was 32: the lowest possible score on any scale was eight. The higher the score the higher the personal value. Table XXXIII shows the personal values and their corresponding items. 
TABLE XXXIII

SCALES FOR PROFILE OF LIFE VALUES

\begin{tabular}{lcccccccc}
\hline \multicolumn{1}{c}{ Scale } & \multicolumn{1}{c}{ Items } \\
\hline Intellectual & 1 & 8 & 15 & 22 & 29 & 36 & 43 & 50 \\
Considerate & 2 & 9 & 16 & 23 & 30 & 37 & 44 & 51 \\
Creative & 3 & 10 & 17 & 24 & 31 & 38 & 45 & 52 \\
Recognition & 4 & 11 & 18 & 25 & 32 & 39 & 46 & 53 \\
Artistic & 5 & 12 & 19 & 26 & 33 & 40 & 47 & 54 \\
Achievement & 6 & 13 & 20 & 27 & 34 & 41 & 48 & 55 \\
Integrity & 7 & 14 & $21 *$ & $28 *$ & $35 *$ & $42 *$ & $49 *$ & $56 *$ \\
& & & & & & & \\
\hline Note: * Reverse Scoring & Used & Bellarts & $(1992, \mathrm{p} .92)$ &
\end{tabular}

Note: * Reverse Scoring Used Bellarts $(1992, \mathrm{p} .92)$

\section{Principal Personal Values}

Research question thirteen asked, "What are the principals' personal values?" The responses to the principals' Profile of Life Values were scored. The means for the value scales ranged from 23.67 for Artistic to 28.39 for Considerate, with standard deviations ranging from 2.70 for Achievement to 4.50 for Artistic. The Coefficient Alphas ranged from .751 for Intellectual to .908 on Artistic. The mean, standard deviation, and Coefficient Alpha for each of the Values scales is reported in Table XXXIV. 
TABLE XXXIV

MEANS, STANDARD DEVIATIONS, AND COEFFICIENT ALPHAS FOR PROFILE OF LIFE VALUES SCALES FOR PRINCIPALS

\begin{tabular}{lccc}
\hline \multicolumn{1}{c}{ Scale } & Mean & $\begin{array}{c}\text { Standard } \\
\text { Deviation }\end{array}$ & $\begin{array}{c}\text { Coefficient } \\
\text { Alpha }\end{array}$ \\
\hline Intellectual & 26.75 & 2.82 & .751 \\
Considerate & 28.39 & 2.76 & .789 \\
Creative & 26.63 & 3.19 & .865 \\
Recognition & 25.35 & 3.35 & .881 \\
Artistic & 23.67 & 4.50 & .908 \\
Achievement & 27.57 & 2.70 & .795 \\
Integrity & 23.74 & 3.10 & .836 \\
& & & \\
\hline
\end{tabular}

The high mean score for Considerate indicates that principals value being sensitive to the needs of others more than any of the other personal values. Considerate also had the second smallest standard deviation, indicating less variation in principals' perceptions of the importance placed on being sensitive to others.

Principals in this sample placed Artistic, mean score of 23.67, in the category of being the least important personal value. Artistic also had the highest standard deviation at 4.50 , showing that principals varied greatly in their perception of this value. 
In order of importance principals placed the personal values as follows: Considerate, Achievement, Intellectual, Creative, Recognition, Integrity, and Artistic.

\section{Principal Gender and Personal Values}

Research question fourteen asked, "Is the gender of the principal related to his/her personal values?" To answer this question, a MANOVA was performed, using the seven personal values scales as dependent variables and principal gender as the independent variable. The multivariate statistical hypothesis was rejected using Wilks' Lambda (with 7,43 df, $\underline{E}=4.77, \underline{p}<.001$ ).

ANOVAs were then performed, using the seven values scales as dependent variables and principal gender as the independent variable. The statistical hypothesis for principal gender was not rejected for Intellectual ( $p=.13$ ), Considerate $(\underline{p}=.28)$, Creative $(\underline{p}=.88)$, Recognition $(\underline{p}=.67)$, Achievement $(\underline{p}=.55)$ and Integrity $(\underline{p}=.39)$.

The statistical hypothesis was rejected for Artistic at the .05 level of significance. Females (mean $=26.15$ ) scored significantly higher than males (mean $=21.08$ ) for the artistic value. See Table XXXV for the results of the analysis of variance of profile of life values by principal gender. 
TABLE XXXV

ANALYSIS OF VARIANCE OF PROFILE OF LIFE VALUES BY PRINCIPAL GENDER

\begin{tabular}{|c|c|c|c|c|c|c|}
\hline \multirow[t]{2}{*}{ Scale } & \multicolumn{2}{|c|}{ Hypothesis } & \multicolumn{2}{|c|}{ Error } & \multirow{2}{*}{$E$} & \multirow{2}{*}{ P } \\
\hline & $\overline{\text { SS }}$ & $\overline{M S}$ & $\overline{\text { ss }}$ & $\overline{M S}$ & & \\
\hline Intellectual & 18.54 & 18.54 & 378.64 & 7.73 & 2.40 & .13 \\
\hline Considerate & 9.16 & 9.16 & 373.00 & 7.61 & 1.20 & .28 \\
\hline Creative & 0.22 & 0.22 & 507.70 & 10.36 & 0.02 & .88 \\
\hline Recognition & 2.10 & 2.10 & 559.54 & 11.42 & 0.18 & .67 \\
\hline Artistic & 328.11 & 328.11 & 683.22 & 13.98 & 23.53 & .00 \\
\hline Achievement & 2.63 & 2.63 & 361.88 & 7.39 & 0.36 & .55 \\
\hline Integrity & 7.62 & 7.62 & 474.42 & 9.68 & 0.75 & .39 \\
\hline
\end{tabular}

Note: Hypothesis $\mathrm{df}=1$, error df $=49$

Pearson correlations were run on values with principal gender. The following correlations for principal gender were found: Intellectual $(.22 ; \underline{p}=.13)$, Considerate $(.15 ; \underline{p}=$ $.28)$, Creative $(.02 ; p=.88)$, Recognition $(-.06 ; p=.67)$, Achievement $(-.08 ; p=.55)$, Integrity $(-.12 ; p=.39)$. None of the correlations were statistically significant at the .05 level. With a $\underline{p}<.001$, Artistic was highly correlated to gender (.57) which confirms the findings above that female principals place more emphasis on artistic values than do male principals. 
Rrincipal Values and Teacher Perceptions of Principal Vision

Research question fifteen asked, "What is the relationship between principal personal values and teacher perceptions of principal vision?" To answer this question, it was necessary to calculate school means for teachers' perceptions on the vision scales. These teacher (school) vision scores were correlated with the values of the principals, using Pearson coefficient of correlation.

A Pearson correlational matrix was developed, using all seven personal values scales and Vision Internalization, Vision Exchange, Vision Sacrifice and Total Vision. Significant correlations were found between Vision Internalization and Integrity $(x=.35, \underline{p}<.01)$, Vision Internalization and Consideration $(\underline{L}=.29, \underline{p}<.05)$, Vision Exchange and Achievement $(\underline{x}=.31, \underline{p}<.05)$, Vision Sacrifice and Artistic ( $\underline{I}=-.33, \underline{p}<.05$ ), Vision Total and Integrity $(x=.30, p<=.05)$.

What is most interesting is that the personal values of Intellectual, Creative and Recognition were not significantly correlated to any of the vision scales or Total Vision. Integrity and Consideration, which both involve a direct appreciation or feeling for others, were highly correlated to Vision Internalization which is the principal's ability to persuade others to accept and share his/her vision of what a school should be. See Table XXXVI. 
TABLE XXXVI

PEARSON CORRELATION MATRIX WITH PROBABILITIES FOR PRINCIPAL VISION AND PERSONAL VALUES

\begin{tabular}{|c|c|c|c|c|}
\hline Scale & Internal & Exchange & Sacrifice & Total Vision \\
\hline Intel lectual & .11 & .17 & -.19 & -.01 \\
\hline Considerate & $\begin{array}{l}.29 \\
(.04) *\end{array}$ & .21 & -.13 & .12 \\
\hline Creative & .09 & .15 & .07 & .14 \\
\hline Recognition & .19 & .24 & .12 & .26 \\
\hline Artistic & .04 & .22 & $\begin{array}{l}-.33 \\
(.02) *\end{array}$ & -.10 \\
\hline Achievement & .15 & $\begin{array}{l}.31 \\
(.03) *\end{array}$ & .11 & .26 \\
\hline Integrity & $\begin{array}{l}.35 \\
(.01) *\end{array}$ & .15 & .16 & $\begin{array}{l}.30 \\
(.03) *\end{array}$ \\
\hline
\end{tabular}

ANALYSIS OF MACH V SCALE OF INTERPERSONAL ORIENTATION

Originally developed by Christie and Geis (1970), the Mach $\mathrm{V}$ scale is designed to measure Interpersonal Orientation. This orientation is reported as a single numerical score ranging from 40 - 160 with 100 being the theoretical neutral point.

Scoring for the Mach $\mathrm{V}$ instrument is based upon the respondent's choice of the statement, which is Most like 
them and the statement which is Least like them, from the set of three statements provided. The three statements, in each set, have been selected to represent one High Mach item, one Low Mach item and, one "buffer" or neutral item. If a respondent chooses the High Mach item as the statement most like themselves and the Low Mach item as the statement least like themselves, they achieve a score of 7 points. If the reverse is true they receive only 1 point. A score of 3 is achieved if the respondent selects the Low Mach statement as the one least like them, as well as selecting the neutral statement. A score of 5 is achieved if the respondent selects the High Mach statement as the one most like them, as well as selecting the neutral statement. Once a raw score has been obtained, a constant of 20 is added to give the Mach V score.

\section{Principal's Interpersonal Orientation}

Research question sixteen asked "What are the principals' interpersonal orientations?" The principals' responses to the Mach $V$ scale were scored. The mean score for principals on the Mach $V$ scale is 95.69. For this sample, 37 principals scored below the theoretical neutral point of 100 and were rated as Low Mach and 14 scored above the neutral point and were rated as High Mach. The range of Mach scores for this sample was 80 to 110 . 
The mean, standard deviation, and Coefficient Alpha are reported in Table XXXVII.

TABLE XXXVII

MEAN, STANDARD DEVIATION, AND COEEEICIENT ALPHA MACH V SCALE FOR PRINCIPALS

\begin{tabular}{lccc}
\hline Scale & Mean & $\begin{array}{c}\text { Standard } \\
\text { Deviation }\end{array}$ & $\begin{array}{c}\text { Coefficient } \\
\text { Alpha }\end{array}$ \\
\hline Mach V & 95.69 & 6.61 & .119 \\
\hline
\end{tabular}

The Coefficient Alpha for this instrument is very low (.119); all subsequent analyses involving this instrument are suspect.

\section{Teacher Perceptions of Principal Vision and Principal Interpersonal orientaticn}

Research question seventeen asked, "Is the interpersonal orientation of the principal related to teacher perceptions of principal vision?" Prior to answering this question, Mach scores were calculated for all principals and they were divided into two groups. Those principals scoring above the theoretical mean of 100 were rated as High Mach, and those below this point were rated as Low Mach. 
To answer this question, a MANOVA was performed, using the Vision Internalization, Vision Sacrifice, and Vision Exchange scales as dependent variables and principal Mach as the independent variable. The multivariate statistical hypothesis was not rejected using Wilks' Lambda (with 4,46 df, $E=0.11, \underline{p}=.98)$. A separate ANOVA was run with Total Vision as the dependent variable and principal Mach as the independent variable. As can be seen, the statistical null hypothesis for principal Mach was not rejected for Total Vision $(\underline{p}=.64)$. See Table XXXVIII.

TABLE XXXVIII

$$
\begin{gathered}
\text { ANALYSIS OF VARIANCE OF VISION SCALES BY } \\
\text { PRINCIPAL MACH }
\end{gathered}
$$

\begin{tabular}{lllllll}
\hline \multirow{2}{*}{ Scale } & \multicolumn{2}{l}{ Hypothesis } & \multicolumn{2}{c}{ Error } & & M \\
\cline { 2 - 7 } & SS & MS & SS & MS & & \\
\hline Total Vision & 1.46 & 1.46 & 323.77 & 6.61 & 0.22 & .64
\end{tabular}

Note: Hypothesis df $=1$, error df $=49$

Pearson correlations were run on Vision Internalization, Vision Sacrifice, Vision Exchange, and Total Vision with principal Mach. The following correlations for principal Mach were found: Internalization $1.03 ; \underline{p}=$ $.81)$, Sacrifice $(.09 ; \underline{\underline{L}}=.52)$, Exchange $(.05 ; \underline{\underline{ }}=.73$ ) and Total Vision $(.07 ; \underline{p}=.64)$. None of the correlations were statistically significant at the .05 level. 


\section{Principal Interpersonal orientation and Personal Values}

Research question eighteen asked, "Is the interpersonal orientation of the principal related to his/her personal values?" To test this question principals were again placed as either High or Low Mach, depending upon if their Mach scores were above or below the theoretical mean.

A MANOVA was performed, using the seven values scales from the erofile of Iife Values as dependent variables and principal Mach as the independent variable. The multivariate statistical hypothesis was not rejected, using Wilks' Lambda (with 7,43 df, $E=0.98, \underline{p}=.46$ ).

Pearson correlations were run on the value scales and with the principal Mach. The following correlations for principal Mach were found: Intellectual $(-0.04 ; \mathrm{p}=.79)$, Considerate $(-0.09 ; \underline{p}=.51)$, Creative $(0.05 ; \underline{p}=.75)$, Recognition $(-0.01 ; \underline{p}=.95)$, Artistic $(0.09 ; \underline{p}=.55)$, Achievement $(0.01 ; p=.94)$ and Integrity $(0.04 ; .76)$. None of the correlations were statistically significant at the .05 level.

\section{SUMMARY}

This chapter presented the results of this research study. Eighteen research questions were analyzed using one or more of the following statistical techniques: MANOVA, 
ANOVA, Chi-Square, Pearson Product correlation. The demographic data for teachers, principals and schools were presented.

Vision, personal values and interpersonal orientation were the three key variables used in this study and they were measured using the Scheol Vision Inventory, Brofile of Iife Values and, Mach $V$ instruments respectively. The following demographic variables were included in the analysis: Teacher gender, teacher age, the length of time that a teacher has worked with a principal, the length of teaching experience, the size of the school, the percentage of students on free and reduced lunch, the number of years of experience of the principal, the length of time that a principal has been in a school, and principal gender. 
CHAPTER V

DISCUSSION, CONCLUSIONS, LIMITATIONS, SIGNIFICANCE AND RECOMMENDATIONS

INTRODUCTION

The purpose of this chapter is to discuss the results of this research study and to offer conclusions drawn from the data analysis. The limitations of the study as well as its significance for education and recommendations for future research, will also be addressed. DISCUSSION OF THE RESULTS

This quantitative study looked specifically at three personal characteristics believed to be associated with effective leadership in elementary schools. The three variables are (1) Principal Vision which was measured by the School Vision Inventory, (2) Principal Interpersonal Orientation which was measured by the Mach $V$ scale and, (3) Principal Personal Values which was measured by the Prefile ef life values. 
The intended purpose of this study was to explore relationships between principal vision, interpersonal orientation, and personal values in elementary principals. The relationship between selected teacher, principal, and school demographic variables and teachers' perceptions of their principal's vision was also examined.

While there is a growing interest in research on principal vision, there have been only limited attempts to study theoretically related variables such as interpersonal orientation, personal values and school demographic characteristics.

Data were collected from 51 principals and 841 teachers in elementary schools from ten school districts in the Portland, Salem and Vancouver metropolitan areas. Teachers from each elementary school were asked to score their perceptions of their principal's vision on the school Vision Inventory, while the principal of each school was asked to predict how he/she felt that their staff might respond to the same instrument.

In addition to the school Vision Inventory, the principal was also asked to complete the Mach $V$ Scale and the Profile of life Values. Data were analyzed by using one or more of the following statistical tests where appropriate; MANOVA, ANOVA, Chi Square, and Pearson correlation. 
The major conclusions drawn from this study are: (1) principals perceived their teachers to be less positive than they in fact were in their perceptions of the principal's ability to encourage others to make personal sacrifices to accomplish the principal's vision; (2) male teachers perceive that their principals include them more in the vision building process than do female teachers; (3) teachers younger than 26 were less positive in their perceptions of their principal's Internalization and tended to be less positive on other scales; (4) principals communicate their vision more effectively with those teachers who are in their first year with their current principal than any other group for vision exchange, sacrifice and total vision; (5) school and principal demographics have little impact on teacher perceptions of principal vision; (6) principals value being sensitive to the needs of others more than any of the other personal values and they value artistic expression and appreciation the least; (7) with the exception of the Artistic values, male and female principals are relatively similar in their personal values; (8) principal vision and personal values are moderately related; and (9) the relationship of interpersonal orientation of the principal to teacher perceptions of principal vision is not statistically significant. Each of these conclusions will be highlighted and discussed in the next section. 
CONCLUSIONS

conclusion \# 1: Principals perceived their teachers to be less positive than they in fact were in their perceptions of the principal's ability to encourage others to make personal sacrifices to accomplish the principal's vision.

This conclusion is based upon the results of Chi square analyses of teacher's responses on the school Vision Inventory and principal's predictions of their staffs' response to the same instrument. No significant differences were found between teacher perceptions and principal predictions of principal vision for the scales of Vision Internalization and Vision Exchange, and for Total Vision.

Four of the five Vision Sacrifice scale items were rejected at the .05 level of significance. In each of the four items where statistically significant differences were found, the majority of principals tended to select the agree or strongly agree category less than did teachers.

This comparison of principal and teacher responses to the items on the Vision Sacrifice scale clearly shows that the principals underestimated the success that they were having in persuading their teaching staff to make sacrifices to achieve the principals' personal vision. While principals were accurately able to predict how well teachers were able to internalize and exchange the principal's vision, they 
seemed almost tentative to state that teachers felt comfortable making "sacrifices" to achieve that vision. One explanation for this discrepancy may be that principals' felt reluctant to claim that others would make "sacrifices" for them because of the emotive nature of the word sacrifice and the negative images that it can conjure up. This may explain why the principals' were accurately able to predict teachers responses on the Vision Exchange and Vision Internalization scales but not on the Vision Sacrifice scale. Principals and Teachers may have been looking at "sacrifice" in slightly different ways and hence the principals were unable to adequately predict for this scale.

Further comparison of the mean scores show that there was no statistically significant difference between teachers' perceptions and principals' predictions of teacher perceptions of principal Total Vision. For both teachers and principals the Total Vision mean scores were very high at 43.49 and 43.51 respectively, with a theoretical range from 16.00 to 54.00 . This indicates that principals seem to be effective in advancing their vision and that they can accurately assess how successful they are at advancing their vision.

One additional factor worth noting is that there were no schools which had "Iow" vision scores which either indicates that all of the principals surveyed were percieved 
by their staff has being high in total vision or that there may have been an element of social desirability response bias in the Vision scales.

conclusion \# 2: Male teachers perceive that their principals include them more in the vision building process than do female teachers.

This conclusion was drawn from the results of a Chi Square analysis on teacher gender and Vision item 18 "MY principal included me in the vision building process". The null hypothesis was rejected at the .05 level for vision item 18. Further examination of the row percents for gender and vision item 18 revealed a greater proportion of males (46.618) gave their principal a rating of 4 (strongly agree) than did females $(29.88 \%)$. Females rated their principal higher in categories 3 (agree) (58.12\%) than males (44.07\%) and they also rated their principals higher in category 2 (disagree) with females (11.98\%) and males (9.32\%). This would indicate that male teachers perceive that their principals include them more than females in the vision building process.

This difference in gender perception might be due to the fact that in elementary schools there are so few male teachers that in order to have gender equity in formal groups such as committees, principals might call upon 
individual male teachers more often than they would

individual female teachers. This over-representation may lead male teachers to feel that they are in fact included in more dialogue with the principal and hence more opportunities for shared vision building.

A series of ANOVAs were run using the vision scales as the dependent variables and the teacher gender as the independent variable. The null hypothesis for Vision Sacrifice was rejected at the .05 level of significance.

conclusion \# 3: Teachers younger than 26 were less positive in their perceptions of their principal's Internalization and tended to be less positive on other scales.

Significant group differences between the pairwise mean comparisons were found in a Tukey HSD analysis of the vision scales by gender. For the Internalization scale, the mean score for teachers 25 years of age or younger (12.67) was significantly lower than for teachers aged 26-30 (13.85), teachers aged 36-40 (13.79), teachers aged 41-45 (13.59), teachers aged 46-50 (13.53) and teachers aged over 51 (13.71). The only age group which was not significantly different from those teachers younger than 26 was the 31-35 year old group and their mean was still higher at 13.31 . For the Exchange scale significant differences were found between mean scores for teachers younger than 26 
(15.35) and those aged over 51 (16.50). Significant differences were also found between mean scores for teachers aged between 31-35 (15.33) and teachers aged over 51 (16.50).

For item 18 on the School Vision Inventory "MY principal included me in the vision building process", a greater proportion of teachers aged less than 26 and aged between 31 and 35 tended to disagree that their principal included them in the vision building process whereas teachers older than 51 strongly agreed that they were included in the process.

Teachers under the age of 26 perceive their principals lower than any other age group for vision exchange, vision internalization and inclusion in the vision building process. Interestingly teachers over the age of 50, feel more than any other age group that their principal includes them in the vision building process.

A possible explanation for this is that older teachers are often the most experienced teachers on the staff and they more often than not are the "sounding board" for principals. Their vast experience and knowledge become a resource for administrators as they go about the business of leadership within the school. Younger teachers on the other hand seem to be approached less frequently to contribute to the vision building process because of their presumed lack of exposure to a variety of educational situations. 
Alternatively, it may be that younger teachers have higher expectations for involvement and consultation than their more senior colleagues.

cenclusion\# 4: Principals communicate their vision more effectively with those teachers who are in their first year with their current principal than any other group for vision exchange, sacrifice and total vision.

This conclusion was drawn from the following results. First, for the MANOVA, using the three vision scales as dependent variables and the years with current principal as the independent variable, the multivariate statistical hypothesis was rejected. Upon rejection of the multivariate analysis, ANOVAs were performed using the three vision scales as dependent variables and teacher years with current principal as the independent variable. To further test this question, an ANOVA was conducted using the Total Vision Score as the dependent variable and teacher years with current principal as the independent. The statistical hypothesis for years of teaching with their current principal was not rejected for Vision Internalization; however, it was rejected at the .05 level for vision Exchange, Vision Sacrifice, and Total Vision.

Following significant ANOVAs, the statistical hypothesis for each pairwise mean comparisons were tested, using Tukey HSD at the .05 level of significance. 
Significant group differences between the pairwise mean comparisons were found in this Tukey HSD analysis. For the Exchange scale, the mean score for teachers with one year of experience with their principal (16.33) was significantly higher than for teachers two years with their principal (15.45), and teachers with four years with their principal (15.53). All other groups had means lower than group one for Exchange.

For the Sacrifice scale, the mean score for teachers with one year of experience with their principal (14.58) was significantly higher than for teachers with five or more years with their principal (13.11). Teachers with one year experience with their principal had higher means than all other years with current principal groups.

For Total Vision, the mean score for teachers with one year of experience with their principal (44.46) was significantly higher than for teachers with four years with their principal $(43.58)$ and those with two years with their current principal (42.61). Teachers with one year experience with their principal had higher means than all other years with current principal groups for Total Vision indicating that something occurs during the first year that principal and teacher are together which causes teachers to be more aware of the visions of their principals. The most logical explanation for this is that each is trying to establish a relationship with the other through interaction. During this 
process the teacher looks for the parameters within which the principal operates and tries to establish an understanding of the focus of the principal. It hypothesized that it is during this "getting to know you phase" that much of the vision exchange and internalization takes place for the new teacher.

cenclusion \#5. School and principal demographics have little impact on teacher perceptions of principal vision. The preceding conclusions have shown that several age and gender differences in teachers, as well as the amount of time that the teacher has been with the principal, are significantly associated with differences in teachers' perceptions of their principal's vision. When comparisons were made, however, between principal demographics and teacher perceptions of their principal's vision, no significant difference was found.

This tends to indicate, that even though the principals in this study were very different in terms of their age, years of experience, years at their current school, and gender, their visions were all perceived by their teachers in very similar ways. It is possible that even though principals may enter the school principalship as very different people, over the years they all end up looking very similar to each other because of role expectations and pressure from superiors, staff, and community to "fit the 
mold". This supports earlier conclusions drawn by Bridges (1982) when he noted that due to the bureaucratization in schools, principals lose a lot of their individuality. Bridges argues that greater understanding needs to occur about the characteristics of the situations in which principals work.

School demographics, such as number of students on free and reduced lunch, student population, and current number of classroom teachers, were all found to have no significant relationship to the perceptions that teachers had of their principal's vision. This too would support the hypothesis that over time principals start to look the same in terms of the way that they communicate their visions to their staff, community, and students. Prior to the analysis of these results, one may have been easily convinced that those principals in smaller schools would have been more effective in communicating their vision than those in the larger schools because of the difference in audience size. This, however, is not the case in the results reported in this study.

conclusion \#6: Principals value being sensitive to the needs of others more than any of the other personal values and they value artistic expression and appreciation the least. 
This conclusion was derived by analysis of the means for the value scales as measured by the profile of life Values. The mean value scale scores ranged from 23.67 for Artistic to 28.39 for Considerate. The Coefficient Alphas ranged from .751 for Intellectual to .908 on Artistic. The results of this analysis show that the high mean score for Considerate indicates that principals value being sensitive to the needs of others more than any of the other personal values. Principals in this sample placed Artistic, mean score of 23.67 , in the category of being the least important personal value. Artistic also had the highest standard deviation at 4.50 showing that principals varied greatly in their perception of this value. In order of importance principals placed the personal values as follows; Considerate, Achievement, Intellectual, Creative, Recognition, Integrity and Artistic.

Blumberg \& Greenfield (1986) state that it is important to note that the study of personal values represents an attempt to study the character of principals and their qualities as human beings. Schools, and particularly those at the elementary level, are people centered organizations and as such, focus more on nurturing and growth rather than on productivity. It is not surprising then to see principals placing consideration of others higher than any other personal value. The role of the principal is to ensure the effective functioning of the 
school as an organization and in that role it is obviously important that the principal consider all of the groups which interact within the school. It is also possible that the emphasis on consideration for others may be a function of the highly normative character of the school as an organization.

Achievement and Intellectual are again fairly obvious values to have present in a school principal as these are closely related to two of the key purposes of education. Intellectual development of the students of the school is achieved through the instructional process for which the principal is directly responsible. Intellectual development of the staff and the principal themselves occurs regularly in the form of staff development and professional enhancement. For the principal then, valuing intellectual pursuits is critical for the success of the school.

It is also possible that there was an element of response bias on the part of the principals in responding to the social desirability of Achievement and Intellectual values. This might also help explain how educators, who are generally more inclined to be practical than intellectual, selected these values as being so high.

Achievement is an important value for any principal to have as it shows his/her emphasis on success in the learning process. By holding achievement up as a high value in their 
school, principals are paving the way for successful

productive students.

These results are almost identical to those found by Bellarts (1992) in her study of the personal values of nursing students. Bellarts also used the profile of Life Values and found that Considerate, Intellectual and Achievement were the three most important personal values for nursing students.

These comparative findings are most likely due to the fact that education and nursing as professions have strong similarities. Both are concerned with providing service to others in not-for-profit organizations with emphasis on the consideration of others in the fulfillment of their jobs. Marshal1 (1992), in a study of 26 administrators whom she labeled "atypical" because they veered away from the norm of white, male, risk-avoiders, found that values came into play when administrators were forced to deal with dilemmas arising from chronic tensions in public schooling. She concluded that administrators value a sensitivity to the needs of teachers and, most of all, a concern for each child's ability and equal opportunity to thrive, even to the point of risking their own careers (p. 382).

Marshall's (1992) emphasis here is clearly that schools are people-centered places and as such principals within schools place the consideration of others as a high personal value. This again supports the findings of this study. 
The actions taken by the principal, as the instructional leader of the school, will be based upon that principal's particular set of personal values. As Greenfield (1987) argues, instructional leadership involves the assignment of values to facts as a necessary part of the decision making and action taking process.

The literature on principal personal values is very sparse. The significance of values in influencing the work of the principal, however, should not be understated. Almost every action taken by the principal and every decision made is consciously or unconsciously tied to that principal's moral and ethical stance regarding the needs of children, staff, and community associated with his/her particular school. It is not surprising then that consideration for others is the most important personal value of principals in this study.

conclusion \# 7. With the exception of the Artistic values, male ard female principals are relatively similar in their personal values.

Using personal values as the dependent variable, the multivariate statistical hypothesis was rejected. However, the univariate statistical hypothesis was not rejected for Intellectual, Considerate, Creative, Recognition, Achievement, and Integrity. The statistical hypothesis was rejected for Artistic at the .05 level of significance. 
A Pearson correlation was run on values and principal gender and the following correlations for principal gender were found: Intellectual (.22), Considerate (.15), Creative (.02), Recognition (-.06), Achievement (-.08), Integrity $(-.12)$. None of the correlations were statistically significant. Artistic, however, was highly correlated to gender (.57), with $\mathrm{p}<.001$.

One possible explanation for this gender similarity in personal values is that each of the personal values would seem to be important in anyone who is in a leadership position. Integrity, consideration for others, importance placed on achievement and intellectual pursuits are all key elements in "people centered" organizations such as schools. Thus, gender differences associated with personal values would not be expected among school leaders. The gender difference on artistic may simply be a result of more traditional "male" and "female" socialization processes. Appreciation of the fine arts, ballet, music and art are not traditionally "male" interest areas so consequently their lower personal value for male administrators.

cenclusion \# 8. Principal vision and personal values are moderately related.

A Pearson correlation matrix was developed, using all seven personal values scales and Vision Internalization, Vision Exchange, Vision Sacrifice, and Total Vision. 
Significant correlations were found between Vision Internalization and Integrity (.35), Vision Internalization and Consideration (.29), Vision Exchange and Achievement (.31), Vision Sacrifice and Artistic (.33) and, Vision Total and Integrity $(.30)$.

It is not surprizing in this correlation that the personal values of Intellectual, Creative and Recognition were not significantly correlated to any of the vision scales or Total Vision. Integrity and Consideration, which both involve a direct appreciation or feeling for others, were highly correlated to Vision Internalization which is the principal's ability to persuade others to accept and share his/her vision of what a school should be.

The most significant observation here is that the personal value of Integrity for the principal is significantly related to teachers' perceptions of principal total vision. The value of Integrity focuses on the principal being correct, sincere and honest with those with whom he/she deals.

While research studies do not exist which examine relationship of the integrity of the principal to his/her personal vision, common sense, societal norms, and ethical administration all point to the importance of honesty and sincerity on the part of the principal in advancing his/her vision. 
Mauriel (1989) states that an effective vision should be one that speaks to the heart and represents values that are important to the individual. This vision should so excite the people in an organization that they feel motivated to support, act on behalf of, and feel proud to belong to that organization. Blase (1987) states that the reduction of goal and vision ambiguity is critical to the ability of the principal to translate his/her vision into action. Effective principals, after defining their vision for their schools, seek the support of staff to implement policies and procedures associated with that vision.

Vision or "moral imagination" was defined by Greenfield (1987) as: "The capacity to see the discrepancy between how things are and how they might be and the need to compel others to act on those imagined possibilities" (p.94). Blumberg and Greenfield (1986) found that the implementation of a particular principal's vision was directly related to the principal's ability to develop warm working relationships with others as well as a shared concern for good practice and the best interests of students.

Blumberg and Greenfield (1986) see vision as the capacity to exercise moral imagination and as the foundation upon which the moral authority of the principal rests. Vision is what allows a principal to lead a school well and as such is of critical importance for principals because it 
is they who will determine what is to become of the school. In their words: "As the principal goes, so goes the school" (p.228).

Each of the theorists refered to above have a slightly different stance or focal point when addressing the vision of the principal. Central to each however, is the importance of the principal as the catalyst for developing the vision. Embedded in each of these theoretical perspectives is the need for honesty, sincerity and integrity on the part of the principal. The results of this study support this theoretical link between integrity and vision.

Conclusion \# 9. The relationship of the interpersonal orientation of the principal to teacher perceptions of principal vision is not statistically significant.

The basis for this conclusion is found in several different analyses, as explained here. Mach scores were calculated for all principals and they were divided into two groups. Those principals scoring above the theoretical mean of 100 were rated as High Mach, and those below this point were rated as Low Mach.

The mean score for principals on the Mach $\mathrm{V}$ scale was 95.69 with a standard deviation of 6.61. For this sample, 37 principals scored below the theoretical mean of 100 and were rated as Low Mach and 14 scored above the neutral point and were rated as High Mach. The range of Mach scores for this 
sample was 80 to 110 . The Coefficient Alpha for this instrument is very low at .119 making all analyses involving this instrument very suspect.

A MANOVA was performed, using the Vision Internalization, Vision Sacrifice, Vision Exchange and Total Vision scales as dependent variables and principal Mach as the independent variable. The multivariate statistical hypothesis was not rejected. A separate ANOVA was run with Total Vision as the dependent variable and principal Mach as the independent variable. The statistical hypothesis for. principal Mach was not rejected for Total Vision. Pearson correlations were run on Vision Internalization, Vision Sacrifice, Vision Exchange, and Total Vision with principal Mach. The following correlations for principal Mach were found: Internalization (.03), Sacrifice (.09), Exchange (.05) and Total Vision (.07). None of the correlations were statistically significant at the .05 level.

Each of these analyses clearly show that no significant results could be found which link teacher perceptions of principal vision with principal interpersonal orientation. This may not be the case if interpersonal orientation were measured via a different instrument. However, it is the direct finding of this study.

Although no studies exist which compare interpersonal orientation as measured by the Mach $\mathrm{V}$ scale and principal 
vision, several studies do exist which have used the Mach $V$ in determining principal interpersonal orientation and school and principal effectiveness.

Grimsley (1985) found, in his study of 30 elementary principals, that no significant relationships exist between principal interpersonal orientation and faculty maturity to school effectiveness. Cockey (1984) in a study of $43 \mathrm{high}$ school principals, also found that there was no significant relationship between principal interpersonal orientation and the job satisfaction of their subordinate teachers. Hichman (1986) in a study of 235 public school principals, found only slight correlations between interpersonal orientation and role clarity and job satisfaction for principals.

These three studies confirm the conclusion of this study that the interpersonal orientation of the principal, as measured by the Mach_ $\mathrm{V}$ scale, is often not significantly related to variables theoretically associated with principal effectiveness. It is highly likely that this may be more due to the accuracy of the Mach $V$ instrument in measuring interpersonal orientation than to the concept of interpersonal orientation itself.

\section{LIMITATIONS OF THE STUDY}

No research is perfect, yet good research is at least honest in admitting the limitations of its methodology, 
conceptual base and possible conclusions. One of the greatest limitations of this study was the time during which the respondents were surveyed. Many districts were reluctant to participate due to the pressures placed upon them by Measure 5. Teachers were responding to the School Vision Inventory at the same time that many of their colleagues were being RIFed because of budget reductions. Principals also were battling to keep the morale of their schools high. It is important to note that this research was conducted under unusually stressful conditions for schools.

A second limitation of the study lies in the length of the questionnaire administered to principals. Some 94 questions make up this instrument and it is anticipated that approximately 30 minutes of the administrator's time was needed for it to be completed. Additionally, teachers needed to take approximately 10 minutes to complete their questionnaire. Time is a scarce commodity in schools, and lack of time rather than lack of interest or motivation, may have limited the number of schools who volunteered to participate.

A third limitation is the inappropriateness of generalizing the results to different educational settings. This study focuses on urban/suburban school districts and should not be generalized to other states or rural areas where the educational processes may be different. 
A fourth limitation of this study is the relatively small sample of principals. Although the researcher is confident that the results presented in this study are very accurate, a greater sample size would allow greater confidence in the conclusions drawn from the research.

A fifth limitation involves the very nature of survey research. The results presented here represent a snapshot in time for those who participated. Longitudinal studies are needed to determine the effects of time on the development of vision, values and interpersonal orientation in education leaders.

A sixth limitation was the very low reliability of the Mach $\mathrm{V}$ scale (.119). This reliability level gives the researcher very little confidence in any conclusions drawn from this instrument. It is possible, but not likely, that changing some of the words in the instrument to eliminate gender bias may have effected the reliability. The drop in reliability from $(.650$ - .670) reported by Christie and Geis (1970) to the (.119) reported in this study is more likely due to the changes in society over the past 20 years as well as the difference in the sample populations which were studied. Original sample populations were drawn primarily from undergraduate volunteers in a variety of programs from several major U.S universities.

It is highly possible that greater variance existed between respondents at the college undergraduate level than 
existed among elementary principals. College students who are primarily young and often undecided about majors and careers represent a more heterogeneous group than do elementary principals who have all usually been in the field of education for a considerable time before entering into school administration and hence represent a much more homogeneous group.

Grimsley (1985), Cockey (1984), and Hichman (1986) in their dissertations did not, as far as the researcher is aware, report reliability coefficient alphas which makes comparisons to this study difficult.

It is also possible that the unique nature of elementary principals as a group may have skewed the results. Very few elementary principals wish to work as high school principals and vise versa. Each is a "principal" but the settings are so different that "principal specialization" seems to develop. This specialization tends to indicate a greater degree of homogeneity of principals as a group. Previous studies using the Mach $y$ instrument have seemed to focused on more heterogeneous groups such as medical students or engineers as reported by Christie and Geis (1970).

A seventh limitation of this study is that in some schools the concept of shared leadership is so strong that principals were reluctant to participate without the approval of their staff. Some teachers and principals felt 
so strongly about vision being a "shared" concept that they chose not to participate. This was also observed by Johnson (1991) .

A final limitation is that another contextual variable which potentially confounded the results of this study is the high incidence of training which has occurred in Northwest schools centered around the onward to Excellence program, which focuses on the vision and mission building process. This combined with the highly prescriptive sentiment in the profession that it is geod for a principal and a school to have a vision, may have added an element of response bias to the study. This may also explain why only 3.48 of the teachers sampled responded false to questions one and two of the School Vision Inventory.

\section{SIGNIFICANCE FOR EDUCATIONAI LEADERSHIP}

This study was about educational leadership and leadership effectiveness. It attempted to look at three personal variables believed to be associated with the effectiveness of the principal's leadership: vision, interpersonal orientation, and personal values.

Burlingame (1987) is one of a growing body of researchers who see the importance of the cultural context of the school and the significance of other members of the organization in ensuring school effectiveness. 
Dwyer and Smith (1987) state that when looking at effective schools the role of the instructional leader is critical; however, the significance of the leaders' role cannot be understood apart from the larger systems and events that have a direct impact on their actions. They state that some of the key variables which can influence school success are demographics, changing student populations, the history of the organization and, the changes in school leadership (pp. 174-176). In this vein, the present study has helped to clarify the significance of some teacher demographic variables and their relationship to principal and leadership effectiveness. Teacher age, gender, and years with the current principal all proved to be significantly related to principal vision. principals need to take time to address the needs of all these groups so that they may equally strive toward the vision.

As with the study by Licata, Greenfield and Teddlie (1989) this study supports the notion that whoever initially creates the vision may be less important than the extent to which the staff of the school actually support the vision. The growing trend in education is for development of a shared vision among all members of the organization.

Building upon his earlier work (Blumberg \& Greenfield, 1980,1986), Greenfield (1987) has suggested that the cornerstones of effective instructional leadership are (1) the ability to exercise "moral imagination", or the ability 
to see how things are and how they might be, in developing a compelling "vision" regarding what is possible or desirable for the school and (2) "interpersonal competence" or the knowledge and skills needed by the principal in order to influence others in desired directions (p. 64).

The results of this study have not necessarily supported the importance of interpersonal orientation in leadership effectiveness; however, given the low reliability of the instrument used to measure this variable these results may not be a true indicator of the significance of the principal's interpersonal orientation. Despite these results, the researcher strongly believes that interpersonal competence is directly related to principal effectiveness. The importance of the interpersonal dimension is reflected in many reports. Two examples illustrate the centrality of this dimension.

Gardner (1990, p. 119) said that, for leaders to be effective and function in the complex world of today, they need critically important skills which involve (1) agreement building by listening to all people at all levels, (2) networking by encouraging people to come together to create change, (3) the exercise of non-jurisdictional power by creating consensus rather than power, and (4) institution building through empowerment of their co-workers. Further, Astin and Leland (1991) state that effective leadership includes the ability to assess a situation, to 
engage others in collective efforts, and to bring about needed change. They continue by saying that leaders need to be politically adept, be willing to take risks, and be perceptive particularly in relationship to their environments. Paramount, however, is the need for the acute development and critical use of outstanding interpersonal skills. Clearly, the study of interpersonal competence is in need of much greater exploration particularly in relation to principal effectiveness.

RECOMMENDATIONS FOR FUTURE RESEARCH

The Profile of Life Values was originally designed by Hales and Bellarts (1991) to measure the personal values of nursing students; however, it has proved to be a valuable tool for assessing the values of educators as well. Given that a data set and results now exist for the profile of Life values for the 51 principals who participated in this study, future researchers might consider follow up studies in schools where the instrument is used with teachers and principals and comparisons drawn between the two. Are the values of principals and teachers the same? Studies could also extend to comparisons between educator personal values and school community personal values by using the instrument 
with teachers and parents in a sample of schools. A comparison between the values of the different groups within a school community may help to illuminate any common values which exist between each of the groups.

Future research should study principal interpersonal competence by using alternative instruments to the Mach $V$ scale. The extremely low reliability (.119) of this instrument, with this sample at least, makes its use in school research questionable. Other interpersonal orientation scales need to be explored, or if not available, developed and tested. This would seem a fruitful avenue of inquiry given the highly normative character of schools and the largely expressive nature of the principal's role as a formal leader (Etzioni, 1965).

The study of principal vision should be expanded to include a much larger sample of school administrators. The sample size of this study was impacted greatly by the negative effects school districts are feeling because of budget limitations bought on by the passage of measure 5 . Schools are currently experiencing very low morale, for example, because many programs and staff are being cut. Principals and teachers are fighting with increasing class sizes and decreasing instructional support. Much talk abounds about re negotiation of teacher contracts with possible wage freezes and cuts in benefit packages. All of 
these conditions make for unfavorable conditions for the type of research undertaken in this study. It is therefore possible that a larger sample and more favorable conditions for research would offer a better test of the questions examined in this study.

Many teachers who responded to the School Vision

Inventory wrote comments in the margin of their surveys indicating that they were unsure of the answer to some questions. It is recommended that this instrument be expanded from a four point to a five point likert scale with the middle value being for those who are truly unsure about aspects of their principal's vision.

Johnson (1991) in his doctoral dissertation, recommended that the word "sacrifice" be replaced in the Schoel Vision Inventory by a term which arouses far less uncomfortable feelings and negative comments from teachers. The present study supports this recommendation as many teachers expressed their concern for how the word "sacrifice" was used.

The growing trend in schools today is toward site-based decision making and, even though the School Vision Inventory is specifically designed to measure the teachers' perceptions of the vision of the principal, future studies need to explore the relationship which is developing between the "shared" vision of the members of the school and the vision of the principal. 
As with most survey research, the results presented in this study represent a snapshot in time for the staff and the principal of the schools which participated. Future research should consider longitudinal approaches to data collection on vision and should address the "development" of vision in principals and how those visions may "change" over time.

Finally, future studies should aim at expanding the research base to include qualitative as well as quantitative studies of principal vision, personal values and interpersonal competence. This would help future" researchers "get behind the numbers" and further explore the nature of principal vision, interpersonal competence and values in schools. These multiple data points lead to greater depth and diversity in the study sample.

Examples of qualitative research questions might be: (1) In what ways does the principal exchange ideas about his/her vision with the school community ?, (2) How do principals differ in regards to their particular visions of what schools should be?, (3) How do principals act upon their personal values in a school?, (4) Do principals vary in their interpersonal interactions/ orientations with different staff members and if so how and why? and, (5) Are vision, interpersonal competence and personal values related in any significant way in schools? 
RECAP ITULATION

This research study has looked at three variables which the literature associates with leadership effectiveness. While this study has not directly studied leadership effectiveness, it has taken vision, interpersonal competence and personal values of the principal and examined any relationships which exist between these three variables.

The binding thread which drove the selection of these three variables for use in this study was that of "change". in education and connection which exists between change and leadership. Implied in the concept of principal vision is the notion that principals who are perceived by their staff as having high total vision are those who are most likely to be looking at an agenda for change in their school. Personal values drive the principal to seek out improvement and change in schools. Principals who are High Mach, more impersonal in their interpersonal orientation, are more theoretically likely to be effective in ambiguous situations which is implicit in the change process.

Sarason (1990) notes that for true educational reform to occur, the participants in that reform process need time to assimilate to the changes that occur as part of that reforming process. This is true also of principal vision and the natural link between what it is that the principal is trying to achieve in a school and change processes that need 
to occur if those visions are to take shape. Surprisingly, however, this study found that there was a great deal of movement on the part of administrators and teachers in schools. Of the principals surveyed in this study, approximately $92 \%$ had been in their schools for five years or less.

Relating the idea of change, as it is implied in the concept of vision, to the demographic data presented in this study, it becomes evident that there is an apparent disparity between the time needed for the change process to take effect and the comparative shortness of tenure of principals in schools.

Future research needs to look at the change process as an integral part of principal vision and examine the relationships which may exist between contextual variables and the principal's ability to advance a vision in his/her school. 


\section{REFERENCES}

Association of Supervision and Curriculum (1985). The effective principal. (Videotape) Alexandria, VA: The Association of Supervision and Curriculum.

Astin, H.S., \& Leland,C.(1991) Women of influence, women of vision: A cross-generational study of leaders and social change. San Francisco: Jossey-Bass.

Baldwin J (1961). Nobody knows my name. New York:Dial Press.

Barnard, C. (1986). Eunctions of the executive. Cambridge, MA. : Harvard University Press.

Barth, R. (1987). The principal and the profession of teaching. In W.D. Greenfield (Ed.), Instructional Leadership (pp. 249 - 270).Boston: Allyn and Bacon.

Barth, R. (1988, December). Leadership and vision. Presentation at the National Staff Development Conference, in Chicago, II.

Barth, R. (1990) Improving schools from within. San Erancisco: Jossey - Bass.

Bellarts, S. (1992) Rersonal values, work values, and job interests of nursing students . Unpublished Doctoral Dissertation: Portland State University, Portland.

Bennis, W. (1984) Transformative power and leadership. In T.J. Sergiovanni \& J.E. Corbally (Eds.). Leadership and organizational culture (pp. 64-71) Urban: University of Illinois Press.

Bennis, W. (1989) on becoming a leader. New York: Addison Wesley

Bennis ,W. \& Nanus,B. (1985) Leaders, strategies for taking charge. New York: Harper Row.

Block, P. (1982). The role of Elementary school principals: A summary of research. Arlington, Virginia: Educational Research Service. 
Block, P. (1987). The empowered manager: Positive political skills at work. San Francisco: Jossey-Bass.

Bloom, B. (1964) Stability and social change in human characteristics. New York: Wiley.

Blumberg, A. (1989). School administration as a craft. Boston: Allyn and Bacon.

Blumberg, A. \& Greenfield, W.D. (1980) The effective principal. Boston: Allyn \& Bacon.

Blumberg, A. \& Greenfield, W.D. (1986) The effective principal. (2nd Ed.). Boston: Allyn \& Bacon.

Bolman, L. \& Deal, T. (1984). Modern approaches to understanding and managing organizations. San Francisco: Jossey - Bass.

Bolman, L. \& Deal, T. (1991). Reframing Organizations: Artistry, Choice, and Leadership. San Francisco: Jossey - Bass.

Bolman, L.G. \& Deal, T.E. (1992 August) Leading and managing. The effects of Context, Culture and Gender. Educational Administration Quarterly, 28, 314-329

Bossert, S., Dwyer, D., Rowan, B., \& Lee, G. (1982, Summer). The instructional management role of the principal. Education Administration Quarterly, 18 (3), $34-64$.

Bridges, E. (1982) Research on the School Administrator: The State of the Art, 1967 - 1980. Educational

Administration Quarterly, Vol. 18 (3), $12-33$.

Bredeson, P. V. (1985, Winter). Analysis of the metaphorical perspectives of school principals. Education Administration Ouarterly, 21 (1), 29 - 50 .

Brookover, W., Beady, C., Flood, P., Schwietzer, J., \& Wisenbaker, J. (1979). School social systems and student achievement: Schools can make a difference. New York: Praeger Press.

Brookover, W., Beamer, L., Efthim, H., Hathaway, D., Lezotte, I., Miller, S., Passalacqua, J., \& Tornatzky, L. (1982). Creating effective schools. Holmes Beach, Florida: Learning Publications. 
Burlingame, M. (1987) Images of leadership in effective schools literature. In W.D. Greenfield (Ed). Instructional leadership (pp. 3-16). Boston: Allyn \& Bacon.

Burns, J.M. (1978) Leadership. New York: Harper Row.

Carlton, M. (1987) A comparison of principal and teacher perceptions of principal leadership skills. Unpublished Dissertation. Portland State University: Portland, Oregon.

Cockey, J.G. (1984). The machiavellian orientation of secondary school principals and the job satisfaction of their subordinate teachers. (Unpublished doctoral dissertation, Vanderbilt University, 1984). Dissertation Abstracts International, 45 (12), 3491-A.

Cohen, W.A. (1990). The art of the leader. Englewood Cliffs, NJ: Prentice Hall.

Conger, J.A. (1989). The charismatic leader. San Francisco: Jossey-Bass.

Cronin, T.E. (1984). Thinking and learning about leadership. presidential studies Quarterly, 14 (1), 22 - 34.

Cuban, I. (1987) The managerial imperative and the practice of leadership in the schools. New York: Sunny Press.

Cunningham, L.I. (1985, September). Leaders and leadership: 1985 and beyond. Rhi Delta Kappan, 67 (1), $17-20$.

Deal, T.E. (1987 a). The culture of schools. In L.T. Sheive \& M.B. Schoenheit (Eds.), Ieadership: Examining the elusive. Association for Supervision and Curriculum Development (pp. 3 - 15), Alexandria, VA.

Deal, T.E. (1987) Effective school principals: Counselors, engineers, pawnbrokers, poets ...... or instructional leaders ? In D.W.Greenfield (Ed). Instructional Leadership (pp. 230-245). Boston: Allyn \& Bacon.

DePree, M. (1989). Leadership as an art. New York: Dell.

Du Four, R. (1991). The principal as staff developer. Bloomington, IN: National Education Service. 
Du Four, R. (1985, January 25 - 29). Must principals choose between teacher morale and an effective school? Paper presented at the 69 th. Annual Meeting of the National Association of Secondary School Principals, New Orleans, LA.

Duttweiler, P.C., \& Hord, S.M. (1988). Dimensions of effective leadership, Aust in TX: Southwest Educational Development Laboratory.

Dwyer, D. (1984, Fall). Forging successful schools: Realistic expectations for principals. Educational Horizons, $63(1), 3-8$.

Dwyer, D.C., Lee, G., Rowan, B., \& Bossert, S. (1983) Five principals in action: Perspectives on instructional management. San Francisco: Far West Laboratory for Educational Research and Development.

Dwyer, D.C., Barnett, B.G., \& Lee, G.V. (1987). The school principal: Scapegoat or the last great hope. In L.T. Sheive \& M.B. Schoenheit (Eds.), Leadership: Examining the elusive. Association for Supervision and Curriculum Development (pp. $30-46$ ), Alexandria, VA.

Edmonds, R. (1979). Some schools work and more can. Social Policy, 9, $28-32$.

Elmore, R. (1990). Restructuring Scheols: The next generation of educational reform. San Francisco: Jossey - Bass.

England, G.W. (1967). Personal value systems of American managers. Academy of Management, 3, 53 - 68 .

England, G.W, \& Lee, R. (1974). The relationship between managerial values and managerial success in the United States, Japan, India, and Australia. Journal of Applied Rsychology, 59, 411 - 419.

Etzioni, A. (1965). Dual leadership in complex organizations. American Sociological Review, $30(5), 690$ - 691.

Etzioni, A. (1988) The meral dimension. Toward a new theory ef economics. New York: The Free Press. 
Firestone, W.A., Herriott, R., \& Wilson, B. (1987)

Explaining differences between elementary and secondary schools: Individual, organizational and instructional perspectives. Philidelphia: Research for Better Schools.

Flinders, D.J. (Fall, 1988). Teachers isolation and the new reform. Journal of Curriculum and Supervision, 4 (1).

French, J. \& Raven, B.H. (1959) The bases of social power. In D. Cartwright (Ed.). Studies of secial power. Ann Arbor, MI: Institute for social research.

Gardner,J.W. (1990) on leadership . New York : Free Press.

Getzels, J.W., \& Guba, E.G., (1957, Winter). Social behavior and the administrative process. The School Review, 65 $423-441$.

Gibb, C. (1954). Leadership. In G. Lindzey (Ed.), Handbook ef Secial Psycholegy. (vol 2). Reading, MA: AddisonWesley.

Gilley, J.W., Fulmer, K.A. \& Reithlingshoefer, S.J. (1986) Searching for academic excellence: Twenty colleges and universities on the move and their leaders. New York: Macmillian.

Goldhammer, K. (1971). Elementary school principals and their schools. Eugene: University of Oregon Press.

Goldman, P., Dunlap,D., \& Conley, D. (1991 April 4-8) . Administrative facilitation and site based school reform projects. Paper presenteed at the annual meeting of the American Educational Research Association, Chigago, Ill.

Good, T.I., \& Brophy, J.E. (1986) School effects. In wittrock, M.C. (Ed.) The Third Handbook on Research on Teaching. (pp. $570-590$ ).

Goodlad, J.I. (1984). A Place called scheol. New York: McGraw Hill.

Gortner, H.F., Mahler, J. \& Nicholson, J.B. (1989) Organization Theory: A public perspective. Pacific Grove, California: Brooks/Cole. 
Grady, M.L., \& LeSourd, S.J. (1990).. Principal's attitudes towards visionary leadership. The High School Journal, 73 (2), 103 - 110 .

Greenfield, W.D. (1982). Research on public school principals: A review and recommendations. (A Report to the National Institute of Education), Washington, D.C.

Greenfield, W.D. (1986) Moral, social, and technical dimensions of the principalship. Unpublished Manuscript, Louisiana State University.

Greenfield, W.D. (1987 a). Moral imagination and interpersonal competence. In W.D. Greenfield (Ed). Instructional leadership, concepts, issues, and controversies (pp. 57 - 73). Boston: Allyn \& Bacon.

Greenfield, W.D. (1987 b). Role-demands of the principal: Implications for principal preparation and selection. Baton Rouge: Louisiana State University.

Greenfield, W.D. (1988) Moral imagination, interpersonal competence, and the work of school administrators. in Leaders for America's schools. Ed. D.E. Griffiths, R.T. Stout, and P.B.Forsyth. Berkeley, CA: McCutchan.

Greenfield, W.D. (1991a April 3-7). The microploitics of leadership in an urban elementary school. Paper presented at the annual meeting of the American Educational Research Association, Chicago, IL.

Greenfield, W.D. (1991b April 3-7). Towards a theory of school leadership. Paper presented at the annual meeting of the American Educational Research Association, Chicago, II.

Greenfield, W.D. (1991c.April 3-7) Rationale and methods to articulate administrator training. Paper presented at theannual meeting of the American Educational Research Association, Chicago, II.

Greenfield, W.D., Licata, J.W., \& Johnson, B.L. (1989) . A guide to interpreting the school vision instrument, Baton Rouge: Louisiana State University.

Griffiths, D.E., Stout, T.T., Forsyth, P.B. (Eds.). (1988). Ieaders for America's schools. The report and papers of the National Commission on Excellence in Educational Administration. Berkeley: McCutchan. 
Grimsley, A.P. (1985). The relationship of the macheivellian orientation of the principal and faculty maturity to school effectiveness. (Unpublished Doctoral Dissertation, Georgia State University, 1985). Dissertation Abstracts International, 46(8), 2146-A.

Gross, N. \& Herriot, R. (1965) Staff leadership in public schools. A sociological inquiry. New York: Wiley.

Hall, R.H. (1991) organizations: Structures, processes and eutcomes. (5th.ed.) London: Prentice - Hall.

Hall, G., \& Hord,S. (1987). Change in schools: Facilitating the process. Albany : SUNY Press.

Heck, R. (1990). Instructional leadership and school achievement. Education Administration Quarterly, 26 (2), $94-125$.

Hemphill, J.K., Griffiths, D.E. \& Frederikson, N. (1962) Administrative performance and personality . New York: Teachers College Columbia University.

Hickman, C.R. (1990). Mind of a manager, soul of a leader. New York: John Wiley.

Hickman, J.A. (1986). Machiavellian interpersonal orientation in the principalship: Role clarity, work satisfaction and principal characteristics. (Unpublished doctoral dissertaion, Louisiana State University, 1986). Dissertation Abstracts International, 47 (8), 268-A.

Hoy, W.K. \& Miskel, C.G. (1986). Educational. Administration: Theory, research and practice (3rd.ed.). New York: McGraw.

Hoy, W.K. \& Miskel, C.G. (1991). Educational Administration: Theory, research and practice (4th.ed.). New York: McGraw.

Johnson, D.N. (1991) Rrincipal vision, environmental robustness, and teacher sense of autonomy in high schools. Unpublished Dissertation. Portland State University: Portland, Oregon.

Kahle, I.R. (1985). Social values in the eighties: a special issue. Rsychelogy and Marketing,2 (4), 231 - 237. 
Kanter, R.M. (1983). The Change Masters. New York: Simon and Schuster.

Katz, D., \& Kahn, R.I. (1987) The social psychology of organizations. New York: Wiley.

Kluckhohn, F. (1961). Variations in values erientation. New York: Row Peterson.

Koestenbaum, P . (1991). Leadership: The inner side of greatness San Francisco: Jossey - Bass.

Kouzes, J.M. \& Posner, B.Z. (1987) The leadership challenge. San Fransisco: Jossey-Bass.

Kushman, J.W. (1990). The role of teacher committment in urban school effectiveness: A study of elementary and middle schools. Paper presented at the Annual Meeting of American Educational Research Association, Boston, MA.

Krathwhol, D.R., Bloom, B.S., \& Masia, B.B. (1964) Taxonomy ef educational objectives. New York: David McKay Co., Inc.

Lassey, W., \& Fernandez, R. (1976). Leadership and social change, (2nd ed.). La Jolla, CA: University Associates.

Leithwood, K.A. (1989). School system policies for effective school administrators. In Holmes, M. (Ed.) Educational policy for effective scheols (pp. 73 - 92). Toronto Canada: Ontario Institute for Studies in Education.

Leithwood, K., \& Montgomery, D. (1986). The principal profile. Toronto, Canada: OISE Press.

Leithwood, K.A., \& Steinbach, R. (1991). "Indicators of Transitional Leadership in the Everyday Problem Solving of School Administrators." Journal of Personnel Evaluation in Education, 4, 111 - 117.

LeSourd, S.J. \& Grady,M.L. (1990) Visionary attributes in principals' descriptions of their leadership. The High School Journal, 73 (2), 111-117.

LeSourd, S.J. \& Grady,M.I. (1991, March). What is a visionary principal? NASSP Bulletin. 75 (533), 107-109. 
Levine, D., \& Lezotte, L.W. (1989). An interpretive review and analysis of research and practice dealing with unusually effective schools. Kansas City, MO: University of Missouri.

Levine, D.U. (1991, January). Creating effective schools: Findings and implications from research and practice. Phi Delta Kappan, $75(5), 389$ - 393.

Licata, J.W., Greenfield, W.D., and Teddlie, C.D. (1989, May). Principal vision, teacher sense of autonomy, and environmental robustness. Unpublished Manuscript, Louisiana State University.

Lieberman, A., \& Miller, L. (1990, June). Restructuring schools: What matters and what works. Bhi Delta Kappan.71(10), 759 - 764.

Lipham, J.M. \& Francke, D. (1966, Spring) Nonverbal behavior of administrators. Educational Administration Quarterly. 2 (2) 101-109.

Lipham, J.M., \& Heoh, J.A. (1974). The principalship: Eoundations and functions. New York: Harper and Row.

McCurdy, J. (1983) The role of the principal in effective schools:Problems and solutions. American Association of School Administrators. Sacramento: Education News Service.

Manasse, A.I. (1986). Vision and leadership: Paying attention to attention. Reabody Journal of Education. $63,150-173$.

Marshall,C. (1992, August) School administrators values.A focus on atypicals. Educational Administration Quarterly, (28) 368-386.

Maslow, A.H. (1970). Motivation and personality (2nd ed). New York: Jossey-Bass.

Mauriel, J.J. (1989) Strategic leadership for schools. San Fransisco: Jossey-Bass.

Miskel,C., Mc Donald,D., \& Bloom, S. (1983, Winter). Structural and expectancy linkages within schools and organizational effectiveness. Educational Administration Quarterly, 19 (1), 49-82. 
Murphy, J., Hallinger, P., \& Mitman, A. (1983, Fall). Problems with research on educational leadership: Issues to be addressed. Educational Evaluation and Policy Analysis, $5(3), 297-305$.

Murphy, J.T. (1988, May). The unheroic side of leadership, notes from the swamp. Phi Delta Kappan, 69(9), 654 659.

Omery,A. (1989) Values, moral reasoning and ethics. The Nursing Clinics of North America. 24 (3) 499-509

Owens, R.G. (1991) Organizational behavior in education. (4th ed.) London: Prentice - Hall

Parker, R.D. \& Partridge, R. (1991 November 3-15) Expectancy, teacher motivation and exemplary schools. Paper presented at the annual meeting of the Mid-South Educational Research Association. Lexington, Kentucky.

Peters, T. (1987). Thriving on chaos. New York: Alfred A. Knopf.

Peters, T. \& Austin,N. (1985) A passion for excellence. New York: Random House.

Peters,T., \& Waterman,R. (1982). In search of excellence. New York: Harper and Row.

Posner, B.Z., \& Schmidt, W.H. (1984). Values and the American manager: An update. California Management Review, 26, $202-216$.

Rescher, N. (1982) Introduction to values theory. Englewood Cliffs, N.J.: Prentice Hall Inc.

Robertson, D.I. (1988). Self-Directed Growth. Muncie, Indiana: Accelerated Developement Inc.

Rokeach, M. (1973). The nature of human values. New York: Free Press.

Sarason, S.B. (1990). The predictive failure of educational referm. SanFrancisco: Jossey-Bass.

Sashkin, M. (1988, May) The visionary principal: School leadership for the next century. Education and urban seciety, 20 (3) p $239-249$. 
Schein, E. (1987) erganizational culture and leadership. San Fransisco, Jossey - Bass.

Schlechty, P. (1990). Schools for the 2lst century. San Fransisco, Jossey - Bass.

Schon, D.A. (1987). Educating the reflective practitioner. San Fransisco, Jossey - Bass.

Sergiovanni, T.J., (1987) The principalship, A reflective practice perspective. Boston: Allyn and Bacon.

Sergiovanni, T.J., (1990) Value added leadership. How to get extraordinary performance in schools. San Diego : Harcourt, Brace, Jovanovich.

Sergiovanni, T.J., (1984, February) Leadership and excellence in schooling the principalship. Educational Leadership, $41(5), 4-13$.

Sergiovanni, T.J., (1987) The theoretical basis for cultural leadership. In L.T.Sheive \& M.B. Schoenheit (Eds.). Leadership examining the elusive. Alexandria, VA: Association for Supervision and Curriculum Development.

Sergiovanni, T.J., \& Corbally, J.E. (1984). Leadership and erganizational culture: New perspectives on administrative theory and practice. Chicago: University of Illinois Press.

Sergiovanni, T.J., \& Moore, J.H. (1989). Schooling for tomorrow: Directing reforms to issues that count. Boston: Allyn and Bacon.

Scheive, L.T., \& Schoenheit, M.B. (1987). Vision and the work life of educational leaders. In L.T. Sheive \& M.B. Schoent (Eds.). Leadership: Examining theelusive (pp. 93 - 104). Alexandria, VA: Association for Supervision and Curriculum Development.

Smith, W.F., \& Andrews, R.I. (1989). Instructional leadership how principals make a difference. Alexandria, Virgina: Association for Supervision and Curriculum Development. 
Spotts, J. (1976) The pronblem with leadership, A look at some recent findings of behavioral science research. In W.R. Lassey \& R.R.Fernandez (Eds.). Leadership and social change (pp.10-15). Ia Jolla, CA: University Associates.

Srivastva, S., Cooperrider, D.L., \& Associates (1990). Appreciative management and leadership: The power of positive thought and actions in organizations. San Fransisco, Jossey - Bass.

Tyack, D. \& Hansot, E. (1982) Managers of Virtue: Public school leadership in America, 1820 - 1980. San Fransisco: Basic Books.

Vaill, P.B. (1989) Managing as a performing art. San Fransisco: Jossey Bass.

Weick, K.E. (1976) Educational organizations as loosely coupled systems.Administrative science guarterly,21, $1-19$

Weick, K.E. (1982, June) Administering education in loosely coupled schools. Phi Delta Kappan, 64 (10), 673 - 676.

White-Hood, M. (1991, October) Meeting the needs of students: Stories of shared leadership. NASSP Bulletin, 75. (537), 19-22.

Yukl, G.A. (1981) Leadership in organizations. Englewood Cliffs, NJ: Prentice -Hall.

Yukl, G.A. (1989) (2nd ed) Leadership in organlzations. Englewood Cliffs, NJ: Prentice -Hall. 
APRENDIX A

SCHOOL VISION INVENTORY 
There are 17 statements about Principal Vision on this questionnaire. For the first two questions please circle either True or False. For statements 3-18 please indicate the extent to which you agree or disagree with the statements. ( VISION is defined for our purposes as "An image one should have about what one's school should be like)

Please circle either TRUE or FALSE for the first two questions.

1. My principal regularly emphasizes the importance of doing what is right for all children in this school.

TRUE FALSE

2. My principal has a vision of what this school ought to be. TRUE FALSE

(If you answered "FALSE" to either of these questions, DO NOT answer the remaining questions on this survey. Go directly to the demographic data section on page two. Thank You)

For the remaining items on this survey please indicate the extent to which you either agree or disagree with the following in relation to your principal's vision.

3. This vision can be achieved.

Strongly Disagree Agree Strongly Disagree

( )

()

( )

4. This vision serves the best interests of all children in this school.

5. I share this vision.

6. I have accepted this vision of my own free will.

( ) ( ) ( ) ( )

() ( ) ( ) ( )

7. My principal effectively exchanges ideas with teachers to achieve this vision.

() ( ) ( ) ( )

8. My principal effectively exchanges ideas with students to achieve this vision.

() ( ) ( ) ( )

() $(1) \quad(1)(1)$

9. My principal effectively exchanges ideas with parents to achieve this vision.

( ) ( ) ( ) ( )

10.My principal effectively exchanges ideas with superiors to achieve this vision.

11.My principal effectively exchanges ideas with members of the community to achieve this vision.

( ) ( ) (

( ) 
12. My principal regularly encourages teachers

\section{Strongly Disagree Agree Strongly}

Disagree

Agree to make personal sacrifices to accomplish this vision.

()

() ( ) ( )

13.My principal regularly encourages other members of the school community to make personal sacrifices to accomplish this vision. ( )

( ) ( ) ( )

14. I make personal sacrifices to accomplish this vision.

() ( ) ( ) ( )

15. Other members of the school community make personal sacrifices to accomplish this vision.

( ) ( ) ( ) ( )

16. My principal regularly makes personal sacrifices to accomplish this vision.

() ( ) ( ) ( )

17. My school is making meaningful progress towards accomplishing our vision.

() ( ) ( ) ( )

18. My principal included me in the vision building process.

() ( ) ( ) ( ) 


\section{APPENDIX B}

PROFILE OF LIFE VALUES 


\section{PROFILE OF LIFE VALUES}

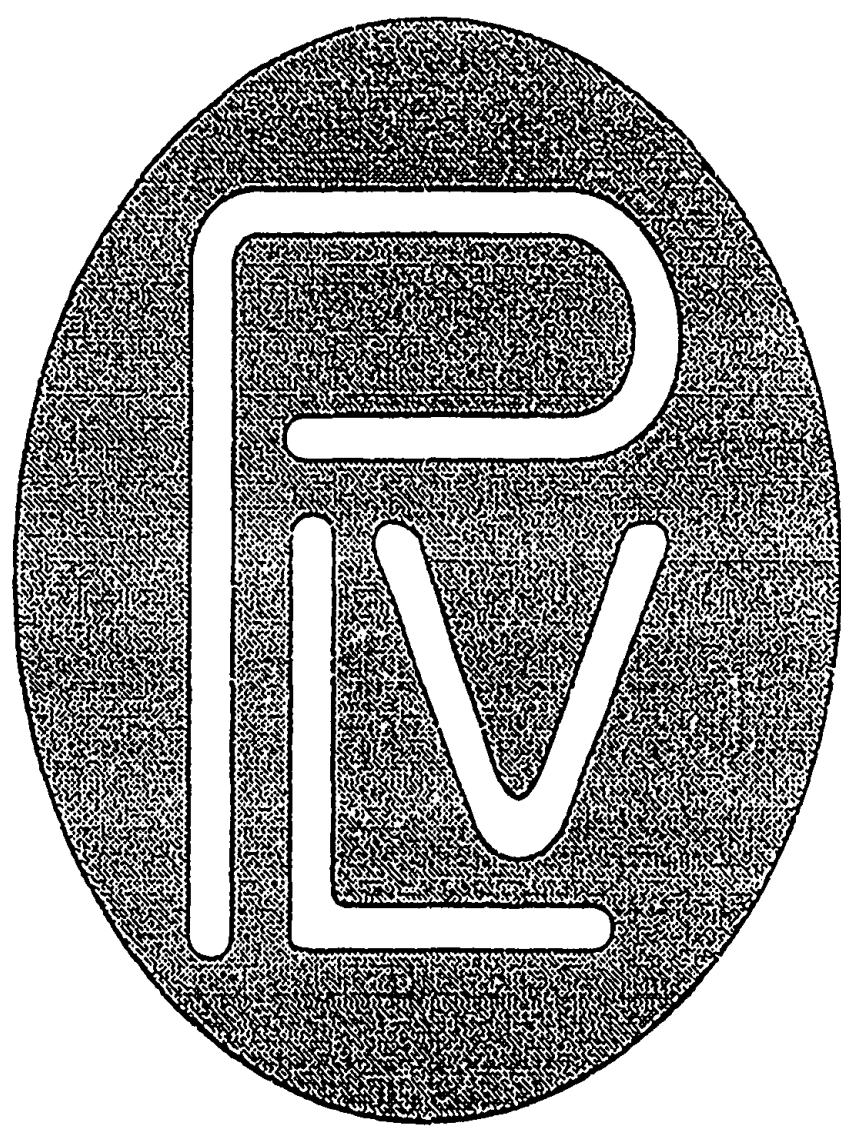

Copyright (c) 1992 by Loyde W. Hales and Stella B. Bellarts 
In this section are statements representing things that you may consider important to you. Please read each of the statements. Decide if the statement represents something you value by placing an $\mathbf{X}$ in the brackets which best represents the extent to which you either agree or disagree with the statement.

\section{Strongly Disagree Agree Strongly
Disagree}

1. I have a strong intellectual curiosity. () ( ) ( ) ( )

2. I show concern when other people are upset. () ( ) ( ) ()

3. I use unique ideas to solve problems.

4. I like to receive recognition for the work that I do in organizing group activities.

5. I have an appreciation for the fine arts, music, drama, ballet and literature.

() $(1) \quad()$

6. I do a good job when I take on added responsibilities.

( ) ( ) ( ) ( )

7. A person should stick to the truth regardless of the circumstances.

() $(1) \quad() \quad(1)$

8. I have an active interest in scholarly activities.( )

( ) ( )

( )

9. I show concern for the welfare of my colleagues.

( ) ( ) ( )

( )

10.I like to develop new and different techniques for doing things.

11.I like to be rewarded for the support I give to those who work with me

() ( ) ( ) ( )

( ) ( ) ( ) ( )

12.I have many cultural interests

( ) $\quad\left(\begin{array}{lll}) & (1)\end{array}\right.$

13.I am good at problem solving.

() ( ) ( )

( )

14.I stick to the truth even if it is unnecessary to do so.

( ) ( ) ( ) ( )

15. I like to be involved in activities that challenge my abilities and skills

() ( ) ( )

( )

16. I am considerate of other people's feelings 


\title{
Strongly Disagree Agree Strongly
} Disagree

17.I like to develop new solutions to problems

()

( ) Agree

18.I like to be in a position where I can recognize people for what they do.

\author{
()
}

()

()

( )

19.I like to express myself artistically.

20.I look for ways to increase my responsibilities ()

21.To make a situation more comfortable, it is all right to tell a white lie.
()
()
()
( )

22. I seek out new knowledge about the world. ()

() () ()

23. I go out of my way to help someone feel at home.

() ()

( )

( )

24. I like to discover alternative methods for doing things.
( )
( )
( ) ( )

25. I like to have others respect me for the things that I do.

() ( ) ( ) ( )

26. I enjoy visiting museums and art galleries ( ) ( ) ( ) ( )

27. Others look to me for advice

() ()$\quad() \quad()$

28. In some situations it is permissible to deceive others.

() ( ) ( ) ( )

29. I read articles that are a challenge to understand

( ) ( ) ( ) ( )

30. I help people feel more comfortable in new places.

() ( ) ( ) ( )

31. When looking for a solution for an issue I use creative approaches.

() $\quad\left(\begin{array}{lll}) & (1)\end{array}\right.$

32. I like others to notice and appreciate what I do

() () ( ) ( )

33. I like to design things that are artistic

() ()

( )

( )

34. When there is a hard job to do, I get it done. ()

( ) ( )

( ) 
35. Some delay in presenting the truth is

\section{Strongly Disagree Agree Strongly Disagree \\ Agree}
permissible in easing a difficult situation.
( ) ( )
( )
( )

36. I investigate ideas that influence changes in our society.

( ) ( )

( )

37. When I am pleased with others, I show it in my behavior.

( ) ( ) ( ) ( )

38. I look for novel ways to get the job done.

() ( )

() ( )

39. People respect me for the things that I do.

40. I like to create beautiful and artistic objects. ( )

() ( )

( )

41. When there is a hard job to be done I see that it gets finished.

( ) ( ) ( )

( )

42. If withholding information will make the job easier, it is all right to do so.

() ()$\quad() \quad()$

43. I enjoy searching for new ways to approach life.

() $\quad\left(\begin{array}{lll}1 & (1)\end{array}\right.$

44. I am sensitive to hurting other people's feelings.

( ) ( ) ( ) ( )

45. I use original ideas when doing things.

() ( ) ( )

( )

46. I like to be acknowledged for my accomplishments.

() ( ) ( )

( )

47. I arrange my time so that I may participate in cultural activities.

( ) ( ) ( ) ( )

48. Achieving what I am capable of is important to me.

( ) ( ) ( ) ( )

49. Stretching the truth is all right if it helps a friend get out of a tight place.

() ( ) ( ) ( )

50. I like to read literature that gives me insight into a problem.

() ( ) ( 
Strongly Disagree Agree Strongly

Disagree

51. I see that other people receive fair treatment ()

52. I like to take a problem and study different ways to solve it.

() ()

()

() () () () important to me.

54. I appreciate unusual works of art.

() $($ ) () ()

55. Providing the leadership needed to solve a difficult task is important to me.

56. Some compromise of the truth is permissible if it helps other people.
(1) Agree

()
53. Being recognized for the work I do is
( )
()
( )
()

() () () () 
APPENDIX C

MACH V SCALE 
PLEASE NOTE

Copyrighted materials in this document have not been filmed at the request of the author. They are available for consultation, however, in the author's university library.

pages $207-211$

University Microfilms International 
,

APPENDIX D

PRINCIPAL DEMOGRAPHICS 
Please complete the following demographic data. (Annonimity is assured)

Current student population :

Percentage of students on free or reduced lunch:

Current number of classroom teachers:

Your age in years

Your Gender

Male

Female

How many years have you been a principal ?

How long have you been in your current position? 
APPENDIX E

SAMPIE LETTER TO SUPERINTENDENTS 


\author{
Allan L.Weston \\ 11703 S.W. Jamaica \\ Wilsonville, OR. 97070
}

Dr.

Director

School District

, Or,

Dear

I am a doctoral student in Educational Leadership at Portland State University and an Administrative Asssitant at Sexton Mountain Elementary School in the Beaverton School District.

As the basis for my doctoral dissertation I am conducting research into the leadership characteristics of elementary principals in urban/suburban school districts. Specifically, I am interested in three variables associated with effective principals; vision, interpersonal orientation and personal values. My research proposal has been reviewed and I am now ready to begin the data collection process.

I am requesting permission to collect data from the principal and teaching staff of each elementary school in your district. Only those schools wishing to participate need do so and $100 \%$ school participation is not necessary to obtain valid results. I will also be conducting this research in most of the Portland metropolitian school districts.

The method of data collection will be via a two-part questionnaire. The first part should be given to all teaching staff in a participating school. This questionnaire asks teachers to respond either true or false to 17 statements about their perceptions of their principal's vision. I would suggest that the surveys be completed at a staff meeting. Teachers will be asked to complete the surveys and return them to a teacher trusted by the staff. That teacher will then place the surveys in the envelope provided and return them to me.

The second part of the survey is to be completed by the principal and consists of three sections. Section one asks the principal to complete the same vision survey completed by the teachers, however, the principal's are to respond to the statements the way that they believe their staff will respond.

Section two asks the principal to either agree or disagree, on a five point Likert scale, to a number of statements aimed at highlighting the personal values of the principal. Section three measures interpersonal competence and asks the principal to select the statement most like them and the statement least like them from twenty sets of statements.

It is anticipated that the second, or principal, part of the survey will take no longer than 25 minutes to complete and it too should be placed in the envelope and mailed to me. 
You can be assured that the surveys contain no right or wrong answers. Confidentiality will be maintained as no teacher, principal, school, or district will be identified. Names or some means of personal identification are not part of the survey questionnaire. Surveys are to be placed in an envelope and sealed before returning to the researcher.

For your convenience, I am enclosing a response letter and a selfaddressed stamped envelope which should be returned to me by December 18, 1992. Should you grant my request I would like to distribute surveys to your participating schools during the week of January 11-15, 1993.

Thank you for your consideration of my request and I look forward to hearing from you in the near future.

Sincerely,

Allan Weston

11703 S.W.Jamaica

Wilsonville, OR.97070

$682-9849$
Dr, Bill Greenfield

School of Education, Portland State University

PO Box 751

Portland, OR. 97201 
APPENDIX F

SAMPLE SUPERINTENDENT RESPONSE FORM 


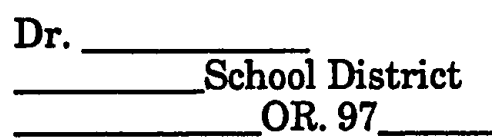

\begin{abstract}
Allan Weston
11703 S.W. Jamaica

Wilsonville OR. 97070

Dear Allan,

After consideration of your application to conduct research on principal vision, interpersonal competence and personal values in School District, I have decided to grant your request,
reject your request. grant your request,
reject your request.
\end{abstract}

I anticipate that approximately participate.

Your district contact person will be;

Name

Title

Telephone Number

Sincerely, district elementary schools will 
APPENDIX G

INSTRUCTION LETTER TO ACCOMPANY SURVEY PACKET 


\author{
Allan Weston \\ 11703 S.W. Jamaica \\ Wilsonville, OR. 97070
}

Sally Sample

Example Elementary School

12345 S.W. Fake St.

Portland OR. 97654

Dear Sally,

Thank you so much for volunteering to participate in my research study. As you may be aware, I am a doctoral student in Educational Leadership at Portland State University, and this is the basis for my doctoral dissertation. Specifically, I am interested in three personal characteristics variables which are believed to be closely related to principal effectiveness. The three variables are: (1) principal vision, which is the image that a principal has about what his/her school should be like, (2) personal values, which are the beliefs or feelings one has about what is important in life and, (3) interpersonal orientation, which is the way in which a principal interacts with the students, staff and community at his/her school.

There are two surveys enclosed with this letter. The first is the Teacher Survey of Principal Vision, which should be distributed to each certified staff member in your school. It is suggested that these surveys be distributed at a faculty meeting and once completed, they should be handed to appointed teacher who would place them in the envelope provided. If time at a faculty meeting is not available, then the surveys could be disseminated and collected in any manner you see as appropriate for your school.

The second survey is for you to complete. There are three parts to this survey; (1) your prediction of your staff's perception of principal vision, (2) principal personal values and, (3) principal interpersonal orientation. Please complete this survey and place it, along with the Teacher Survey of Principal Vision, in the envelope provided and return it to me prior to March 6, 1993.

As a fellow administrator I know that your time is valuable so once again thank you for your participation. Also, please be assured that anonymity is guaranteed.

Sincerely

Allan Weston

Ph. 682-9849 